University of Redlands

\title{
Finding Missing American Airmen: Using GIS for Mapping World War II Aircraft Crash Locations in Papua and New Guinea
}

\author{
A Major Individual Project submitted in partial satisfaction of the requirements \\ for the degree of Master of Science in Geographic Information Systems \\ by
}

Abdulelah A. Aljudibi

Douglas M. Flewelling, Ph.D., Committee Chair

Mark Kumler, Ph.D.

December 2016 
Finding Missing American Airmen: Using GIS for Mapping World War II Aircraft Crash Locations in Papua and New Guinea

Copyright (C) 2016

by

Abdulelah A. Aljudibi 
The report of Abdulelah A. Aljudibi is approved.

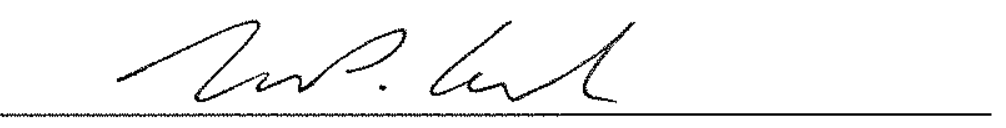

Mark Kumler, Ph.D.

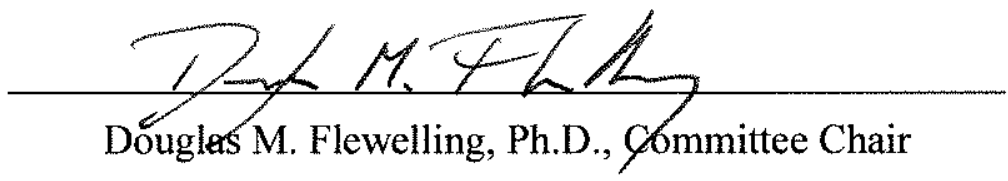

December 2016 



\section{Acknowledgements}

First of all, I thank Allah for all his blessing, and for giving me the opportunity to pursue and successfully finish my education.

I would like to extend my gratitude to my family who has always stood by my side, encouraged, and supported me. Many thanks to the MS GIS Program faculty members for sharing their expertise and knowledge with us. Special thanks to my advisor Dr. Douglas Flewelling for his guidance during the development of the project, and for taking the time to explain things clearly. I extend my gratitude to Dr. Mark Kumler who took the time to read and discuss my thesis. I want to take this opportunity to thank all my friends

in Cohort 27.5 and Cohort 29 for the good days we spent together. I specially thank Fahad Dalbouh who was always there to offer his help.

I would like to seize the opportunity to enormously thank my wife Montaha for her countless support and encouragement during the two years of the Program. 



\begin{abstract}
Finding Missing American Airmen: Using GIS for Mapping World War II Aircraft Crash Locations in Papua and New Guinea

by

Abdulelah A. Aljudibi

Searching for historical locations, most of the time, requires the search for related information in many documents. The Defense POW/MIA Accounting Agency (DPAA) works to locate War World II (WWII) aircraft wreckage locations in order to find and bring home United States missing in action (MIA) soldiers' remains. The DPAA has historical documents included tables and maps that provide information about WWII aircraft crash locations in Papua and New Guinea. Use of the documents is limited because they are in a portable document format (PDF) file, which does not allow users to interactively compare the data with other related datasets. Also, working with such documents require more resources and takes more time. Implementing a geographical information system (GIS) was the solution to bring the data into a reliable format that solved the addressed problems. A geodatabase within ArcGIS Desktop was built which allows users to query the data and view them in an interactive map. The new system allows the DPAA to add different datasets and compare them all together in one map. This project also provides analytical maps that may help the DPAA to plan for search and recovery missions as well as map series to be used in the field.
\end{abstract}





\section{Table of Contents}

Chapter 1 - Introduction ............................................................................................ 1

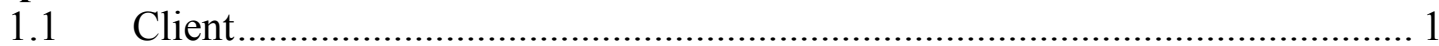

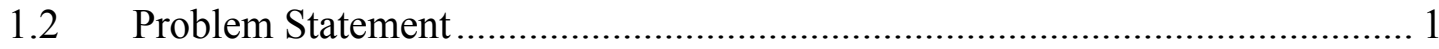

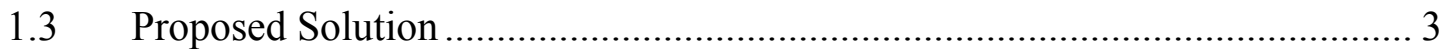

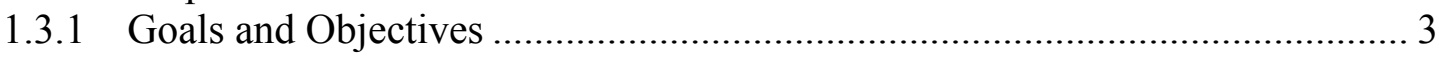

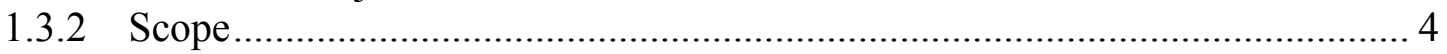

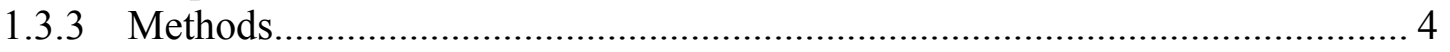

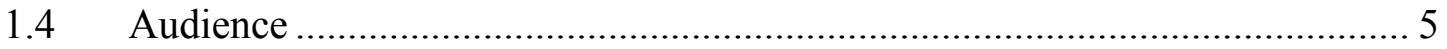

1.5 Overview of the Rest of this Report ............................................................ 5

Chapter 2 - Background and Literature Review ............................................................ 7

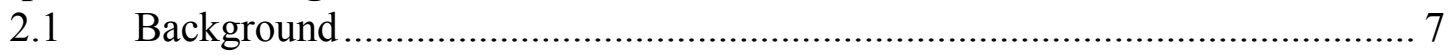

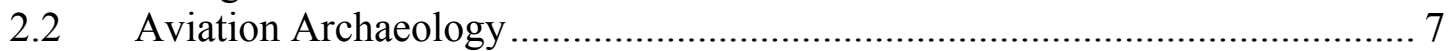

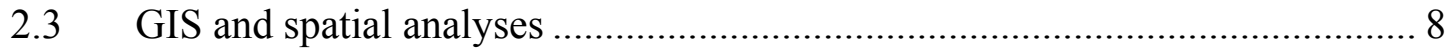

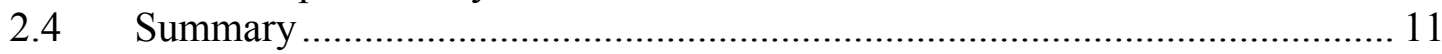

Chapter 3 - Systems Analysis and Design............................................................... 13

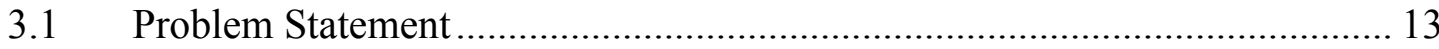

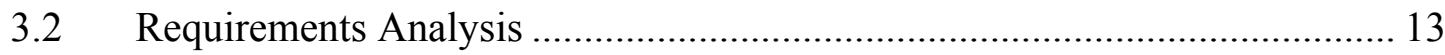

3.2.1 Functional Requirements .......................................................................... 13

3.2.2 Non-functional Requirements ................................................................ 14

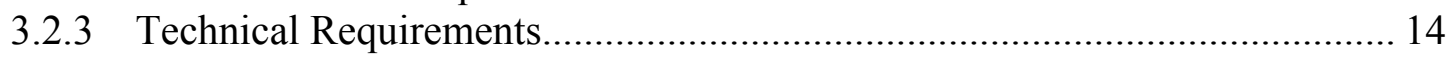

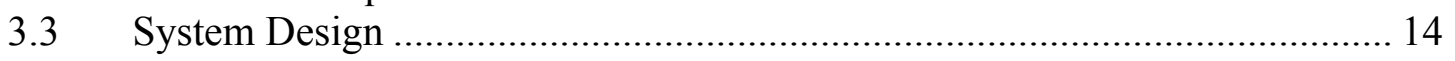

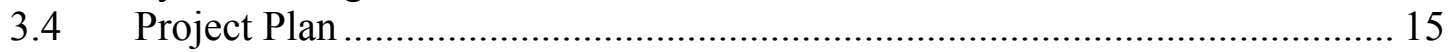

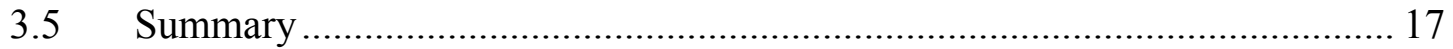

Chapter 4 - Database Design........................................................................................... 19

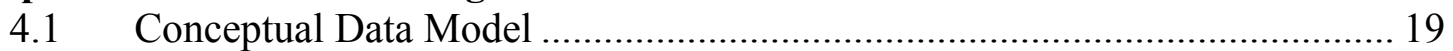

4.2 Logical Data Model .......................................................................... 19

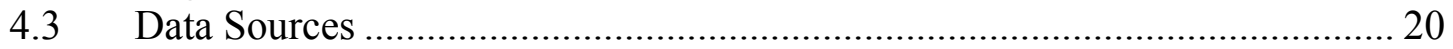

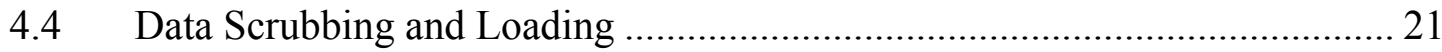

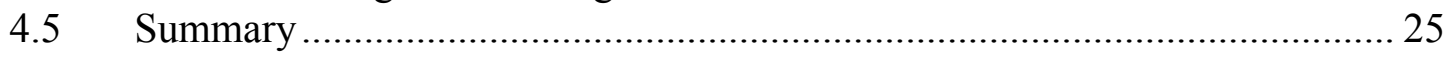

Chapter 5 - Implementation............................................................................................... 27

$5.1 \quad$ Royal Australian Air Force Geodatabase ……………………………….... 27

5.2 Spatial Statistical Analyses ....................................................................... 30

5.2.1 Number of Crashes Per Province.............................................................. 31

5.2.2 Most Concentrated Provinces with Crashes ............................................... 33

5.2.3 Number of Crashes Per Square Kilometer................................................... 36

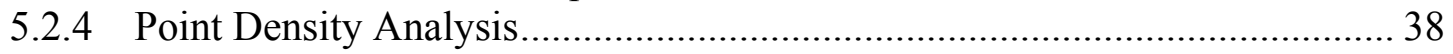

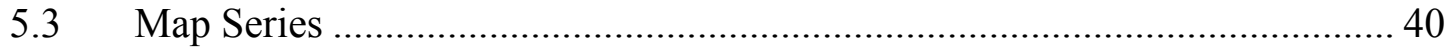

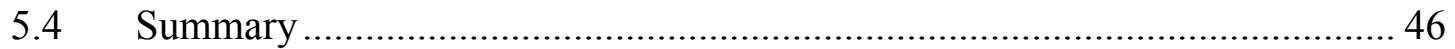

Chapter 6 - Results and Analysis....................................................................................... 47

6.1 Royal Australian Air Force Geodatabase …………..................................... 47

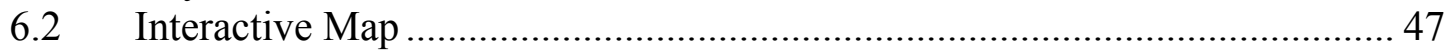




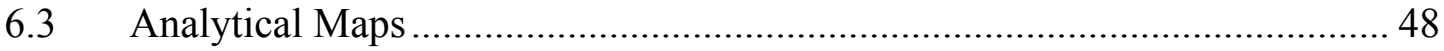

6.3.1 Number of Crashes Per Province Map...................................................... 48

6.3.2 Most Concentrated Provinces with Crashes Map .......................................... 49

6.3.3 Number of Crashes Per Square Kilometer Map ......................................... 49

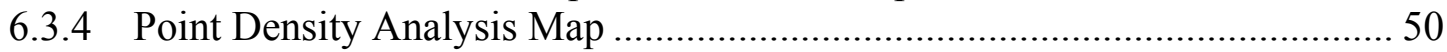

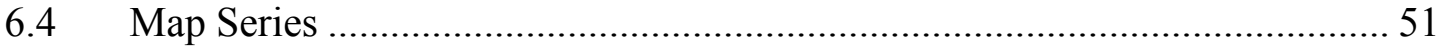

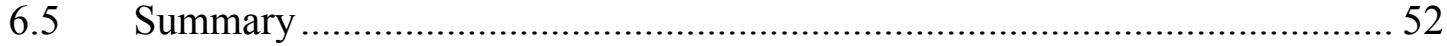

Chapter 7 - Conclusions and Future Work .............................................................. 53

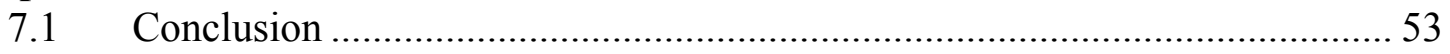

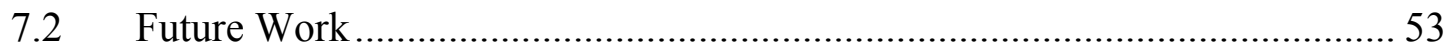

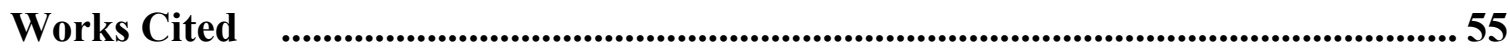

Appendix A. Royal Australian Air Force Survey.................................................. 57 


\section{Table of Figures}

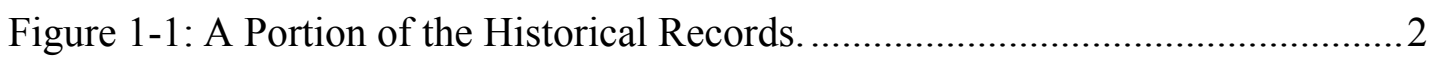

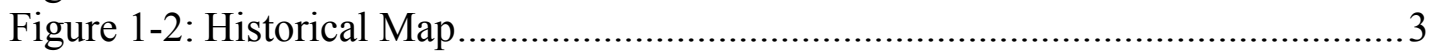

Figure 2-1: Wreck Locations. ………………………..................................... 8

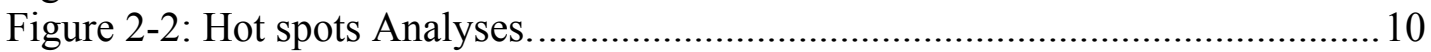

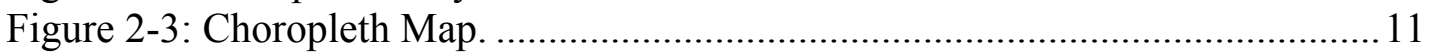

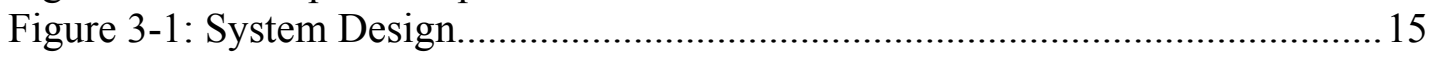

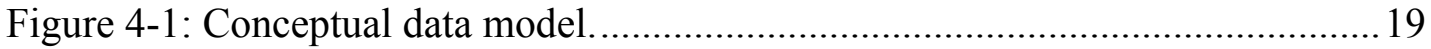

Figure 4-2: Logical data model...........................................................................2

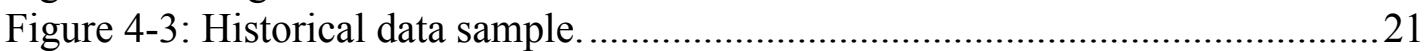

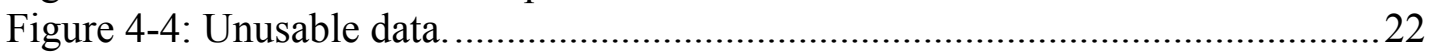

Figure 4-5: A Portion of three data versions...........................................................22

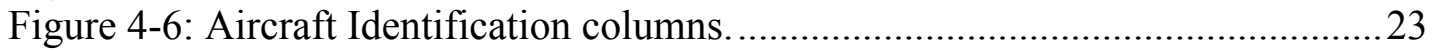

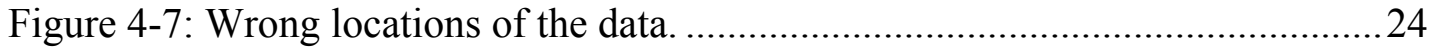

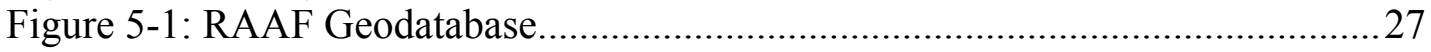

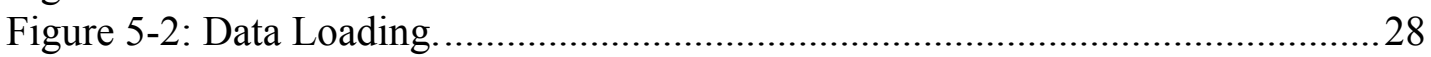

Figure 5-3: Symbolized Data Based on Country of Origin. .......................................2

Figure 5-4: Symbolized Data Based on US Designation Code. ................................29

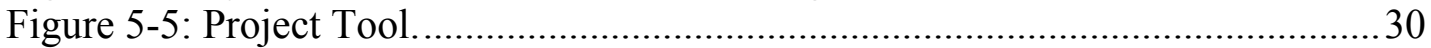

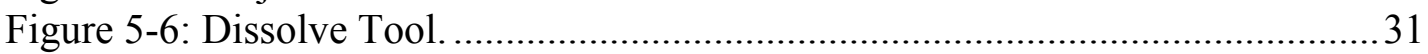

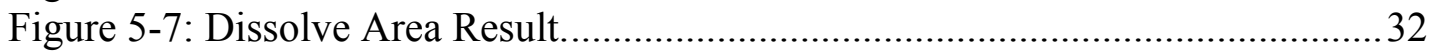

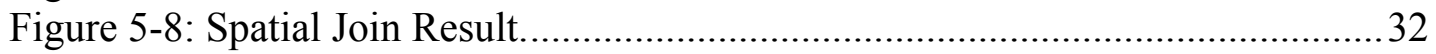

Figure 5-9: Number of Crashes Per Province Map.................................................. 33

Figure 5-10: Most Concentrated Provinces Selection. ................................................34

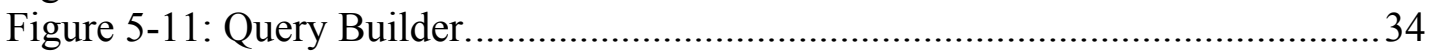

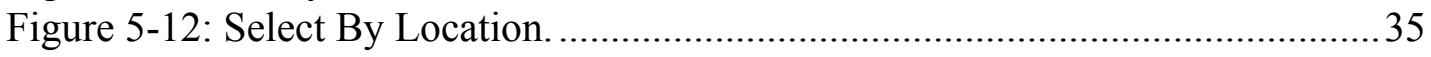

Figure 5-13: Most Concentrated Provinces with Crashes...........................................36

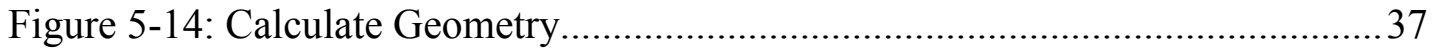

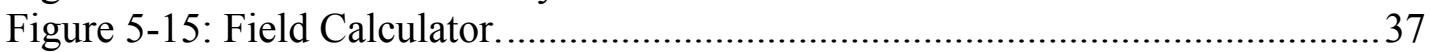

Figure 5-16: Number of Crashes Per Square Kilometer Map......................................38

Figure 5-17: Point Density Tool. .............................................................................. 39

Figure 5-18: Point Density Analysis Result..........................................................39

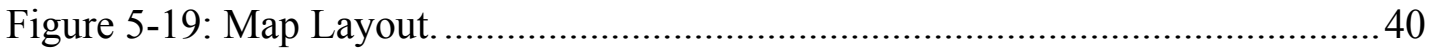

Figure 5-20: Overlapped Labels. ......................................................................... 41

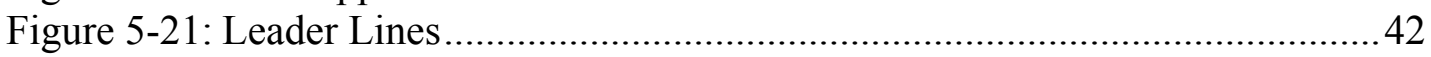

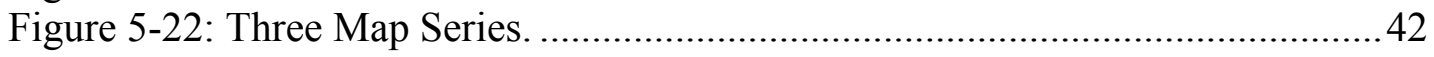

Figure 5-23: Grid Index Features Tool. ...............................................................4

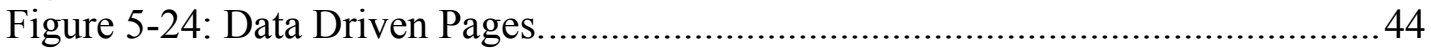

Figure 5-25: Aircraft Locations Map..................................................................... 45

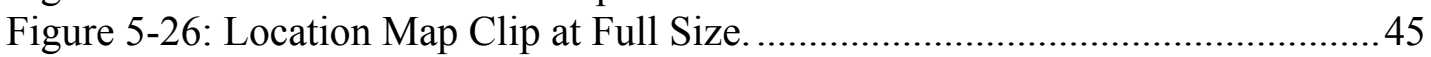

Figure 6-1: Number of Crashes Per Province...........................................................4

Figure 6-2: Most Concentrated Provinces with Crashes Map....................................49

Figure 6-3: Number of Crashes Per Square Kilometer...........................................50

Figure 6-4: Point Density Analysis Map. ........................................................... 51 
Figure 6-5: Map Series Symbolized by Country of Origin.......................................52 


\section{List of Tables}

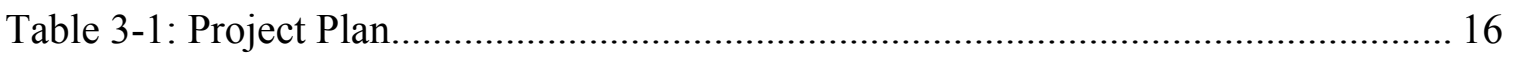





\section{List of Acronyms and Definitions}

$\begin{array}{ll}\text { DPAA } & \text { The Defense POW/MIA Accounting Agency } \\ \text { GIS } & \text { Geographic Information System } \\ \text { MIA } & \text { Missing in Action } \\ \text { OCR } & \text { Optical Character Recognition } \\ \text { PDF } & \text { Portable Document Format } \\ \text { PNGMG } & \text { Papua and New Guinea Map Grid } \\ \text { POW } & \text { Prisoner of War } \\ \text { RAAF } & \text { Royal Australian Air Force } \\ \text { US } & \text { United States } \\ \text { UTM } & \text { Universal Transverse Mercator } \\ \text { WWII } & \text { World War II }\end{array}$





\section{Chapter 1 -Introduction}

Historical documents are often rich with valuable data. However, it is difficult to fully benefit from them as they cannot be moved from one place to another without damaging them. They are also limited in how they can be used to extract the data. Therefore, the Defense POW/MIA Accounting Agency (DPAA) wanted the data in these documents to be converted to a reliable form that can be accessed remotely and interactively manipulated to support their mission. Implementing a geographic information system (GIS) will support the DPAA's need to more fully use the data.

\subsection{Client}

The Defense POW/MIA Accounting Agency (DPAA) was founded by the Department of Defense on January 30, 2015, to be responsible for the search, recovery, and accounting of missing service members from past conflicts. The DPAA's research and operational missions include collaboration with other countries around the world. Their objective is to inform the families of missing in action service members and the US government how and where their personnel were lost (Defense POW/MIA Accounting Agency, n.d.). The DPAA vision is to carry out the United States government's obligation by "maximizing the number of missing personnel accounted for while ensuring timely, accurate information is provided to their families" (Defense POW/MIA Accounting Agency, n.d.). Mr. Anthony Hewitt was the point of contact for this project and he provided the primary data that were used for creating the database.

\subsection{Problem Statement}

The client has historical documents that contain data of aircraft wreckage locations in Papua and New Guinea from World War II (WWII) in a portable document format (PDF) file. The documents also included 13 maps. These documents are of limited use for several reasons. First, the search for a record takes a long time due to the fact it is done manually and the records extend to several pages. Figure 1-1 shows a portion of the records. 


\begin{tabular}{|c|c|c|c|c|c|}
\hline \multicolumn{6}{|c|}{$\frac{\text { INDEX OF CRASHISD AIRCRAFT }}{\text { II }}$} \\
\hline$\frac{\text { SERTLL }}{\underline{\text { PO. }}}$ & 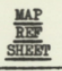 & LAT, LOMG. & $\underline{A B E A}$ & AIRCRAFr IDENTIFICATIOY & REMARS \\
\hline $\begin{array}{l}1 \\
2 \\
3 \\
3 \\
4 \\
5 \\
6 \\
7 \\
8 \\
9 \\
10 \\
11 \\
12 \\
13 \\
14 \\
15 \\
16 \\
17 \\
18 \\
19 \\
20 \\
22 \\
22 \\
23 \\
24 \\
25 \\
25 \\
27 \\
29 \\
29 \\
93 \\
32 \\
33 \\
134 \\
35 \\
36\end{array}$ & $\begin{array}{r}12 \\
9 \\
12 \\
9 \\
9 \\
9 \\
9 \\
9 \\
10 \\
10 \\
10 \\
10 \\
10 \\
3 \\
3 \\
1 \\
12 \\
12 \\
12 \\
12 \\
10 \\
10 \\
10 \\
10 \\
13 \\
10 \\
10 \\
10 \\
5 \\
10 \\
10 \\
10 \\
10 \\
10 \\
10 \\
10\end{array}$ & $\begin{array}{l}09.05-147.47 \\
097.53-147.11 \\
08.40-148.24 \\
06.42-147.00 \\
05.34-148-34 \\
05.30-148.30 \\
06.44-147.01 \\
06.43-149.50 \\
04.24-152.17 \\
06.54-151.10 \\
05.33-150.54 \\
05.33-150.54 \\
05.07-151.08 \\
03.35-143.40 \\
03.24-143.38 \\
02.50-132.53 \\
09.32-147.16 \\
09.32-147.15 \\
10.08-148.01 \\
08.10-148.29 \\
05.14-151.55 \\
06.14-150.14 \\
06.09-150.19 \\
06.20-150.21 \\
09.53-152.03 \\
06.13-150.22 \\
04.14-152.10 \\
06.30-154.02 \\
02.51-150.59 \\
04.10-152.10 \\
04.10-152.10 \\
04.10-152.10 \\
04.09-152.13 \\
06.14-150.21 \\
05.26-150.25 \\
04.14-152.10\end{array}$ & 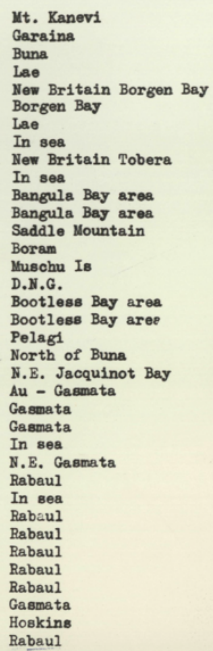 & 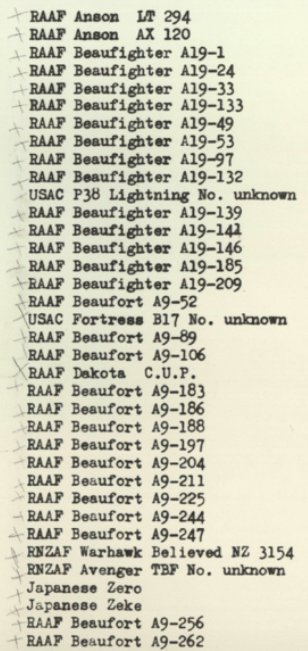 & 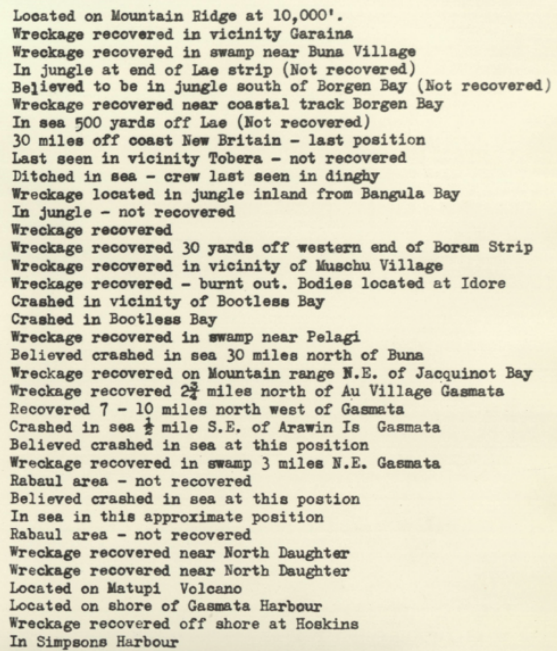 \\
\hline
\end{tabular}

Figure 1-1: A Portion of the Historical Records.

Second, finding the corresponding data to this record - such as country name, province name, or town name - may require searching external datasets. Third, locating a point that represents an aircraft wreckage location in the maps is very difficult because there are many locations that are close to one another, as well as many overlapping locations (Figure 1-2). 


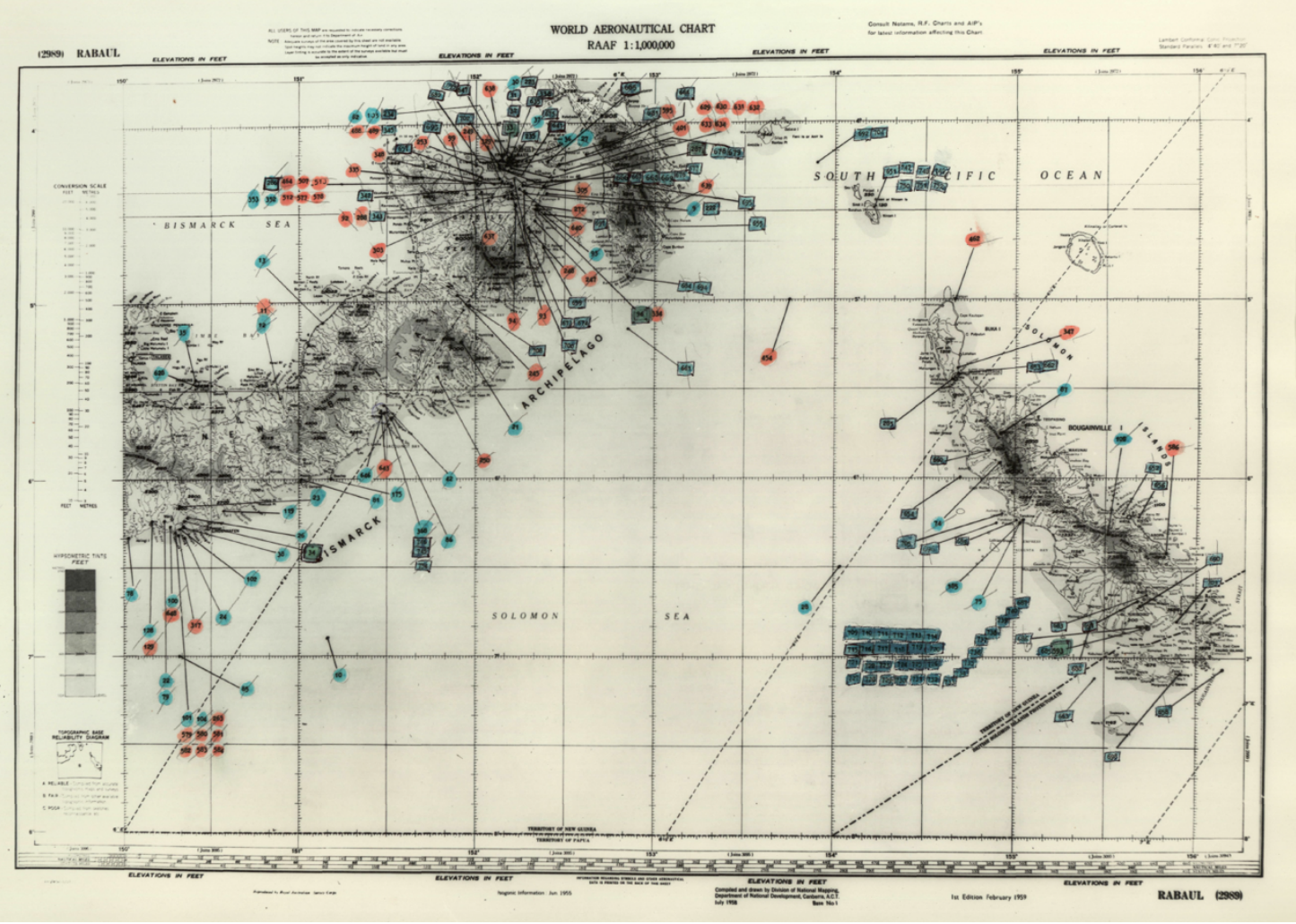

Figure 1-2: Historical Map

Additionally, the inability to conduct spatial analyses on the data and compare them to other datasets is a great reason that this problem needs to be solved.

\subsection{Proposed Solution}

To solve these problems for the DPAA, the contents of these historical documents needed to be converted into a GIS platform. The solution allowed active interaction with the data since they were stored in a geodatabase. The geodatabase allowed storing spatial data and allowed conducting spatial analyses on them as they were mapped in the system. The records were stored in tables that allowed automated search for records.

\subsubsection{Goals and Objectives}

The project goals were to convert the historical data from a PDF format to a GIS format. In addition, designing and producing a series of maps that show the data is required. The project involved designing and creating a geodatabase, converting photos of historic tabular data into a GIS attribute tables to be stored in the geodatabase, creating a feature class to store the locations of the aircraft wreckage presented as points in maps, and to design and produce a map series to show the locations of aircraft wreckage.

By December of 2016, the three following project objectives were completed. First, a file geodatabase to store the feature class of the aircraft wreckage locations. The geodatabase design allowed users to differentiate country of origin and type of aircraft. Second, a point feature class showing the locations of aircraft wreckage was achieved by 
converting the historic tabular data from the PDF file. Third, producing a map series to show the locations of the aircraft wreckage categorized by country of origin.

Achieving these objectives allowed the user to conduct different analyses on the data, one of which was a point density analysis to locate the concentrated areas of wrecks.

\subsubsection{Scope}

To meet the client's requirements, a project was developed to convert historical data into a GIS platform. The project included converting historic tabular data about missing aircraft wreckage in Papua and New Guinea from static images in a PDF file into GIS feature classes and tables. The process included the use of the following software: Adobe Acrobat, Microsoft Excel, and ArcGIS 10.3.1. A file geodatabase was designed and built to store the newly created feature classes and tables using ArcCatalog. The database would organize and relate the different feature classes and tables together for easier, faster data retrieval. Having the data in ArcGIS format allowed conducting analyses on them. Moreover, a series of maps of the data were designed and produced using ArcMap. Some of these maps represent the locations of the aircraft wreckage, and others show analyses on them.

\subsubsection{Methods}

This section discusses the methods that were used to accomplish the different components of the project. These components were divided into four phases.

Phase 1-Planning: The client's requirements were identified and implemented in the planning phase. The data were collected, including a PDF file that contained the client's historic tabular data of aircraft wreckage locations in Papua and New Guinea from WWII. A polygon shape file of the boundaries of the study area was acquired from GADM.org.

Phase 2-Data conversion: The data in the PDF file were converted into Excel format files in order to create a point feature class. Adobe Acrobat was used to convert the tabular data from images to text using the optical character recognition (OCR) capability. The records from the tables were moved manually by copying and pasting them into an Excel file. Next, ArcMap was used to convert the data from Excel to GIS format using the Add XY Data tool. A point shape file was created from these data. In addition, to install ArcGIS Desktop, the computer operating system had to be Windows.

Phase 3-Database Design and Development: A file geodatabase was developed using ArcCatalog. The database was designed to allow the user to distinguish aircraft type and country of origin. A point feature class was created and the data from the shape file were loaded to it. A polygon feature class of the study area was also created. Other tables were created to store non-spatial data: country of origin and aircraft general information. All the components of the database were related to each other using database relationships.

Phase 4- Map Design and Production: This component involved the design and production of a series of maps using ArcMap. Some of these maps show the locations of aircraft wreckage in Papua and New Guinea presented as points. 


\subsection{Audience}

The intended audience for this report includes individuals with little to no GIS experience. The report provides methods to migrate data from PDF files to ArcGIS and how to build a geodatabase within ArcCatalog, which can be helpful for those who are new to these tools.

\subsection{Overview of the Rest of this Report}

The report consists of seven chapters. Chapter 2 discusses the background and literature review. It provides background information about the project's topic. It also addresses case studies about similar topics within the field of GIS.

Chapter 3 addresses the system analysis and design. It includes the problem statement, functional and non-functional requirements, technical requirements, system design, and the project plan. The system design describes the components used to complete the project.

Chapter 4 illustrates the geodatabase design. Additionally, it addresses the data sources, data collection methods, data scrubbing and loading. In the data scrubbing and loading, it discusses in detail all the issues encountered with the data preparation.

Chapter 5 demonstrates how the different parts and analyses of the project were implemented. Chapter 6 discusses the results of the analyses. Chapter 7 provides the conclusion for this project, and it lists suggested future work. 



\section{Chapter 2 - Background and Literature Review}

GIS is very useful in visualizing, analyzing, and manipulating spatial data. It facilitates further understanding of the data, and helps to find patterns and trends that contribute to decision-making. This chapter addresses a background of research on casualties from World War II (WWII) and the efforts to bring their remains home (section 2.1). Aviation Archaeology (section 2.2) discusses what is involved in recovering aircraft wreckage. GIS and spatial analyses address the capability of GIS dealing with spatial data (section 2.3). A summary provides the outcome from the literature review (section 2.4).

\subsection{Background}

Wars have always caused the loss of thousands of lives. During WWII alone, the United States lost more than 400,000 lives, and about 79,000 Americans remained unaccounted for when the war ended (Defense POW/MIA Accounting Agency, n.d.) Unaccounted for is a general term used to refer to those who were listed as Prisoner of War (POW), Missing in Action (MIA), killed in Action-Body Not Recovered, or Presumptive Finding of Death (Henning, 2006). From 1945 to 1951, more than 280,000 dead were identified and brought home for a proper burial within a program called The Return of the World War II Dead Program (Vento, 2012). This program ended in 1951, but efforts continued and by 2003, 546 more missing Americans were found and identified according to the Defense Prisoner of War/Missing Personnel Office (DPMO) as cited in The Missing in Action (MIA) of World War II by Vento (2012). Two hundred out of the 546 were found between the years from 1951 and 1976 primarily because of citizens' reports that contained evidence of American remains. The remaining 346 were found between 1976 to 2003 by the Army Central Intelligence Lab, that was charged with recovering WWII remains. According to the Defense POW/MIA Accounting Agency (DPAA) the unaccounted-for Americans from WWII, as of today, are more than 73,000 (Defense POW/MIA Accounting Agency, n.d.). The DPAA is still searching for over 3000 missing American servicemen lost in the defense of Papua and New Guinea during World War II (Port Moresby. Papua New Guinea - Embassy of The United States, 2016). According to the Royal Australian Air Force survey of aircraft wreckage in Papua and New Guinea, there were 455 US aircraft crash locations (1961). This indicates that there would be at least 455 airmen's remains to be recovered.

\subsection{Aviation Archaeology}

The search for and recovery of aircraft wrecks has been conducted by the US government for decades. The purpose of finding these wrecks is to gather information about the missing service members from WWII and other past conflicts and provide them to the deceased's families, as well as to moving their remains back to home to be reinterred. According to Bruce D. Callander, "finding remains of lost servicemen is a combination of science, detective work, and archeology" (2005, p. 69). For example, Project RECOVER uses the most advanced oceanographic technology combined with advanced archival research methods to find downed aircraft underwater. They collect and study 
data on currents around a crash location to find out where the currents had possibly moved the aircraft. Then they use technologies such as scanning sonar, thermal cameras, and underwater robotics to locate the vessels (Dickerson, 2014).

It takes a long time to find the crash site and recover it because "knowing that an airplane went down, and finding the actual crash site, are two different things" (Callander, 2005, p. 68). The process of finding a crash site involves several steps according to Chief of the Missing Persons Branch, Jim Russell (Callander, 2005). The first step is gathering information from documents which may not have enough information to lead to the exact location of a crash site. The second step is investigating in the country where the aircraft crashed. The last step is an archeological operation to excavate a crash site. In addition, finding a crash site depends on the nature of the search area. For instance, many wreck locations in Papua and New Guinea are in high mountains and heavy jungles (Figure 21). Therefore, wrecks can be covered by big bushes and trees or scattered behind mountain cliffs which blocks vision and as a result, it becomes a difficult task to recover the wrecks.

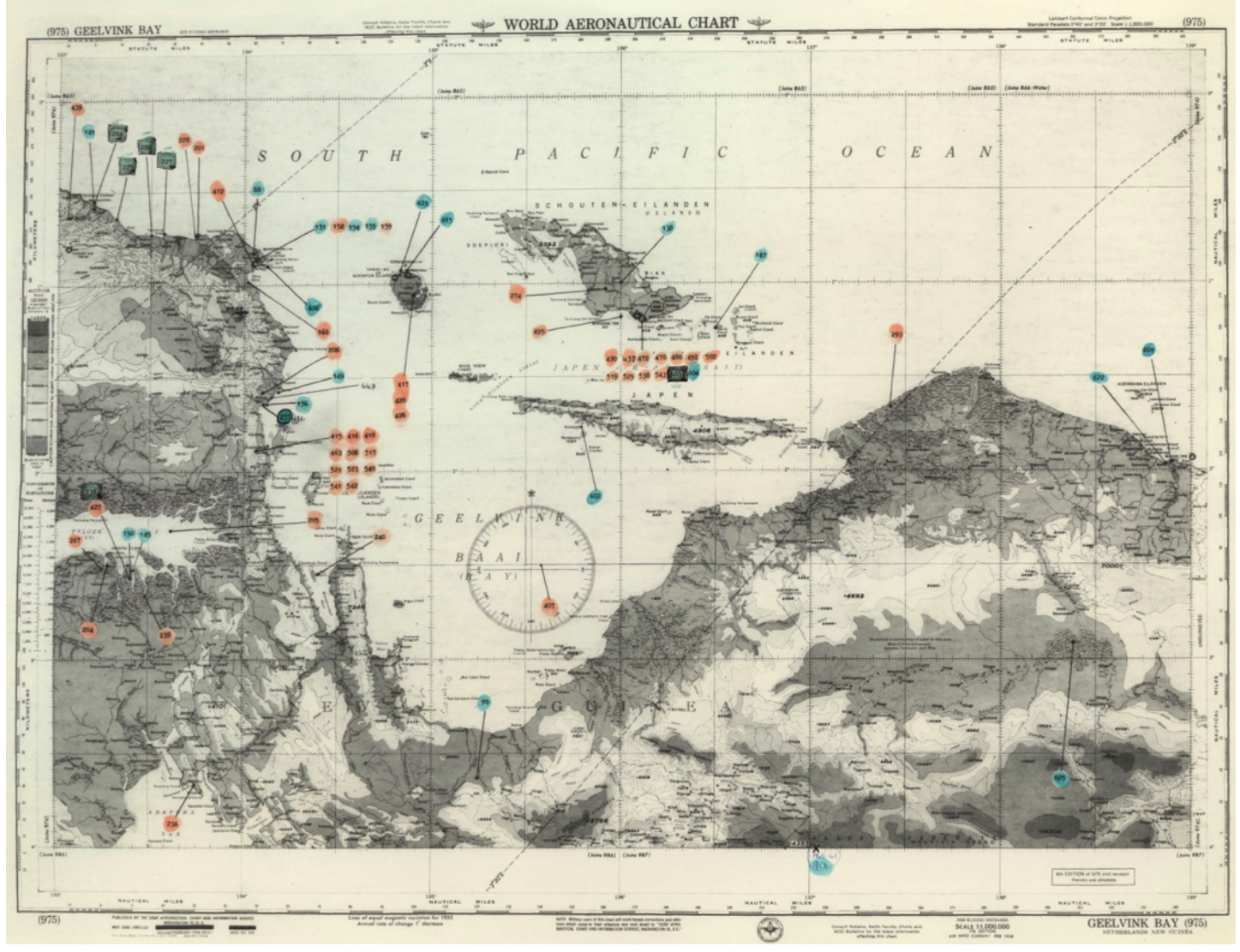

Figure 2-1: Wreck Locations.

\subsection{GIS and spatial analyses}

A geographic information system (GIS) is a useful technology for making decisions that are related to locations. "GIS is a system of hardware, software and procedures designed to support geographical decision-making through the acquisition, management, manipulation, analysis and display of spatially referenced information" (Church and 
Murray, as cited in Advances in Location Modeling: GIS Linkages and Contributions, 2010). Moreover, GIS provides the ability to represent spatial locations accompanied by attribution of these locations (Murray, 2010) With this quality, GIS provides a variety of geoprocessing tools. "This begins with data collection (digitizing/editing) and load or transfer, integration, storage and management, proceeds through data maintenance, and ends with data query, analysis, and visualization/mapping" (Maguire, Batty, \& Goodchild, 2005, p. 22) The capacity of GIS, especially spatial analysis, plays a big role in minimizing the time and effort to locate aircraft wrecks by applying different analyses on the data.

Representing aircraft wreck locations as points in GIS would show different patterns that can provide a further understanding of the spatial relationship of them. It would also allow for conducting different analyses on the data. Deciding on the analysis type depends on the question(s) asked or the problem that needs to be solved. For instance, a case study was conducted by Esri (2016a) to analyze violent crimes. The question was to determine if there is a relationship between violent crime and liquor establishment locations. The data were point layers for both the crime locations and the liquor establishment locations. Hot spot analyses were conducted on each of the layers, and the hot spot locations were compared to decide whether there was or there was not a correlation between the crimes and the liquor establishment locations. The result for each of the layers showed different hot spot locations which indicated that the crime locations are not correlated to the liquor establishment locations (Figure 2-2). 


\section{Violent Crime Hot Spots}

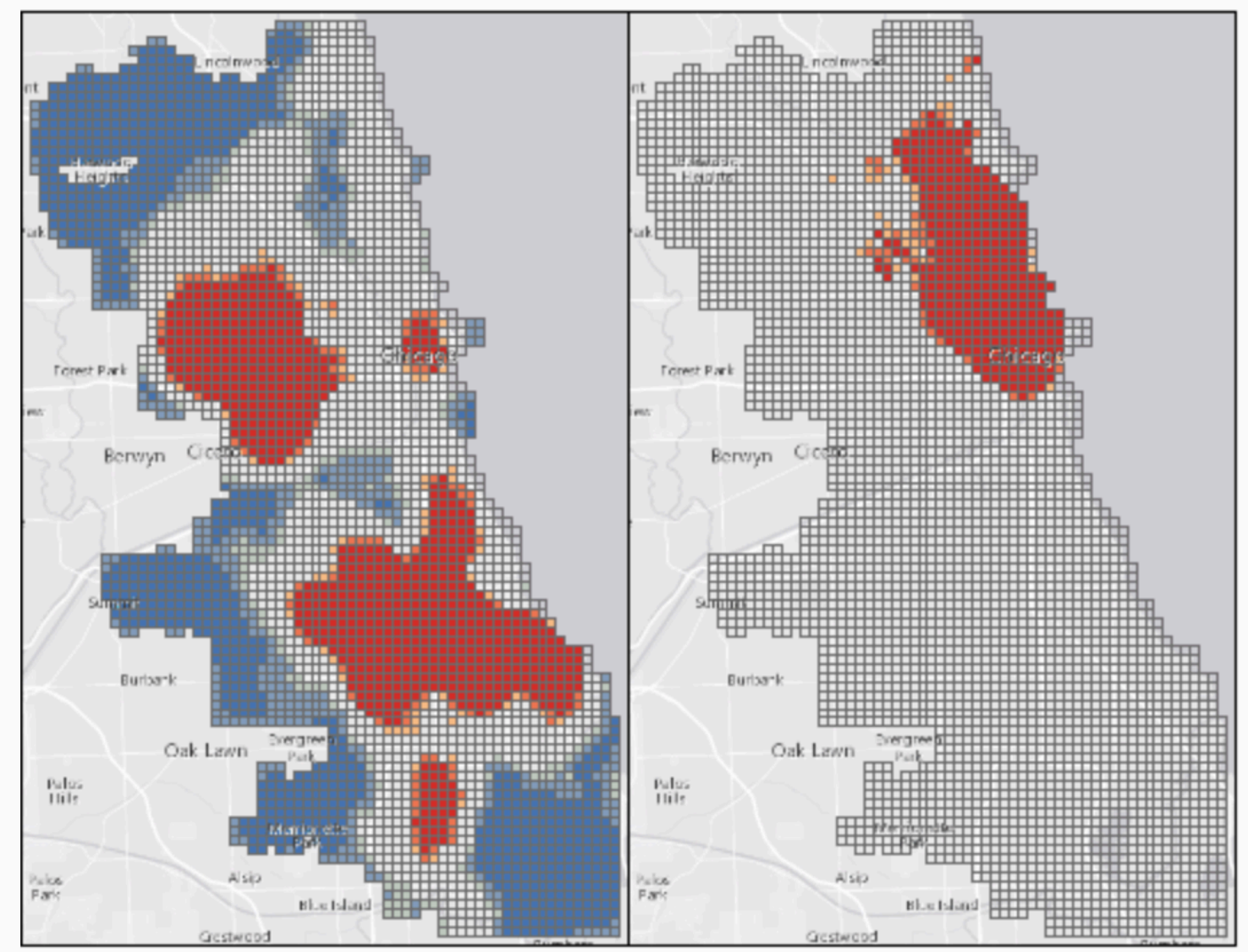

Figure 2-2: Hot spots Analyses.

Another case study by Esri (2016b) showed tornado data in the United States. One question was to find how many tornadoes occurred in each state. The approach taken was aggregating tornadoes data to the states data. This was done by using Spatial Join tool. The result of this analysis added a field in the output feature class containing the count of the tornadoes in each state. The field was then used to symbolize the state data by giving them a color range where dark colors represent high numbers of tornadoes and light colors represent lower numbers of tornadoes (Figure 2-3). 


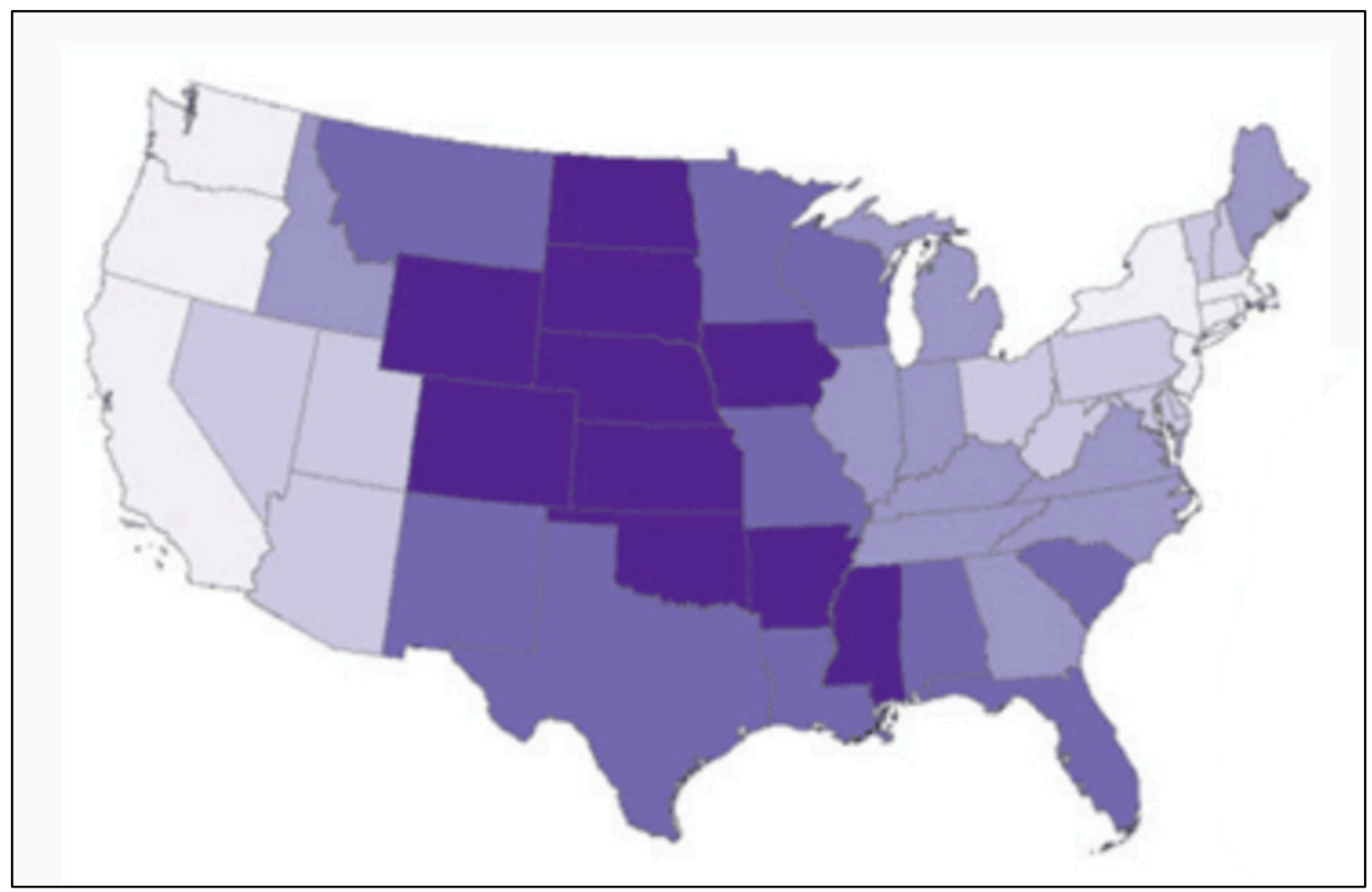

Figure 2-3: Choropleth Map.

Furthermore, applying density analysis on the data would visually highlight these patterns. According to Krause, "one of the most common uses of the Kernel Density and Point Density tools is to smooth out the information represented by a collection of points in a way that is more visually pleasing and understandable" (2013, pg. 2). Determining the most concentrated areas to plan for search and recovery missions increases the likelihood of finding wreckage sites due to the fact that the probability of finding one location among many other locations is higher than finding one discrete location.

Terrain can be an influencing factor in determining the locations of wreckage sites. According to Shilpi Jain (2015),

Terrain plays an important role while calculating the impact of an accident, whether it is a car crash, an airplane crash, or any other. Different angles and directions of terrain can result in very different debris area even if all the other parameters are [the] same. (p.6)

Jain improved a mobile application that was developed by Janzen in 2012, Crash Site Debris Recovery Mobile Application (CSDRMA), to include the influence of terrain. While in his case the CSDRMA would help to find all debris, terrain data, if added to this project, could assist in locating the cockpit to search for human remains.

\subsection{Summary}

The purpose of this chapter was to review previous works and to gather information about the problem and how to solve it. It discussed the efforts involved in aviation archaeology and how it can be used to locate and recover aircraft wreckage. It also 
addressed how GIS can be a useful tool for representing the data of such a project and applying different analyses to them to gain a more complete understanding to make the best decisions. 


\section{Chapter 3 -Systems Analysis and Design}

\subsection{Problem Statement}

The Defense POW/MIA Accounting Agency work relies on extracting information from different data sources. The primary data sources used in this project was historical documents created in 1961 which contain information about aircraft wreckage locations in Papua and New Guinea from WWII. These documents were in a PDF file which limited their use for several reasons. First, extracting a piece of information about a wreck location takes a long time because it requires looking through approximately 800 rows of records manually. Second, finding corresponding data to a specific record may require searching external datasets. Third, a PDF lacks the ability to visualize spatial data in an interactive way and does not allow spatial analyses on them.

\subsection{Requirements Analysis}

A requirements analysis describes in detail the requirements a project needs to achieve its goal. These requirements are divided into functional and non-functional requirements. The functional requirements describe what the final product or the system will do; the non-functional requirements describe how the system does it. Defining these requirements ensures a system design that meets the client's needs.

\subsubsection{Functional Requirements}

The functional requirements defined what functions the system must provide for this project.

- The system must allow the user to store and add different feature classes and tables and relate them to one another in one place. The capacity of the file geodatabase had to be sufficient for the intended work. Storing all the feature classes and tables in one place allows faster retrieval of the data.

- The system should enable the user to select features by attribute. For instance, the attribute contains a field that stores aircraft names and the user only wants to select all the aircraft named Anson; using this functionality will allow selecting them all automatically. Selecting aircraft by country of origin and type of aircraft are parts of attribute selection. However, it needed to be stated separately because the client required them specifically. Thus, separate fields were created for them to achieve that.

- Select by location allows selecting features from one layer based on where they lie on another layer. For example, the user wants to select all the aircraft located at Moresby area; the function will allow selecting them based on the spatial relationship between the aircraft location layer and the area layer.

- The geodatabase shall allow the user to edit, add, and delete an entry because the work on finding the wrecks locations is still ongoing. Therefore, updating an attribute, such as the status of a wreck location whether it is recovered or not, 
needs to be updatable. Furthermore, spatial analyses may result in the creation of new feature classes, so the system must allow the addition of derived data.

The system shall allow map design and creation. The client required a series of maps to be designed and produced. Therefore, the system shall provide the ability to design maps and provide the necessary tools, such as scale bar, legend, north arrow, etc. Also, the system shall allow exporting these maps to PDF files for sharing purposes or printing.

\subsubsection{Non-functional Requirements}

Non-functional requirements define measures to be used to assess how a system operates.

- Efficiency of the system: The system should take minimal time, effort, and resources to create the solution within one minute.

- Scalability of the system: The system can take a varying amount of data, which means that it can hold a much larger amount of data than the ones already loaded.

\subsubsection{Technical Requirements}

The technical requirements needed to produce the solution for this project consisted of hardware and software. These requirements were a computer run on Windows operating system with at least the minimum specs to operate ArcGIS for Desktop 10.3.1. ArcGIS for Desktop included ArcMap and ArcCatalog, which were the two main software packages used to develop the solution. Adobe Acrobat and Microsoft Excel were needed in the data migrating phase.

\subsection{System Design}

The system components were classified into three general parts, shown in Figure 3-1: input, process, and output. Input illustrates the data components. Process illustrates the software and methods used to produce the final products. Output illustrates the final products of the project. 


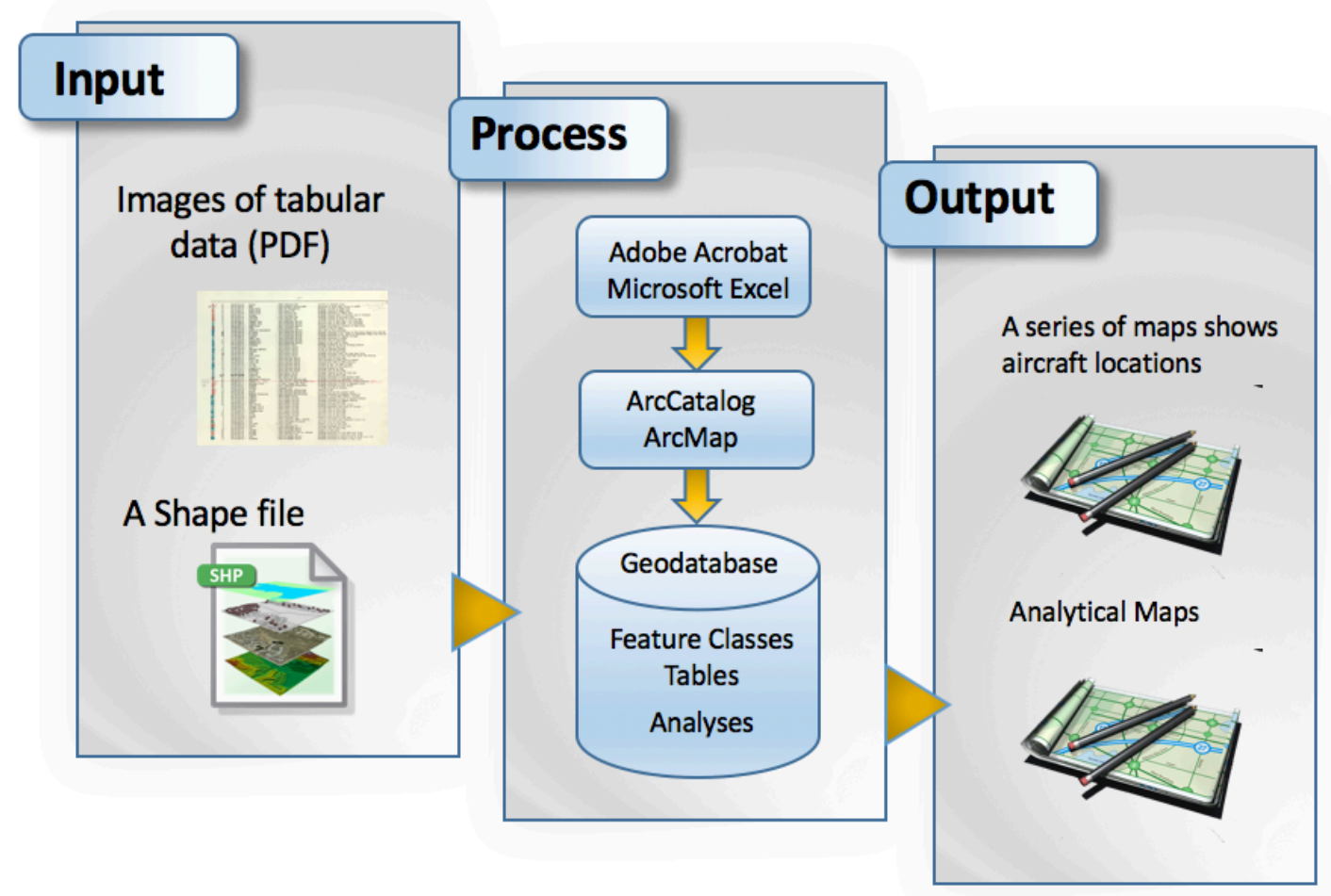

Figure 3-1: System Design.

The input component is the data acquired for the project, which are images of tabular data and a shapefile for the study area. The images of tabular data were provided by the client in a PDF file which contained 14 tables of approximately 800 rows. Each row contained information about an aircraft's location, as well as aircraft name, type, and serial number. The shapefile represented the study area as polygons. It was acquired from gadm.org, a website that provides data of administrative areas of the world.

The process component consisted of the software and the file geodatabase used to process the data. The software that were used were Adobe Acrobat and Microsoft Excel to prepare the data from the PDF file to migrate them to ArcMap. ArcCatalog was used to build the file geodatabase and create the feature classes and non-spatial tables. ArcMap was used to process the data and run analyses on them to produce the final products. The output component consisted of the final products that were developed using the previous two components: a series of maps that cover the study area and show the aircraft wrecks locations; and analytical maps that show the results of the analyses conducted on the data.

\subsection{Project Plan}

This section presents the plan that was taken to accomplish the objectives of the project (see Table 2). Each task was given an estimated time to accomplish it. Three milestones were set to the project to track its progress. These milestones were the data converted and ready in Excel format, the file geodatabase including the feature classes and tables are created and reviewed, and the map series produced. 
- Phase 1: Planning. The estimated time for this phase was two months. This phase determined the needs for proceeding with the work of the project. It included reviewing the client's requirements to decide what requirements this project would need and how long each task would take.

- Phase 2: Data conversion. The estimated time for this phase was two months. This phase included two tasks. The first one was converting the data from PDF file into Microsoft Excel. The second one was importing the data from Excel to ArcMap.

- Phase 3: Database design and development. This phase was estimated to be done in two months. It included the conceptual design of the database, the logical design, and developing it in ArcCatalog.

- Phase 4: Data loading and testing. This phase was estimated to take one month and followed the data conversion and the database development. It involved importing the data into the file geodatabase, then testing whether the database met the client's criteria. If not, it would be redeveloped to meet them.

- Phase 5: Map design and production. This phase was estimated to be finished in one month. It included designing and producing a series of maps.

- Phase 6: Completion of project. This phase was estimated to take two months. It included reviewing and delivering the project to the client, as well as finishing the project report and submitting it to the MS GIS department.

Table 3-1: Project Plan

\begin{tabular}{|c|l|l|l|l|l|}
\hline WBS & Task Title & Duration & $\begin{array}{l}\text { Start } \\
\text { Date }\end{array}$ & $\begin{array}{l}\text { End } \\
\text { Date }\end{array}$ & $\begin{array}{l}\text { Budgeted } \\
\text { Hours }\end{array}$ \\
\hline $\mathbf{1}$ & Planning Phase & $\mathbf{2}$ Months & $\mathbf{2 / 2 5 / 1 6}$ & $\mathbf{4} / \mathbf{2 5} / \mathbf{1 6}$ & $\mathbf{1 0 5}$ \\
\hline 1.1 & $\begin{array}{l}\text { Confirm project scope and work } \\
\text { plan }\end{array}$ & 28 days & $2 / 25 / 16$ & $4 / 5 / 16$ & 84 \\
\hline 1.2 & Data Evaluation & 7 days & $4 / 6 / 16$ & $4 / 25 / 16$ & 21 \\
\hline $\mathbf{2}$ & Data Conversion & $\mathbf{2}$ Months & $\mathbf{4 / 2 6 / 1 6}$ & $\mathbf{6 / 2 7 / 1 6}$ & $\mathbf{1 2 6}$ \\
\hline 2.1 & Convert from PDF to Excel & 40 days & $4 / 26 / 16$ & $6 / 23 / 16$ & 120 \\
\hline 2.2 & Import Excel to ArcMap & 2 days & $6 / 24 / 16$ & $6 / 27 / 16$ & 6 \\
\hline $\mathbf{3}$ & Database Design and Developing & $\mathbf{2}$ Months & $\mathbf{6 / 2 8 / 1 6}$ & $\mathbf{8} / \mathbf{2 6} / \mathbf{1 6}$ & $\mathbf{1 3 2}$ \\
\hline 3.1 & Conceptual data model & 8 days & $6 / 28 / 16$ & $7 / 7 / 16$ & 24 \\
\hline 3.2 & Logical data model & 10 days & $7 / 8 / 16$ & $7 / 21 / 16$ & 30 \\
\hline 3.3 & $\begin{array}{l}\text { Develop the database in } \\
\text { ArcCatalog }\end{array}$ & 26 days & $7 / 22 / 16$ & $8 / 26 / 16$ & 78 \\
\hline $\mathbf{4}$ & Data Loading and Testing & $\mathbf{1}$ Months & $\mathbf{8 / 2 9 / 1 6}$ & $\mathbf{9 / 3 0 / 1 6}$ & $\mathbf{6 6}$ \\
\hline 4.1 & data loading to geodatabase & 5 days & $8 / 29 / 16$ & $9 / 2 / 16$ & 15 \\
\hline 4.2 & Test the geodatabase & 17 days & $9 / 5 / 16$ & $9 / 30 / 16$ & 51 \\
\hline $\mathbf{5}$ & Map Designing and Production & $\mathbf{1}$ Months & $\mathbf{1 0 / 3 / 1 6}$ & $\mathbf{1 0 / 3 1 / 1 6}$ & $\mathbf{6 6}$ \\
\hline $\mathbf{6}$ & Completion of Project & $\mathbf{2}$ Months & $\mathbf{1 1 / 1 / 1 6}$ & $\mathbf{1 2 / 1 0 / 1 6}$ & $\mathbf{3 2}$ \\
\hline 6.1 & $\begin{array}{l}\text { Deliver the project to the client } \\
\text { and to MS GIS Department }\end{array}$ & 32 days & $11 / 1 / 16$ & $12 / 10 / 16$ & 32 \\
\hline
\end{tabular}




\subsection{Summary}

This chapter presented the problem statement, requirements analysis, system design, and project plan. The project problem was restated in the problem statement. The requirements analysis included the system functional and non-functional requirements, as well as the technical requirements for the project. The system design included three components: input, process, and output. The input contained the acquired data needed for the project. The process discussed the software used to build the new system and what software would be used for what part of the project. The output defined the final products of the project, which are a series of maps of aircraft wrecks locations and analytical maps. 



\section{Chapter 4 -Database Design}

This chapter discusses the database design, which involved creating the conceptual and logical data models. These models help the users understand the different entities of the database and the relationships between them. Furthermore, it addresses where the data were obtained and how they were collected. Lastly, it discusses data preparation needed before loading them into the database.

\subsection{Conceptual Data Model}

The conceptual data model provides a high-level understanding of the different entities of the data and the relationships between them. Figure 4-1 shows the conceptual data model of the geodatabase that was designed to solve the DPAA's problem.

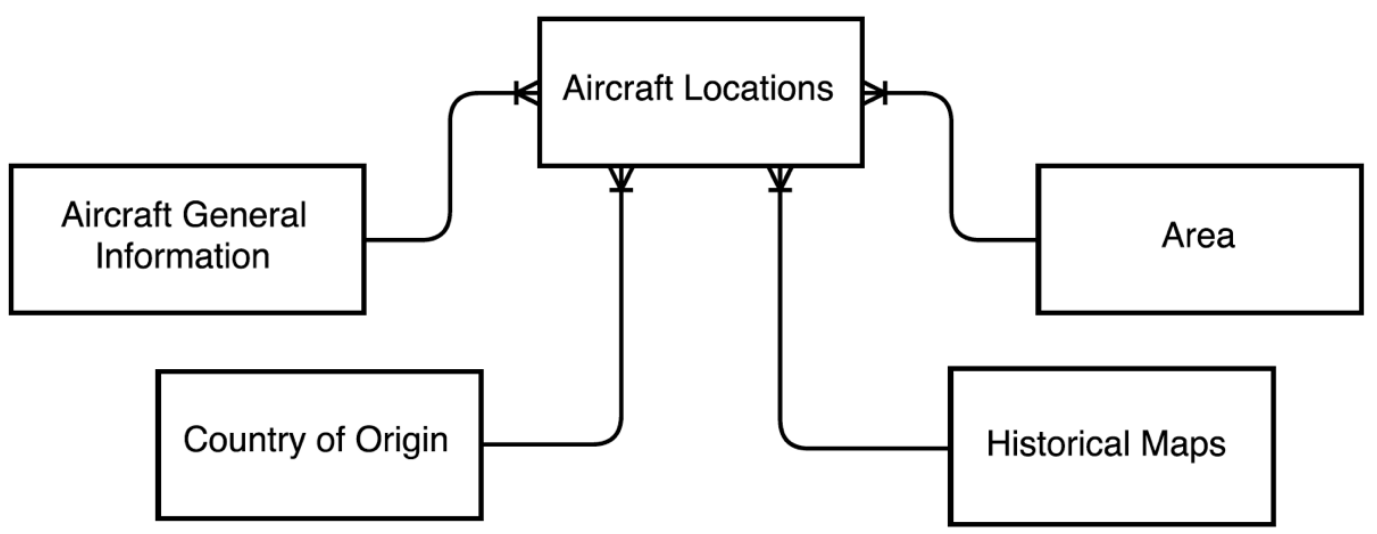

Figure 4-1: Conceptual data model.

The database was comprised of two types of entities: feature classes, and non-spatial tables. The feature classes are Aircraft Locations and Area. Aircraft Locations is a point feature class that shows the locations of the aircraft wrecks, whereas the Area is a polygon feature class that shows the administrative areas in which aircraft wrecks are located. Aircraft General Information, Country of Origin, and Historical Maps are nonspatial tables that contain additional related information of the features about the Aircraft Locations. The data they hold were created in tables separate from the Aircraft Locations feature class to normalize the database. Furthermore, the relationship between Aircraft Locations and other entities is one to many, which means that, for instance, more than one aircraft wreckage can be located in one area, as well as many aircraft can belong to one country, and so on with the rest of the entities.

\subsection{Logical Data Model}

The logical data model adds to the conceptual data model by providing additional information about the entities in the database, including the field name for each entity and 
the type of each field. Moreover, it shows the primary and foreign keys used to relate each entity with another. Figure 4-2 lays out the logical model for this project.

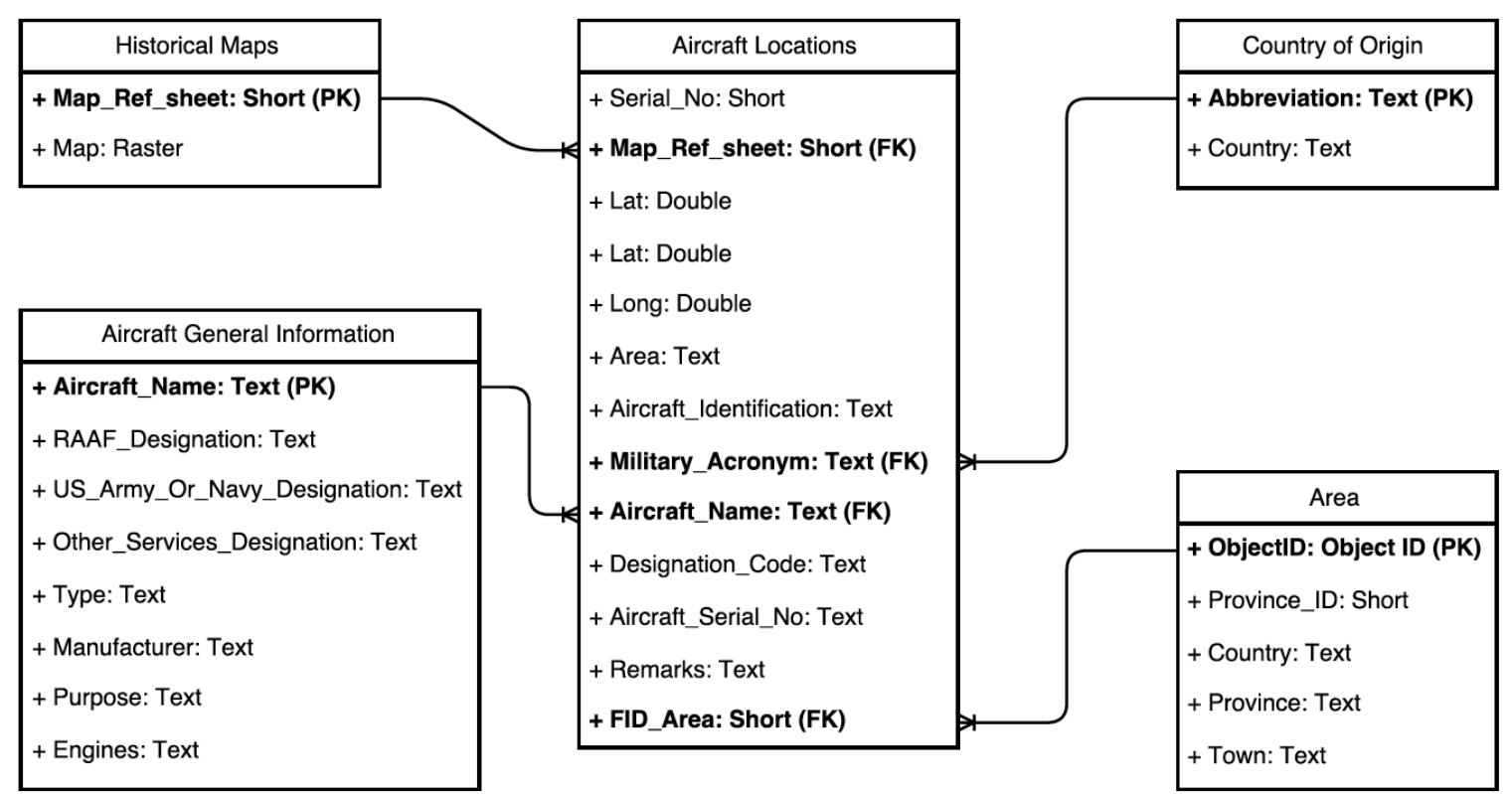

Figure 4-2: Logical data model.

The main feature class for the project is Aircraft Locations, which is why all the other entities are related to it. Country of Origin is associated with Aircraft Locations using the primary key Abbreviation in Country of Origin and the foreign key "Military_Acronym" in Aircraft Locations. The abbreviation and "Military_Acronym" fields contain military force names abbreviations such as RAAF, USAC, and RNZAF. They are used to indicate which aircraft wreckage belongs to which country by identifying it. The area is associated with Aircraft Locations using the primary key "ObjectID" and the foreign key "FID_Area." This association allows the user to look up the name of the country, province, and town where an aircraft wreckage is located. Aircraft General Information contains data about the aircraft manufacturer, types, and engines, as well as the military purpose and other identification fields. "Aircraft_Name" primary and foreign keys were used to associate the Aircraft General Information and Aircraft Locations to each other. Historical Maps contains images (raster data) of historical maps that show the locations of the aircraft wreckages. It was suggested to the client that the historical maps be added to the geodatabase in case the users needed to extract some information from them. "Map_Ref_Sheet" primary and foreign keys were used to associate the Historical Maps and the Aircraft Locations to each other.

\subsection{Data Sources}

The data used in this project were obtained from the Defense POW/MIA Accounting Agency (DPAA) and GADM.org. The Aircraft Locations, Aircraft General Information, and Historical Maps feature class and tables were created from the PDF file provided by 
the client. The PDF file is a survey of aircraft wreckage locations in Papua and New Guinea that was conducted by the Royal Australian Air Force (RAAF). The data in this survey were compiled from all the available records at Department of Air Canberra and is based on reports from searches that were conducted during WWII until 1961 (Royal Australian Air Force, 1961). The client provided GADM's website link where a shapefile of the whole world administrative areas was downloaded; then a feature class that covers the study area was derived from that shapefile. The Country of Origin table was created to store and relate country names to the associated military force abbreviations.

\subsection{Data Scrubbing and Loading}

The data for this project needed a great deal of preparation before they were ready for loading into the geodatabase. The data preparation involved two stages: converting the data from PDF file into Microsoft Excel, and importing them from Excel to ArcMap.

The PDF file included tables that contain records of approximately 800 aircraft wreckages (Figure 4-3).

\begin{tabular}{|c|c|c|c|c|c|c|}
\hline \multicolumn{7}{|c|}{$\frac{-4-}{\text { INDEX OF CRASHED AIRCRAFT }}$} \\
\hline$\frac{\text { SERPLLL }}{\text { BOC. }}$ & 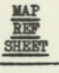 & LAT. LONG. & $\underline{A B A}$ & & AIRCRAFT IDENTIFICATIOI & BFYABKS \\
\hline $\begin{array}{l}1 \\
2 \\
3 \\
4 \\
5 \\
5 \\
6 \\
7 \\
8 \\
9 \\
10 \\
11 \\
12 \\
13 \\
14 \\
15 \\
16 \\
17 \\
18 \\
19 \\
20 \\
22 \\
22 \\
23 \\
24 \\
25 \\
25 \\
27 \\
29\end{array}$ & $\begin{array}{r}12 \\
9 \\
12 \\
9 \\
9 \\
9 \\
9 \\
9 \\
10 \\
10 \\
10 \\
10 \\
10 \\
3 \\
3 \\
1 \\
12 \\
12 \\
12 \\
12 \\
10 \\
10 \\
10 \\
10 \\
13 \\
10 \\
10 \\
10\end{array}$ & $\begin{array}{l}09.05-147.47 \\
07.53-147.11 \\
08.40-148.24 \\
06.42-147.00 \\
05.34-148-34 \\
05.30-148.30 \\
06.44-147.01 \\
06.43-149.50 \\
0.44-152.17 \\
06.54-151.10 \\
05.33-150.54 \\
05.33-150.54 \\
05.07-151.08 \\
03.35-143.40 \\
03.24-143.48 \\
02.50-132.53 \\
09.32-147.16 \\
09.32-147.15 \\
10.08-148.01 \\
08.10-148.29 \\
05.14-151.55 \\
06.14-150.14 \\
06.09-150.19 \\
06.20-150.21 \\
09.53-152.03 \\
06.13-150.22 \\
04.14-152.10 \\
06.30-154.02\end{array}$ & 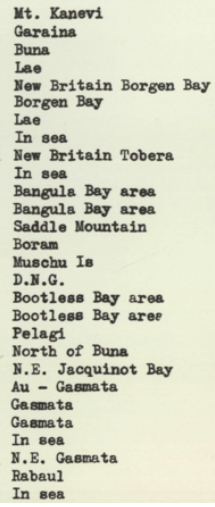 & 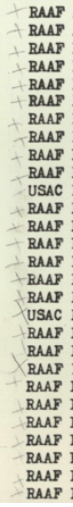 & 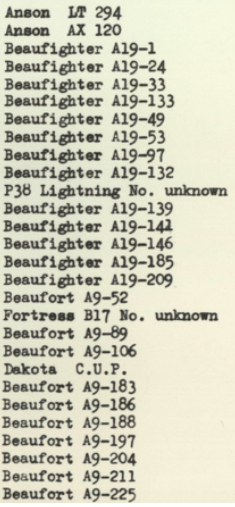 & 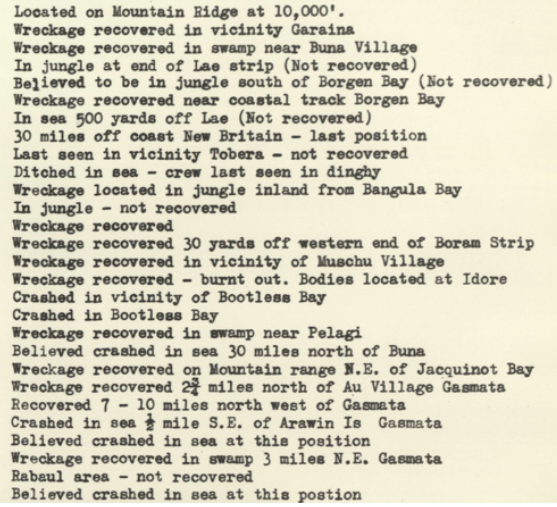 \\
\hline
\end{tabular}

Figure 4-3: Historical data sample.

These records had to be converted into Excel format in order to move them to ArcMap. Since the data were static images, the use of optical character recognition (OCR) tool was necessary. The OCR tool within Adobe Acrobat was used to convert the data to text so they could be exported to an Excel file automatically from Adobe Acrobat. Unfortunately, the exporting result was not usable (Figure 4-4). Thus, the records had to be moved manually by copying them from the PDF file and pasting them into an Excel file. 


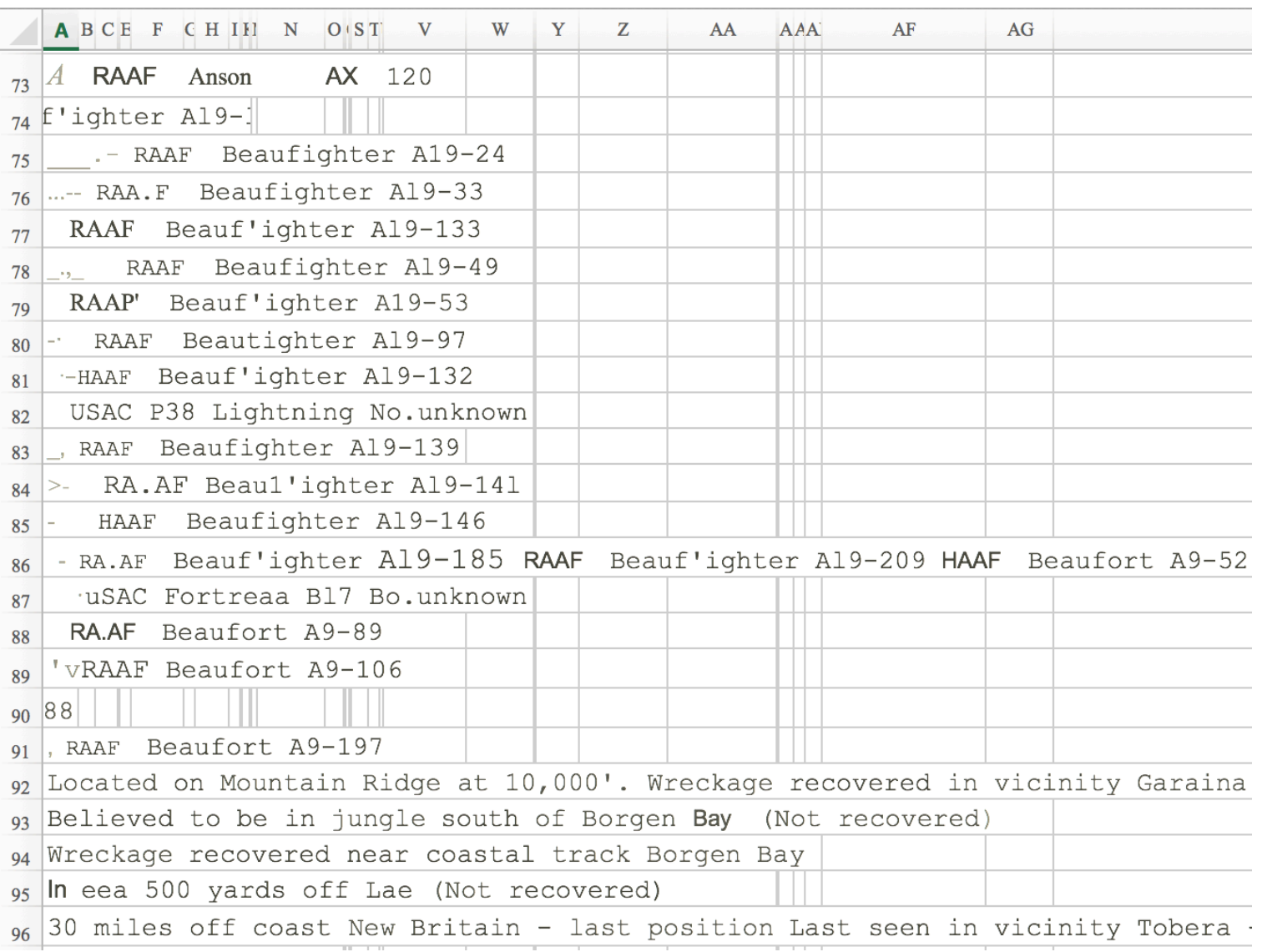

Figure 4-4: Unusable data.

To further illustrate the issue of the automation exporting, a portion from the original documents (scanned image from the PDF file), the result from the automated export in Excel, and the result from the manually exported Excel are presented next to one another Figure (4-5).

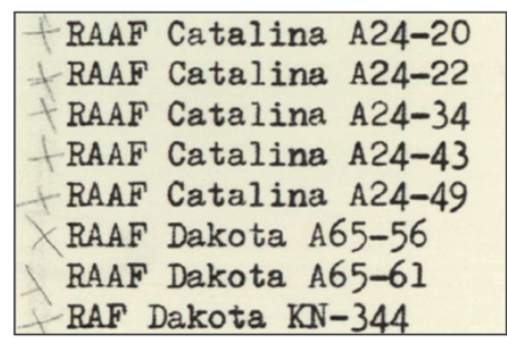

Original Document

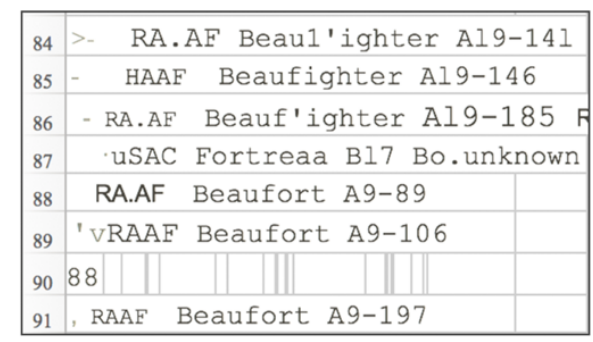

Automated

Export

\begin{tabular}{|l|}
\hline RAAF Catalina A24-20 \\
\hline RAAF Catalina A24-22 \\
\hline RAAF Catalina A24-34 \\
\hline RAAF Catalina A24-43 \\
\hline RAAF Catalina A24-49 \\
\hline RAAF Dakota A65-56 \\
\hline RAAF Dakota A65-61 \\
\hline RAF Dakota KN-344 \\
\hline
\end{tabular}

Manually

Exported

Figure 4-5: A Portion of three data versions.

The same rows were captured in the three photos shown above. There were several issues with the automated export. First, it failed to keep the data organized. It can be noticed 
when comparing the original document's photo with the automated export's photo that they do not present the same texts even though they were captured to present the same rows. Second, when the data were exported to the Excel sheet, some of the letters were incorrectly recognized, such as the " $\mathrm{f}$ " in "beaufighter" that was exported as " 1 ". On the other hand, the manually exported data were the same as the original document data because they were controlled when they were moved to the Excel sheet.

As shown in Figure 4-3, the tables contained six columns: "Serial No.," "Map Ref Sheet," "Lat.Long.," Area, Aircraft Identification, and Remarks. "Serial No." gave a unique number to every record so they could be easily distinguished from one another. The PDF file had 13 maps, numbered from one to 13, that showed the records as points; the "Map Ref Sheet" defined on which map each record was presented. The "Lat.Long." column gave the $\mathrm{X}$ and $\mathrm{Y}$ coordinates for each point, which represent the aircraft wreckage locations. The latitude and longitude were separated into two different columns when they were moved to the Excel file to have them ready to be imported to ArcMap. The Area column provided the name of the area where a wreck is located. The provided names in this column could be a name of a province, a town, or simply a vague piece of information such as "In sea." The Area column was considered problematic for users who are not familiar with the study area. Therefore, in the geodatabase, the Area feature class attribute table was set to have a separate field for provinces and towns so to be easier to distinguish provinces from towns. Aircraft Identification column involved distinct data such as an acronym for the military force name which an aircraft belongs to, aircraft name, aircraft designation code, and aircraft serial number. Each of these distinct data was placed in a separate column after they were moved to the Excel file to normalize the data. Figure 4-4 shows the columns before and after the separation in the Excel file.

\begin{tabular}{|l|}
\hline \multicolumn{1}{|c|}{ Aircraft_Identification } \\
\hline RAAF Anson LT 294 \\
\hline RAAF Anson AX 120 \\
\hline RAAF Beaufighter A19-1 \\
\hline RAAF Beaufighter A19-24 \\
\hline RAAF Beaufighter A19-33 \\
\hline RAAF Beaufighter A19-133 \\
\hline RAAF Beaufighter A19-49 \\
\hline RAAF Beaufighter A19-53 \\
\hline RAAF Beaufighter A19-97 \\
\hline RAAF Beaufighter A19-132 \\
\hline USAC P38 Lightning No. unknown \\
\hline RAAF Beaufighter A19-139 \\
\hline RAAF Beaufighter A19-141 \\
\hline RAAF Beaufighter A19-146 \\
\hline RAAF Beaufighter A19-185 \\
\hline RAAF Beaufighter A19-209 \\
\hline RAAF Beaufort A9-52 \\
\hline USAC Fortress B17 No. unknown \\
\hline RAAF Beaufort A9-89 \\
\hline RAAF Beaufort A9-106 \\
\hline RAAF Dakota C.U.P. \\
\hline RAAF Beaufort A9-183 \\
\hline RAAF Beaufort A9-186 \\
\hline RAAF Beaufort A9-188 \\
\hline RAAF Beaufort A9-197 \\
\hline
\end{tabular}

\begin{tabular}{|l|l|c|c|}
\hline Abbreviation & Aircraft_Name & Designation_Code & Aircraft_Serial_No. \\
\hline RAAF & Anson & LT & 294 \\
\hline RAAF & Anson & AX & 120 \\
\hline RAAF & Beaufighter & A19 & 1 \\
\hline RAAF & Beaufighter & A19 & 24 \\
\hline RAAF & Beaufighter & A19 & 33 \\
\hline RAAF & Beaufighter & A19 & 133 \\
\hline RAAF & Beaufighter & A19 & 49 \\
\hline RAAF & Beaufighter & A19 & 53 \\
\hline RAAF & Beaufighter & A19 & 97 \\
\hline RAAF & Beaufighter & A19 & 132 \\
\hline USAC & Lightning & P38 & \\
\hline RAAF & Beaufighter & A19 & 139 \\
\hline RAAF & Beaufighter & A19 & 141 \\
\hline RAAF & Beaufighter & A19 & 146 \\
\hline RAAF & Beaufighter & A19 & 185 \\
\hline RAAF & Beaufighter & A19 & 209 \\
\hline RAAF & Beaufort & A9 & 52 \\
\hline USAC & Fortress & B17 & \\
\hline RAAF & Beaufort & A9 & 189 \\
\hline RAAF & Beaufort & A9 & 106 \\
\hline RAAF & Dakota & A.U.P. & \\
\hline RAAF & Beaufort & A9 & 183 \\
\hline RAAF & Beaufort & & 186 \\
\hline RAAF & Beaufort & Aeaufort & \\
\hline RAAF & A9 & \\
\hline & & & \\
\hline
\end{tabular}

Figure 4-6: Aircraft Identification columns. 
It was also crucial to separate them to meet the client's requirement to have the ability to view the aircraft by their designation codes. In addition, aircraft names had to be in separate field to use them to relate the feature class Aircraft Locations to the table Aircraft General Information. The column Remarks contained descriptive information about the locations of the wreckage or the status of the wreckage such as that the aircraft wreckage is located on mountain ridge at 10,000 feet, wreckage was recovered, and wreckage was not recovered.

Following moving the data from the PDF file, it was time to import them to ArcMap. The Add XY data method was used to import the data to ArcMap. Esri's base map was added to see if the points were located where they were supposed to, but unfortunately, they were not at the correct place (Figure 4-5).

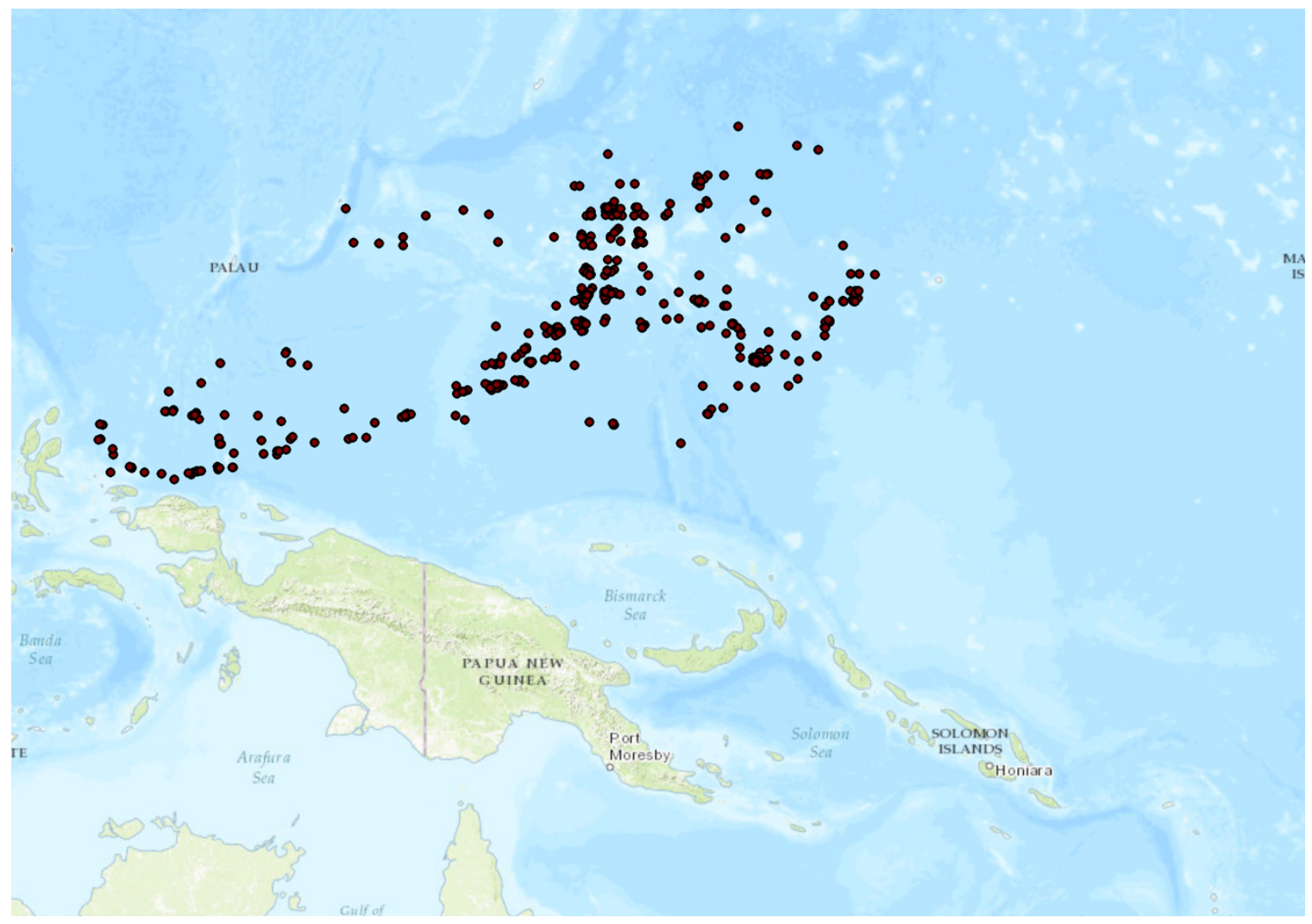

Figure 4-7: Wrong locations of the data.

Two issues were found with the latitude and longitude. First, they were in degrees, minutes, and seconds format, yet they were written as if they were decimal degrees. Second, the latitude values were positive even though the study area was south the equator. Consequently, the two issues were edited back in the Excel file and the data were imported to ArcMap again. Another issue was found with some of the aircraft wreckage locations, which occurred during the separation and conversion of their coordinates from degrees-minutes format into decimal-degrees format in the Excel file. When separating the degrees and minutes into two separated columns, the minutes' values that were for example, 10, 20, or 40 were written 1,2, or 4 instead of the correct values, which caused having incorrect decimal-degrees values after the conversion 
occurred. This problem happened because the degrees-minutes values were written as if they were decimal-degrees values and when the separation occurred the system omitted the zero on the right because it does not have a value in that format.

The shapefile Area, which was acquired from GADM.org, needed scrubbing. Initially, the administrative areas of the world were deleted except the study area. The attributes were then scrubbed by omitting fields that were not in English and by changing the names of the fields with meaningful names that described their contents.

\subsection{Summary}

This chapter addressed the conceptual and logical data model, data sources, and data scrubbing and loading. The conceptual data model defined the different feature classes and tables used in the system and their relationship to one another. The logical data model described the attribute fields for each feature class and table, and defined the fields that were used to relate every two entities to each other. The data sources addressed where the data were obtained from. The major work addressed in this chapter was data scrubbing and loading. It took a lot of time because it involved converting the data from a PDF file into Microsoft Excel, and then moving them to ArcMap as shapefiles before they were ready to be load into the geodatabase. 



\section{Chapter 5 -Implementation}

This chapter discusses the implementation of the geodatabase and the analyses that were conducted on the data. The tools and methods that were used to conduct the analyses are also addressed. The developed geodatabase would help the Defense POW/MIA Accounting Agency (DPAA) to more efficiently compare the Royal Australian Air Force (RAAF) survey data with other datasets and records by combining them in ArcMap.

\subsection{Royal Australian Air Force Geodatabase}

The geodatabase for RAAF survey data was produced using ArcCatalog. The process involved creating the file geodatabase, then creating each of the feature classes and nonspatial tables individually. After all the feature classes and non-spatial tables were created, the relationships between them were created (Figure 5-1).

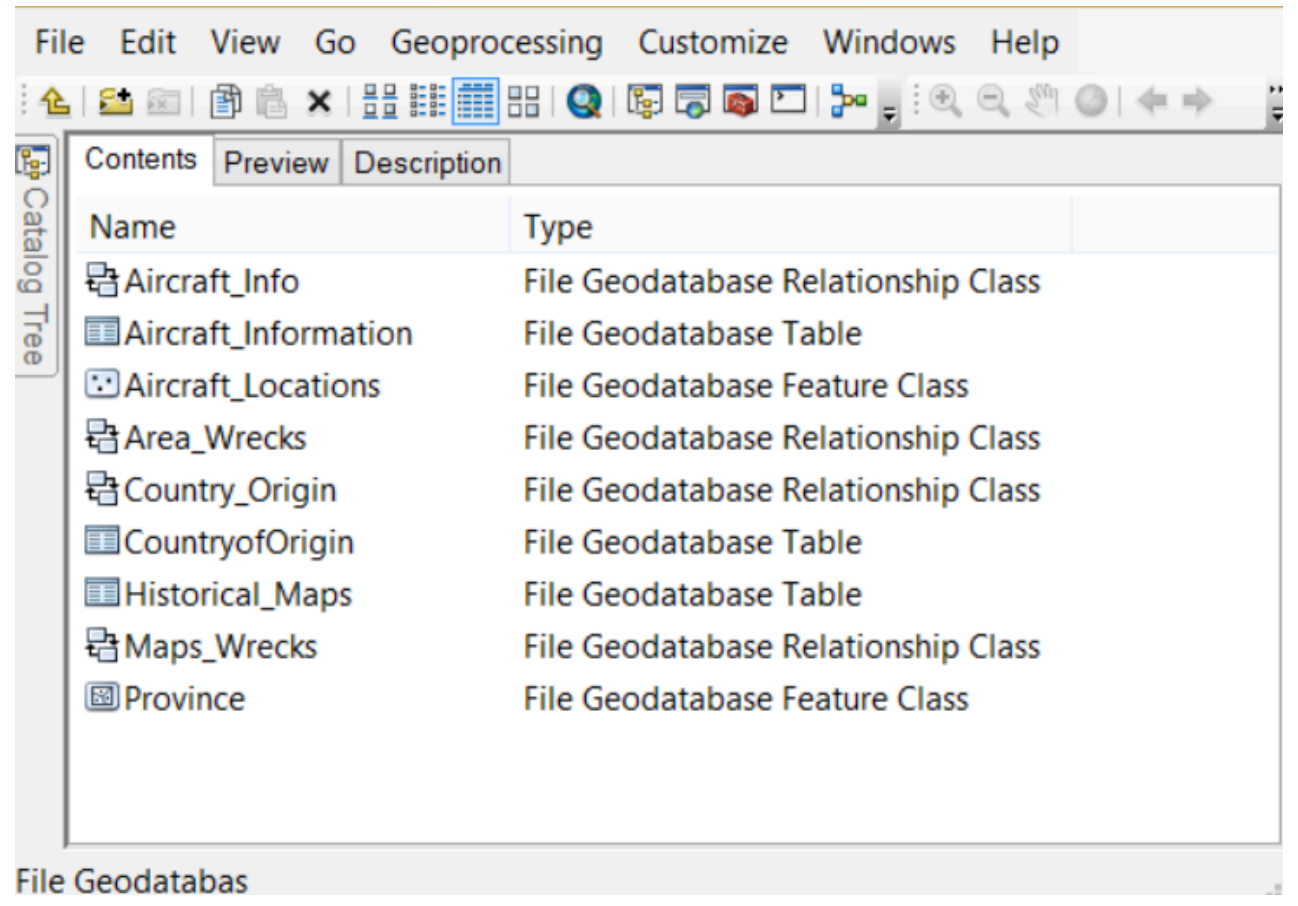

\section{Figure 5-1: RAAF Geodatabase.}

Following the creation of the geodatabase, the data that were moved from the PDF file into ArcMap were loaded into the Aircraft Locations feature class using the Simple Data Loader in ArcCatalog (Figure 5-2). 


\begin{tabular}{l} 
Simple Data Loader \\
For each target field, select the source field that should be loaded into it. \\
\begin{tabular}{|l|l|}
\hline \multicolumn{1}{|c}{ Target Field } & \multicolumn{1}{c}{ Matching Source Field } \\
\hline Serial_No [short int] & Serial_No [short int] \\
\hline Map_Ref_Sheet [short int] & Map_Ref_Sheet [short int] \\
\hline Lat [double] & Lat [double] \\
\hline Long [double] & Long [double] \\
\hline Area [string] & Area [string] \\
\hline Aircraft_Identification [string] & Aircraft_Identification [string] \\
\hline Military_Acronym [string] & Military_Acronym [string] \\
\hline Aircraft_Name [string] & Aircraft_Name [string] \\
\hline Designation_Code [string] & Designation_Code [string] \\
\hline Aircraft_Serial_No[string] & Aircraft_Serial_No[string] \\
\hline _..... & \\
\hline
\end{tabular} \\
\hline
\end{tabular}

Figure 5-2: Data Loading.

The same method was used to load the data into the Area feature class and the table Aircraft General Information. The data in the Country of Origin table and Historical Maps were entered during an edit session in ArcMap. In the Country of Origin table, the field Country contains the country name for each military force acronym that exists in the data.

The Country of Origin table was created to meet the client's requirement to show the aircraft wreckage by country of origin. To accomplish this, the Country field was joined into the Aircraft Locations feature class and it was used to symbolize the data. The feature class was then saved as a layer file to retain the symbolized data. Figure 5-3 shows the data symbolized based on the country of origin. 


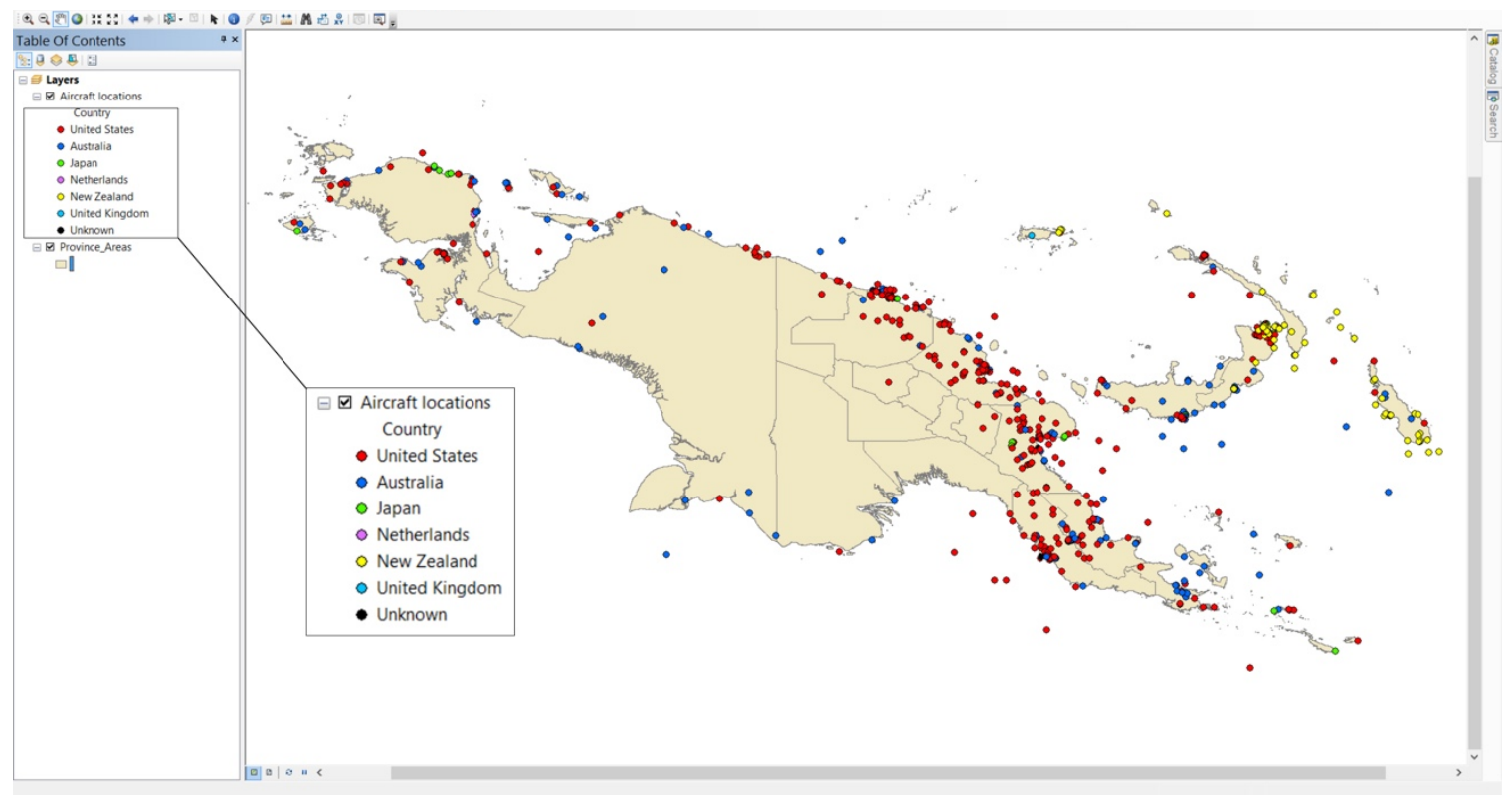

Figure 5-3: Symbolized Data Based on Country of Origin.

Another layer file was created to show the aircraft locations with symbols based on the US designation code (Figure 5-4). The designation code is used to identify the aircraft type or purpose. It identifies whether an aircraft was a fighter, bomber, transporter, or used for other purposes.

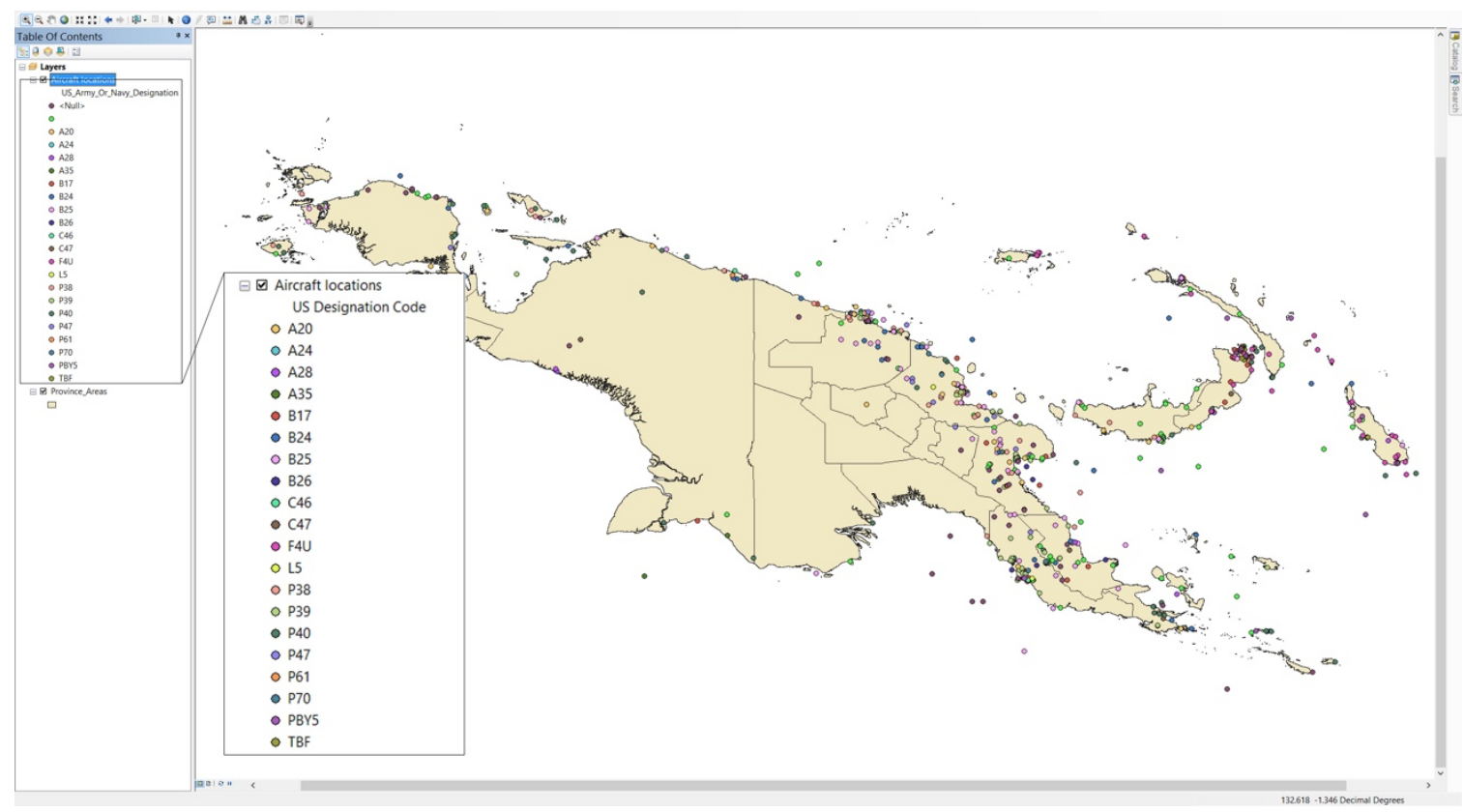

Figure 5-4: Symbolized Data Based on US Designation Code. 


\subsection{Spatial Statistical Analyses}

For spatial analyses, the data needed to be projected to an appropriate coordinate system that preserves distance and area to have reliable results; the Papua New Guinea Map Grid 1994 (PNGMG94) was used. Since the study area was large and the data were spread across three different Universal Transverse Mercator (UTM) zones, zone 55 was chosen because it covers most of the aircraft wreckage locations. Even though UTM is a conformal projection that preserves angles and distorts distance and area, the distortion for this data is minimal because the study area is very close to the equator. The data were projected by using the geoprocessing tool Project (Figure 5-5).

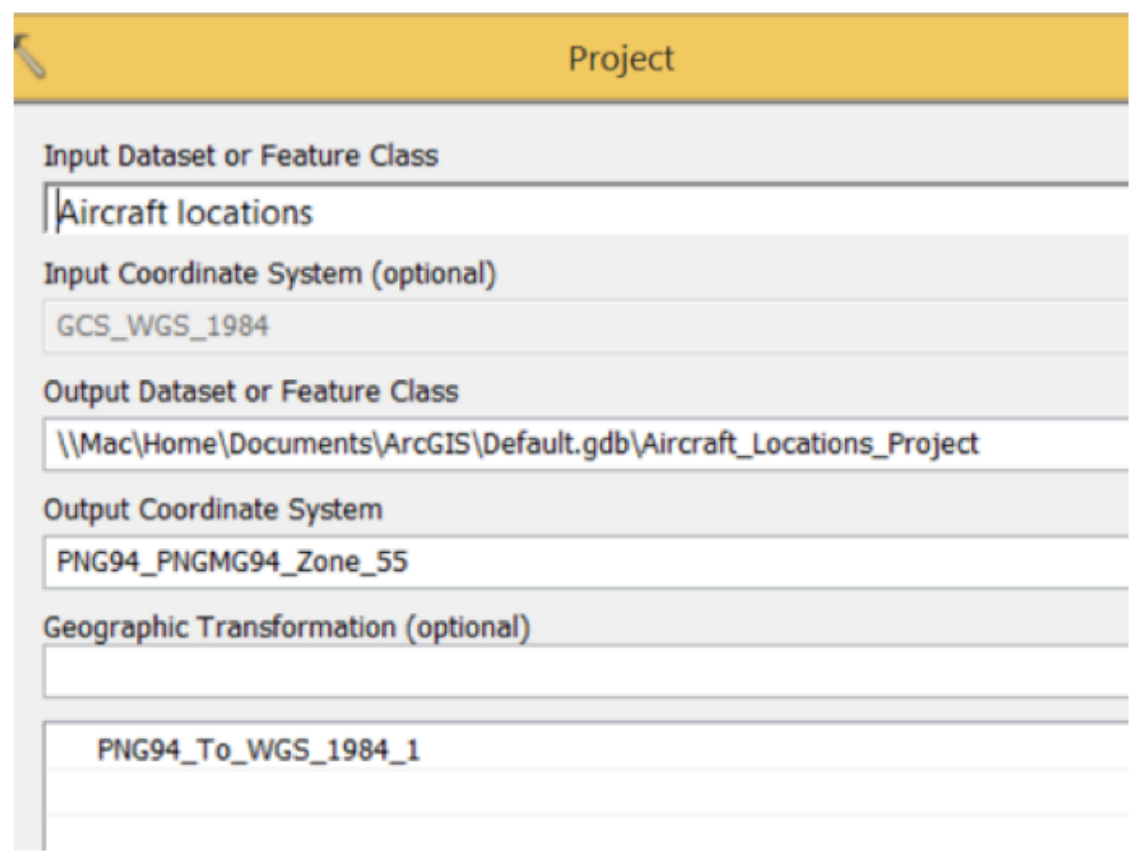

\section{Figure 5-5: Project Tool.}

Within the tool's window, the targeted feature classes - the Aircraft Locations and the Area-were selected as the input data and the output feature classes were set to be saved in a new file geodatabase created to contain the projected data. The purpose of this geodatabase was to use it for analyses and map production work, while leaving the original file geodatabase intact.

A variety of spatial statistical analyses were conducted on the data. Each analysis answers a question about the aircraft crash sites that are located on land. The first analysis provides information about the number of aircraft crashes in each province. The second analysis communicates which provinces have the highest number of crashes per square kilometer. The last analysis shows where US aircraft crashes are clustered in some of the provinces. 


\subsubsection{Number of Crashes Per Province}

To spatially calculate the number of the aircraft crashes per province, two steps had to be taken. First, the Area feature class's features represented the cities of the study area so they needed to be dissolved into province areas. The attributes contained province data which made it an easy task. Using the Dissolve geoprocessing tool, a feature class representing the province areas was created (Figure 5-6).

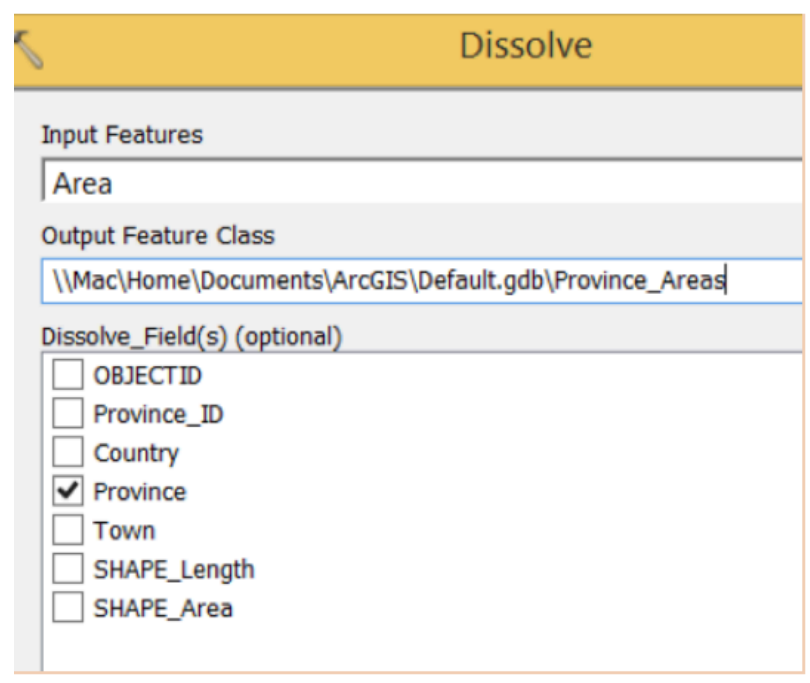

Figure 5-6: Dissolve Tool.

The tool takes the data and aggregates the features based on the specified attributes, which was in this case the province field. The result of this process (Figure 5-7) allows using the province areas to calculate the number of aircraft per province. 


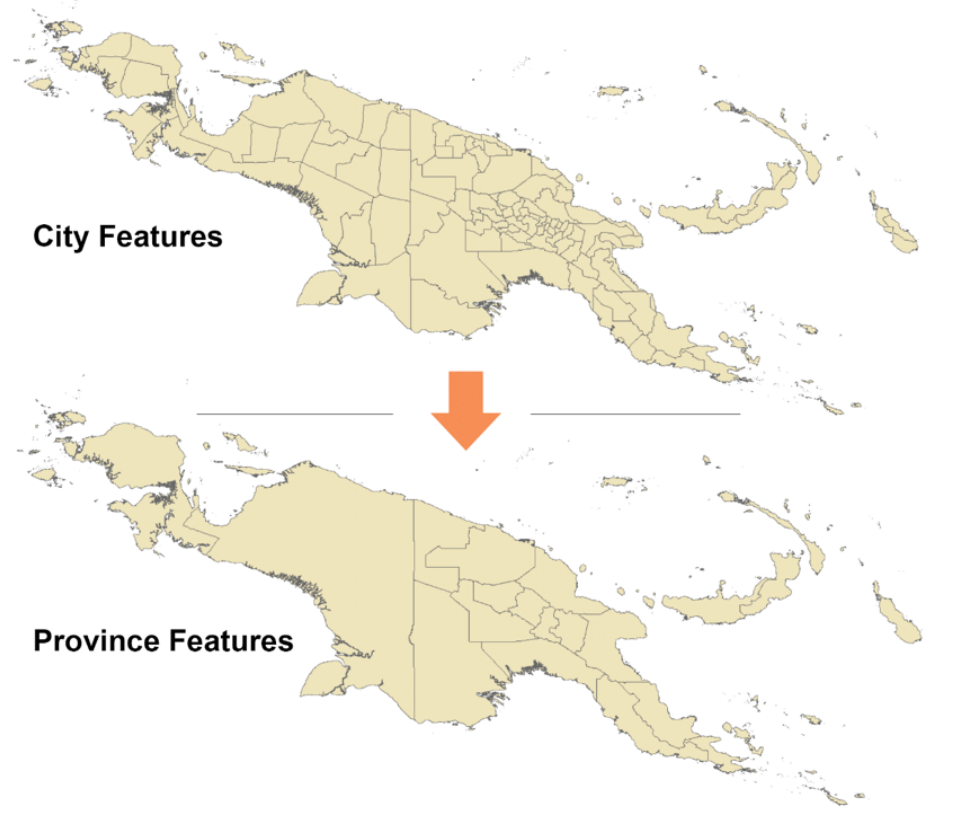

Figure 5-7: Dissolve Area Result.

The Spatial Join geoprocessing tool was used to calculate the number of aircraft crashes for each province area by joining the Aircraft Locations features to the Province Areas features. The result of this process was a polygon feature class that contained the attributes from the Province Areas feature class with a new field named "Crash_Count" that included the number of joined features representing the number of crashes in each province (Figure 5-8).

\begin{tabular}{||r|r|l|r|l||}
\hline \multicolumn{1}{|l|}{ Province_Areas_SpatialJoin } \\
\hline OBJECTID * $^{*}$ & SHAPE * & Crash_Count & \multicolumn{2}{|c|}{ Province } \\
\hline 1 & Polygon & 52 & Central \\
\hline 2 & Polygon & 0 & Chimbu \\
\hline 3 & Polygon & 66 & East New Britain \\
\hline 4 & Polygon & 35 & East Sepik \\
\hline 5 & Polygon & 4 & Eastern Highlands \\
\hline 6 & Polygon & 1 & Enga \\
\hline 7 & Polygon & 1 & Gulf \\
\hline 8 & Polygon & 41 & Irian Jaya Barat \\
\hline 9 & Polygon & 54 & Madang \\
\hline 10 & Polygon & 1 & Manus \\
\hline 11 & Polygon & 20 & Milne Bay \\
\hline 12 & Polygon & 63 & Morobe \\
\hline 13 & Polygon & 3 & New lreland \\
\hline 14 & Polygon & 51 & North Solomons \\
\hline 15 & Polygon & 36 & Northern \\
\hline 16 & Polygon & 21 & Papua \\
\hline 18 & Polygon & 6 & Sandaun \\
\hline 19 & Polygon & 0 & Southern Highlands \\
\hline 20 & Polygon & 17 & West New Britain \\
\hline 21 & Polygon & 2 & Western \\
\hline 22 & Polygon & 0 & Western Highlands \\
\hline
\end{tabular}

Figure 5-8: Spatial Join Result. 
The "Crash_Count" field was then used to symbolize the Province Areas features. A gradient color was used to visually show which province has the highest number of crashes by giving it the darkest color. A table was added to the Number of Crashes Per Province Map to show the number of crashes in each province (Figure 5-9).

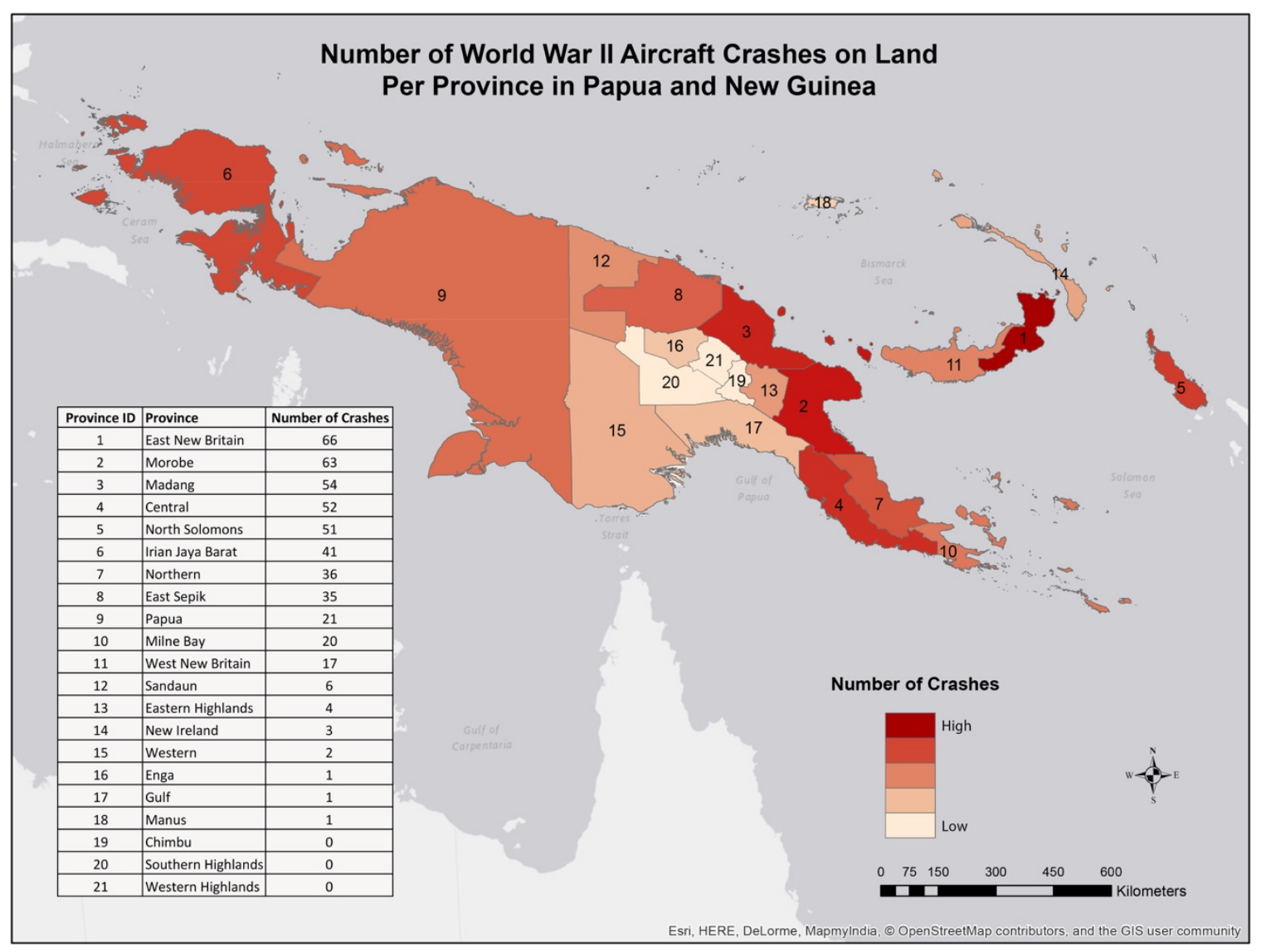

Figure 5-9: Number of Crashes Per Province Map

\subsubsection{Most Concentrated Provinces with Crashes}

The five most concentrated provinces from the previous result were selected from the attribute table using their names (Figure 5-10). The selected provinces were then exported as a new layer and symbolized gradually based on the number of crashes. The number of crashes for each country was calculated in two steps. First, using Query Builder to only show the targeted country data (Figure 5-11). Second, Select By Location to select the crashes in the targeted province, which can be done by selecting the province first and then selecting the crashes that intersect with the selected province (Figure 5-12). 


\begin{tabular}{|c|c|c|c|c|c|c|c|}
\hline \multicolumn{8}{|c|}{ Table } \\
\hline \multicolumn{8}{|c|}{ 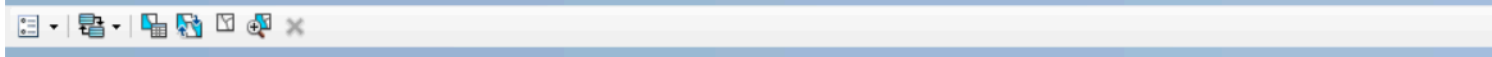 } \\
\hline \multicolumn{8}{|c|}{ Province_Areas } \\
\hline & OBJECTID * & SHAPE * & Province_ID & Country & Province & SHAPE_Length & SHAPE_Area \\
\hline \multirow[t]{15}{*}{ 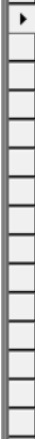 } & 1 & Polygon & 1 & Papua New Guinea & Central & 1823368.826947 & 29683872123.916737 \\
\hline & 2 & Polygon & 2 & Papua New Guinea & Chimbu & 455396.722162 & 6144552631.806941 \\
\hline & 3 & Polygon & 3 & Papua New Guinea & East New Britain & 1187449.899813 & 15443399651.755022 \\
\hline & 4 & Polygon & 4 & Papua New Guinea & East Sepik & 1635870.107067 & 43834031839.339127 \\
\hline & 5 & Polygon & 5 & Papua New Guinea & Eastern Highlands & 501190.720148 & 11143385630.356262 \\
\hline & 6 & Polygon & 6 & Papua New Guinea & Enga & 509422.761966 & 11768493661.922771 \\
\hline & 7 & Polygon & 7 & Papua New Guinea & Gulf & 2939048.798836 & 34837494476.240524 \\
\hline & 8 & Polygon & 8 & Indonesia & Irian Jaya Barat & 14863519.577863 & 101890550457.64977 \\
\hline & 9 & Polygon & 9 & Papua New Guinea & Madang & 1364414.798703 & 28943328818.7952 \\
\hline & 10 & Polygon & 10 & Papua New Guinea & Manus & 1202659.815296 & 2239703840.900695 \\
\hline & 11 & Polygon & 11 & Papua New Guinea & Milne Bay & 4528171.780635 & 14424659120.41744 \\
\hline & 12 & Polygon & 12 & Papua New Guinea & Morobe & 1639466.651037 & 33943295578.496231 \\
\hline & 13 & Polygon & 13 & Papua New Guinea & New Ireland & 2605746.854058 & 9742370700.518551 \\
\hline & 14 & Polygon & 14 & Papua New Guinea & North Solomons & 1165395.815327 & 9598836498.401566 \\
\hline & 15 & Polygon & 15 & Papua New Guinea & Northern & 1156620.120224 & 22700511383.950096 \\
\hline
\end{tabular}

\section{Figure 5-10: Most Concentrated Provinces Selection.}

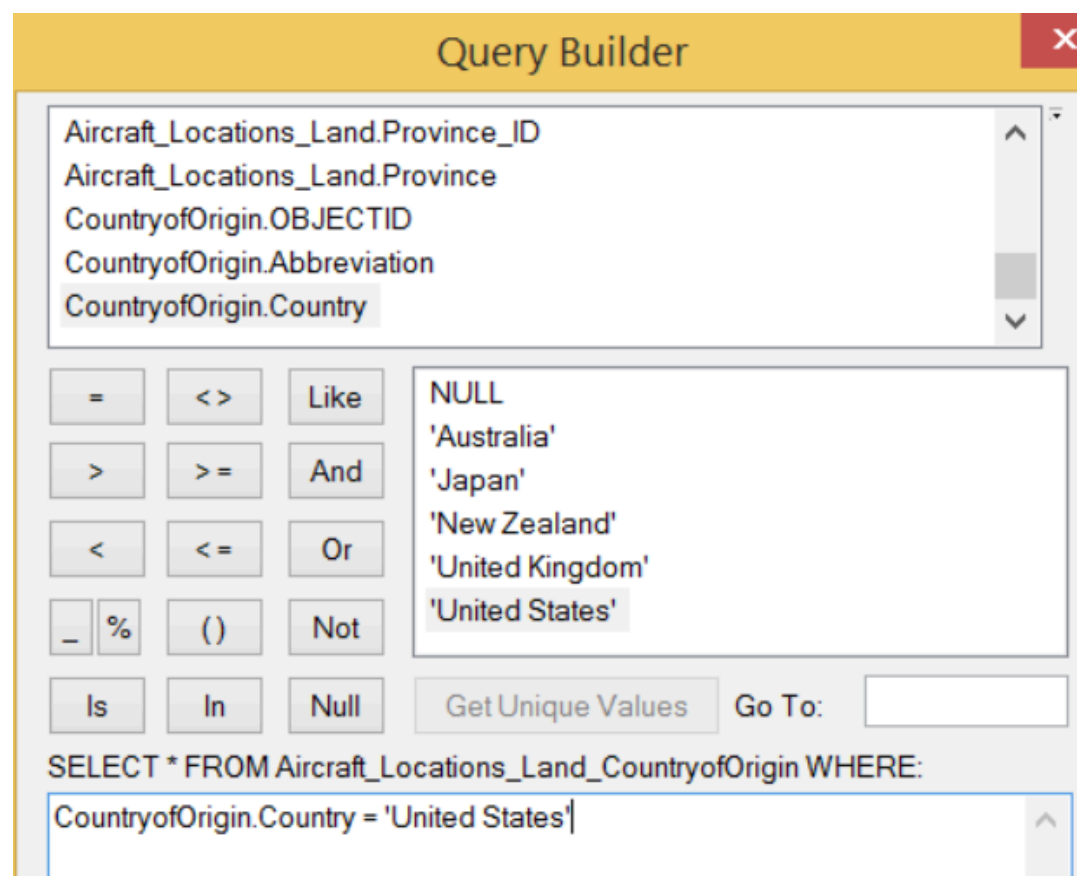

Figure 5-11: Query Builder. 


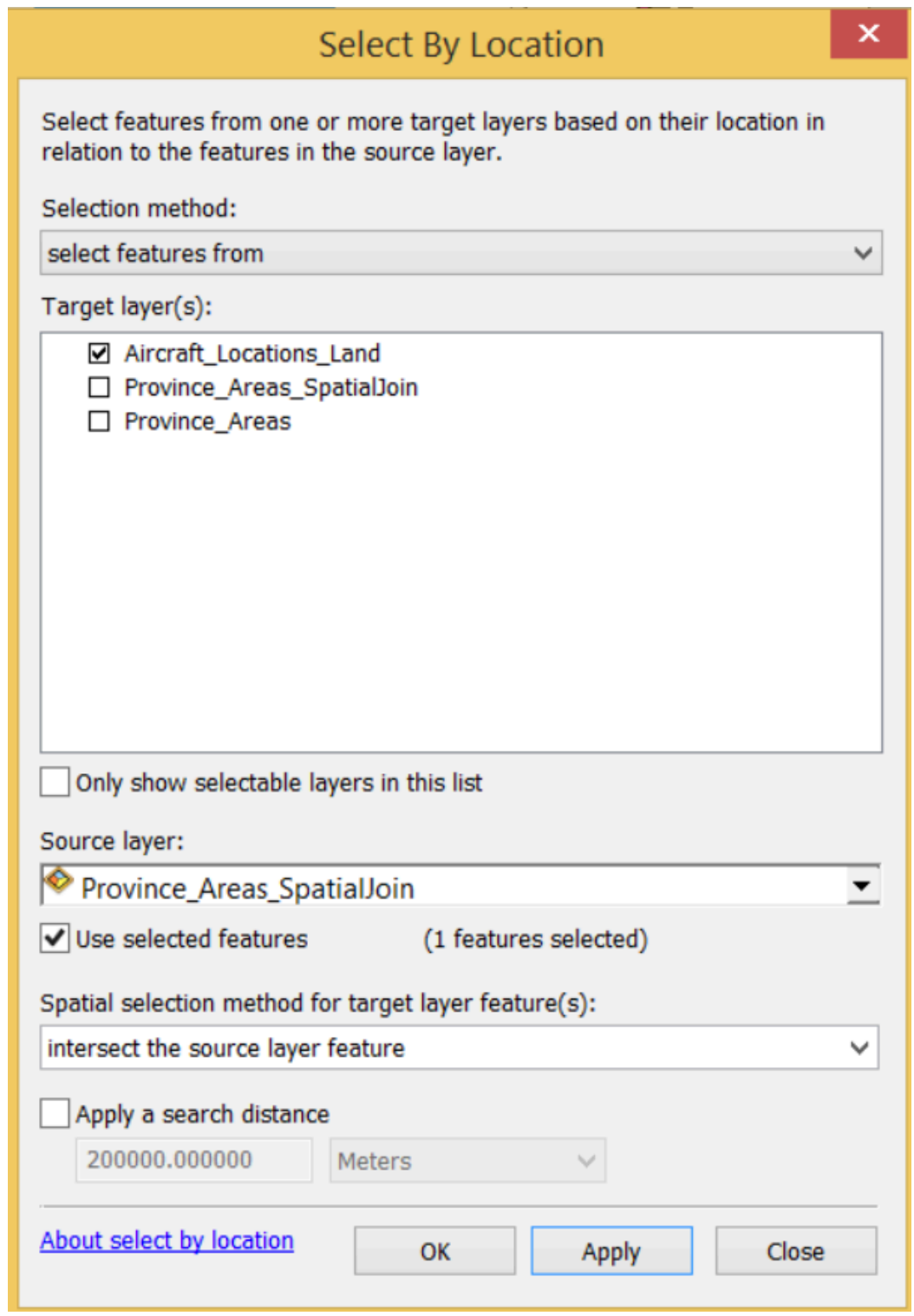

\section{Figure 5-12: Select By Location.}

The number of crashes for each country and the province names were imported to Excel to represent them in a bar chart. The bar chart was then brought to ArcMap and a map that shows statistical information about the five most concentrated provinces was produced (Figure 5-13). 


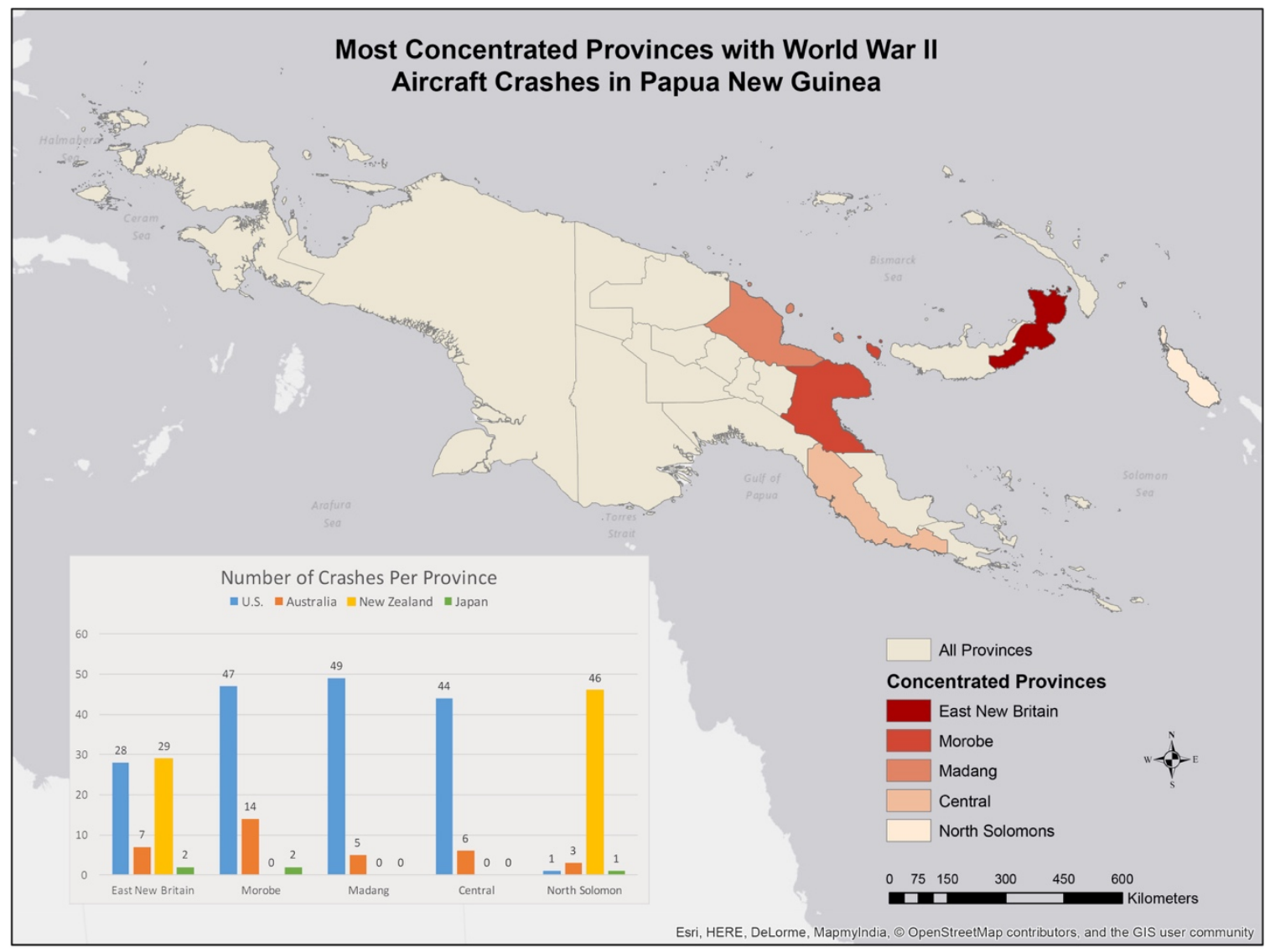

Figure 5-13: Most Concentrated Provinces with Crashes.

\subsubsection{Number of Crashes Per Square Kilometer}

Dividing the number of crashes by the area gives a normalized value that indicates the number of crashes per areal unit. In this analysis, the areal unit used was square kilometers because the study area was relatively large. To establish the work on the normalized values, the area in square meters for each province needed to be converted. A field named "Area_km2" was added into the attributes of the "Province_Areas_SpatialJoin" feature class to calculate the area in square kilometers. Calculate Geometry was used to calculate the area in square kilometers (Figure 5-14). 


\begin{tabular}{l}
\hline \multicolumn{1}{|c|}{ Calculate Geometry } \\
Property: $\quad$ Area \\
Coordinate System \\
Use coordinate system of the data source: \\
PCS: PNG94 PNGMG94 Zone 55 \\
Use coordinate system of the data frame: \\
PCS: PNG94 PNGMG94 Zone 55 \\
Units: \\
Calculate selected records only
\end{tabular}

\section{Figure 5-14: Calculate Geometry.}

After calculating the area in square kilometers, another field was added to contain the normalized values. Using Field Calculator, the normalized values were calculated by dividing the "Crash_Count" field by the "Area_km2" field (Figure 5-15).

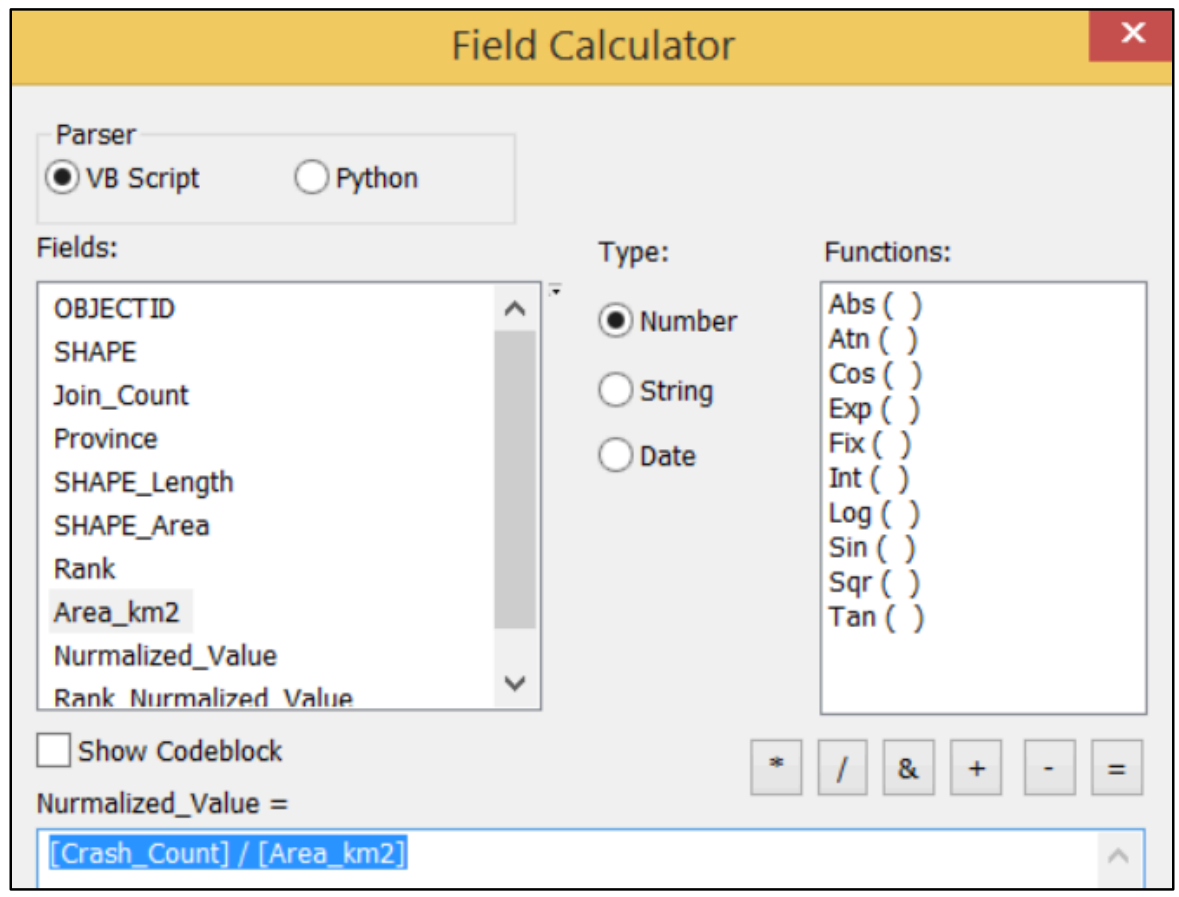

Figure 5-15: Field Calculator. 
This new field containing the normalized values was used to symbolize the data to show which provinces had the highest number of crashes per square kilometer (Figure 5-16).

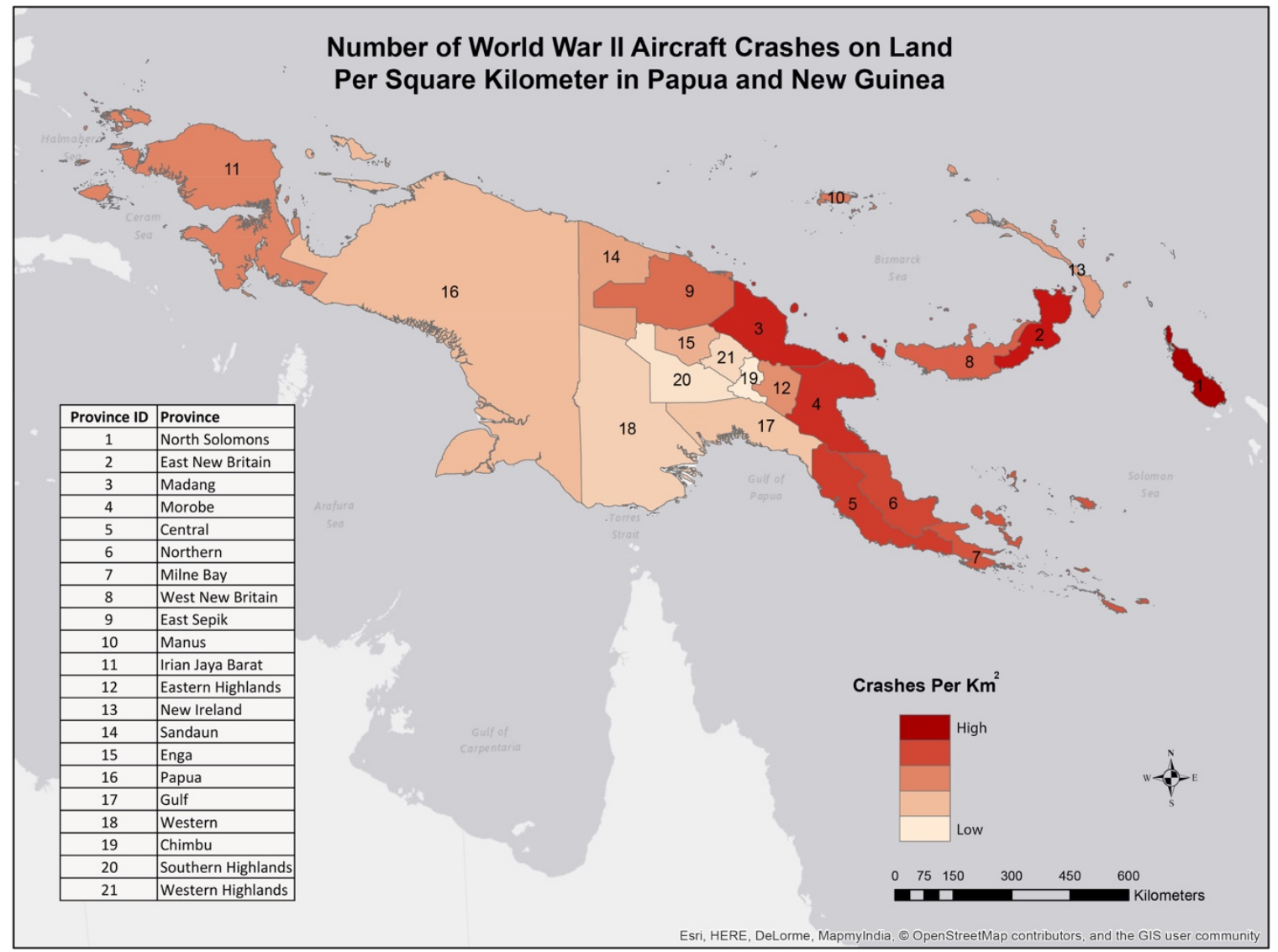

Figure 5-16: Number of Crashes Per Square Kilometer Map.

\subsubsection{Point Density Analysis}

The aircraft locations were distributed all over the study area. However, many of them were clustered in different parts of the study area. To visualize the clustered areas, the Point Density tool was used (Figure 5-17). 


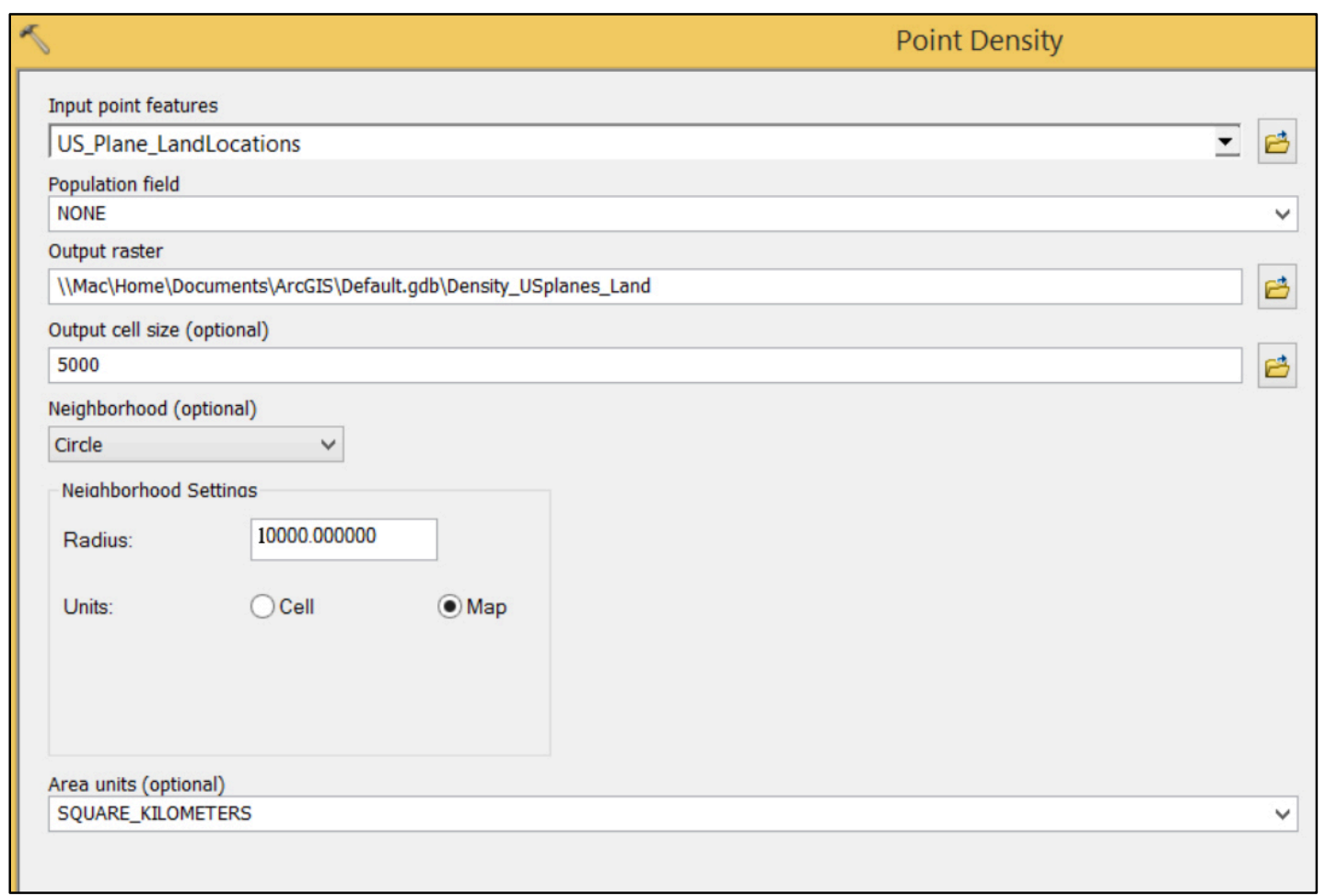

\section{Figure 5-17: Point Density Tool.}

The radius was set to 10000 meters because search and recovery missions cover about 5 to 10 kilometers in one area and so it was intended to visualize the clustering of the data in such a radius. The result of the Point Density tool shows the highly clustered areas in orange. Each of these areas is about 10 square kilometers (Figure 5-18).

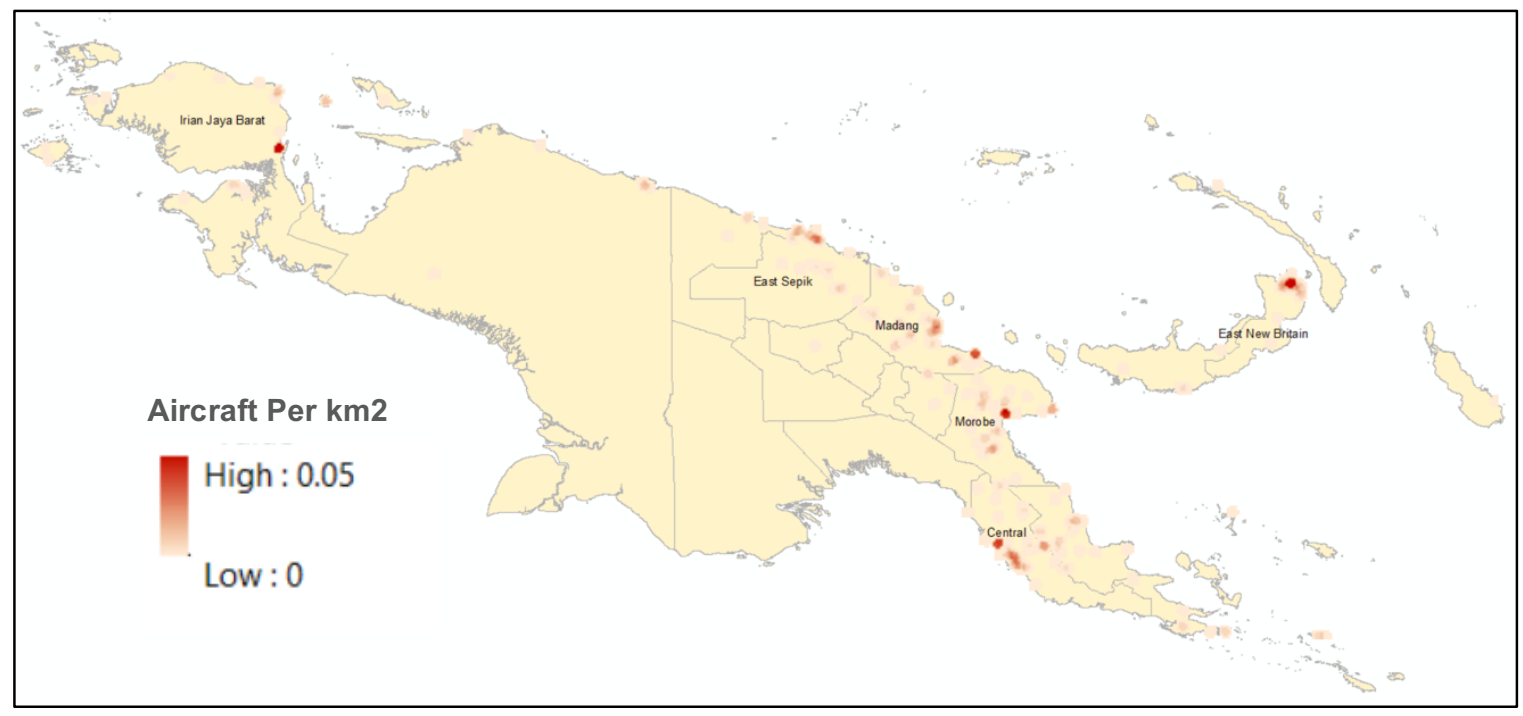

Figure 5-18: Point Density Analysis Result. 


\subsection{Map Series}

The client required a map series to be produced for the aircraft crash sites. Some issues needed to be addressed before producing the maps: the scale, page size, base map, and map elements. The scale for the maps was set to 1:1,000,000 so it matched the scale of the historical maps the client provided. To decide on the page size, two aspects were considered. One was that the study area was large and the page needed to be large enough so that the map series covered the study area with a minimal number of pages. Second, the page needed to be small enough so it could be used in the field while searching for aircraft wreckage. Therefore, a page size of 27 x 22 inches was chosen to serve the addressed aspects. The client needed maps showing basic terrain and major rivers, so a topographic base map was used in the series. Deciding on the elements that go in the map layout did not take much time. However, deciding on the place for each one needed to be examined. Thus, all the elements - title, scale in text, scale bars, legend, coordinate system and projection information, north arrow, map index, and the producer info-were added to the map and after several placements a decision on the design was made (Figure 5-19).

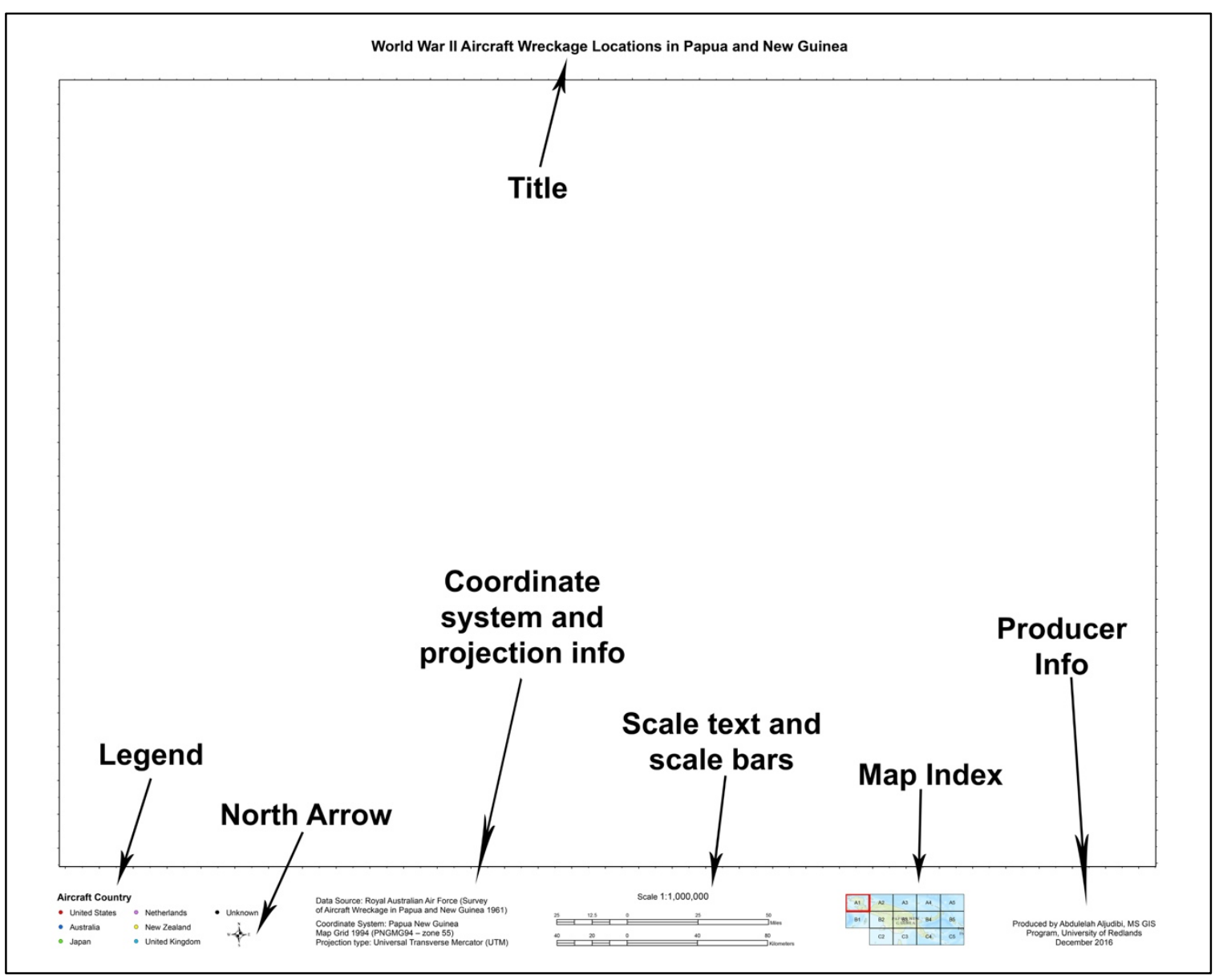

Figure 5-19: Map Layout. 
Once the map template was designed, the map series could be produced. The aircraft crash locations (points) data were added into the map and the labels that show the serial number of each point were turned on. Yet there was a problem of having too many labels overlapping each other because the points in many locations were too close to each other in 1:1,000,000 scale, and in many other locations there were overlapped points (Figure 520).

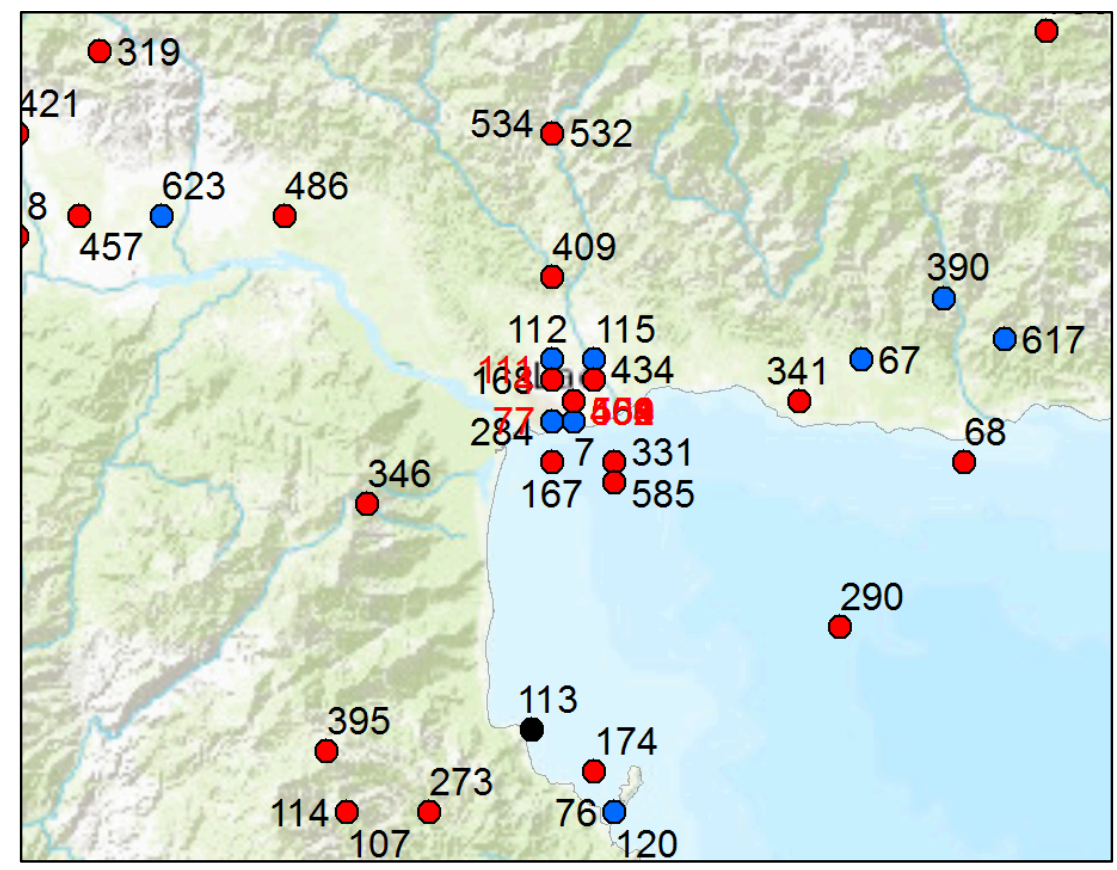

Figure 5-20: Overlapped Labels.

To solve this problem, all the available options within the Label Engine and the Maplex Label Engine were used, yet the problem was not easy to solve. One method used was the leader lines (Figure 5-21). 


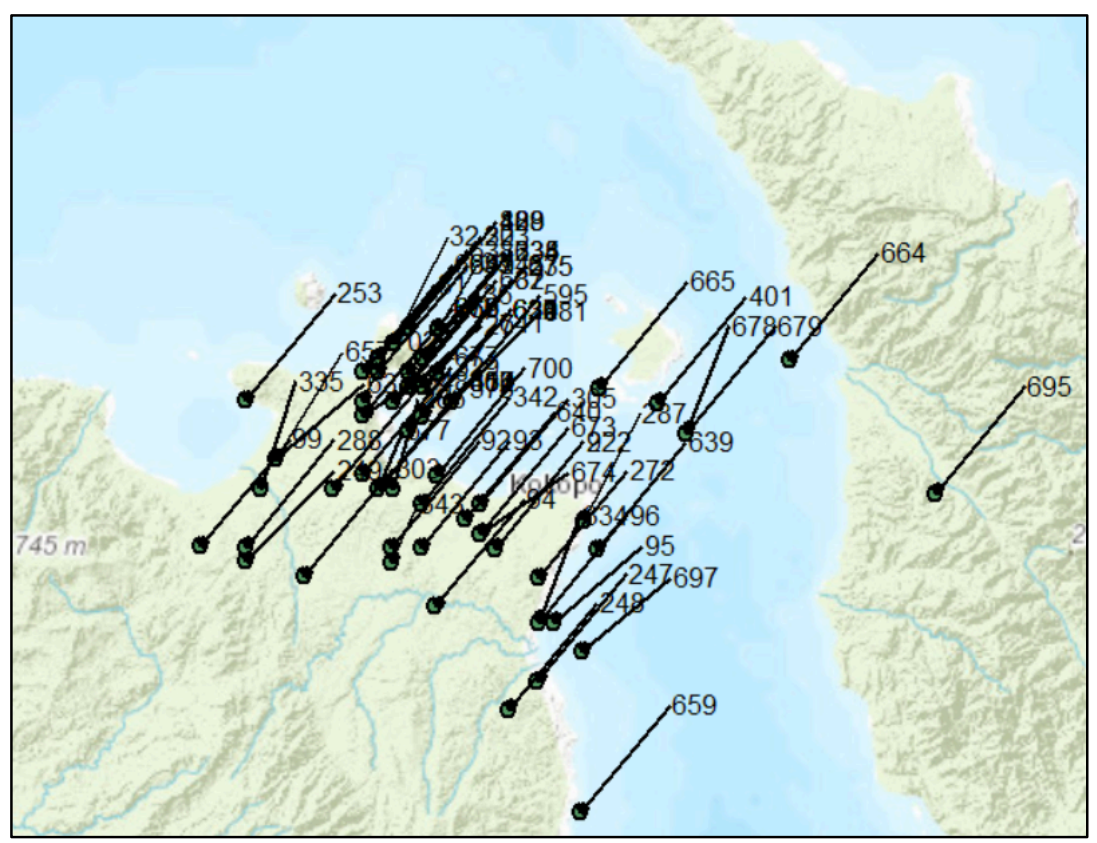

Figure 5-21: Leader Lines

Therefore, it was decided to produce three map series: all crash locations, single crash locations, and multiple crash locations. The first series would show all arircraft crash locations without the point serial number labels, differentiating the multiple crash locations by giving them a squared symbol instead of circular. It also showed labels of the number of overlapped aircraft in each crash location. The second series would show single aircraft crash locations with labels, and the third would show multiple aircraft locations (Figure 5-22).

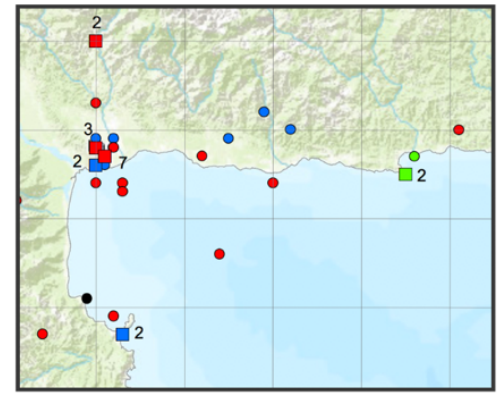

All crash locations

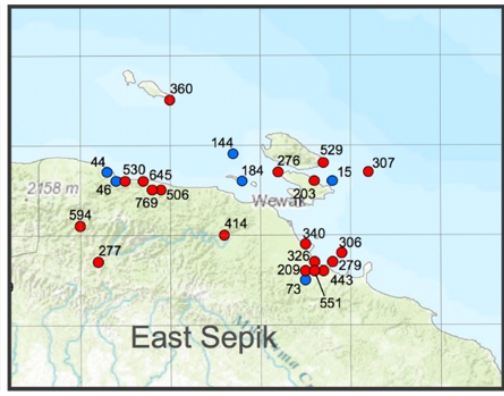

Single crash locations

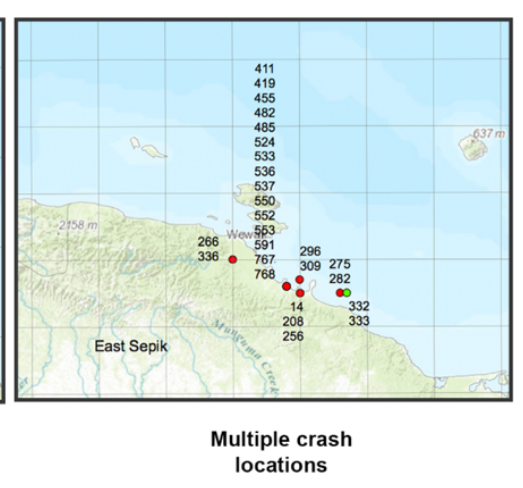

locations

Figure 5-22: Three Map Series.

Automated map production required the use of two tools: the Grid Index Features geoprocessing tool and the Data Driven Pages tool. The Grid Index Features tool was used to create indexes of the extent of the aircraft locations data (Figure 5-23). 


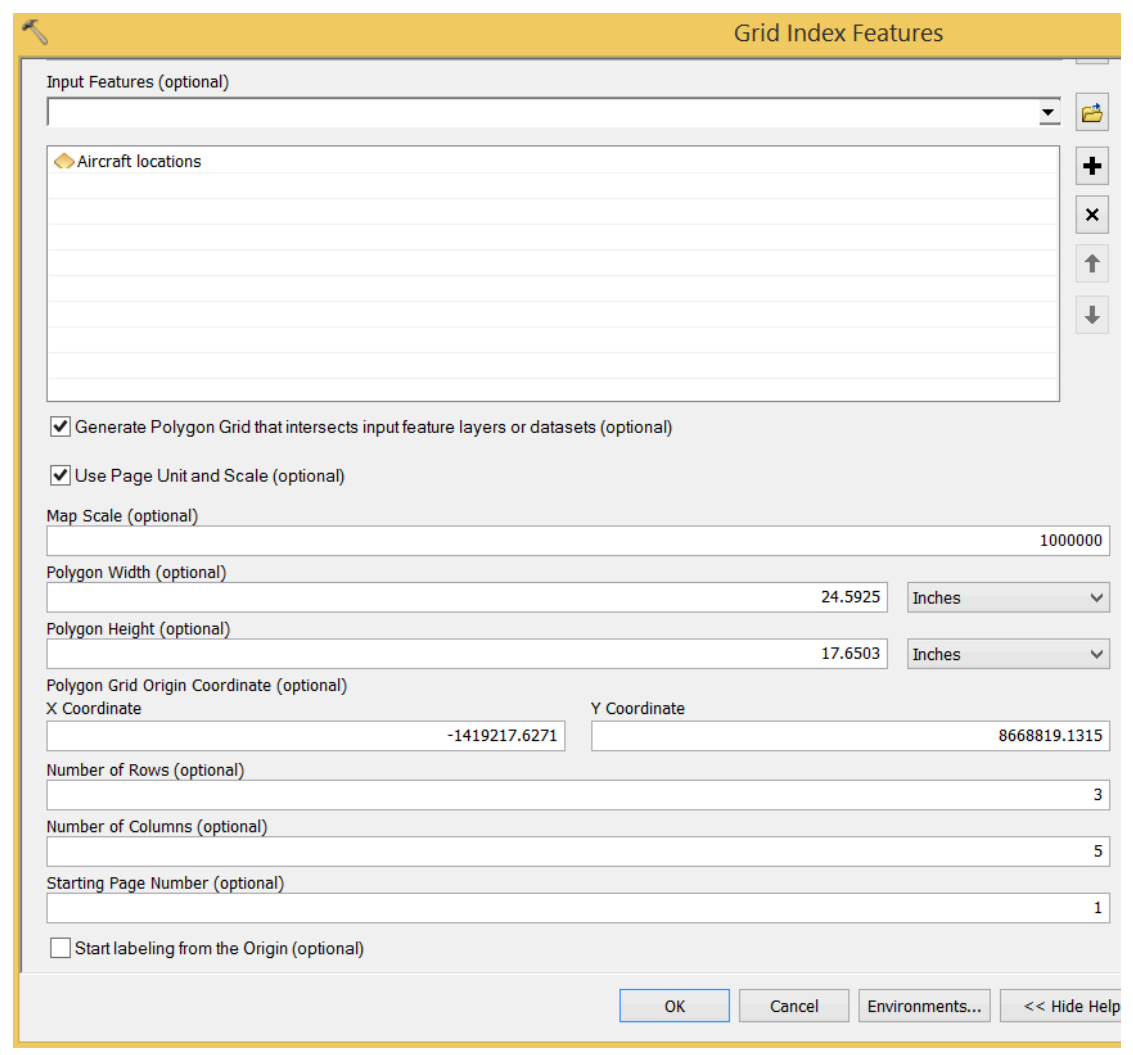

Figure 5-23: Grid Index Features Tool.

The extent of each of these indexes was used to produce a map by using the Data Driven Pages tool, which defines the indexes that were created using Grid Index Features tool as pages and uses the single layout that was designed for all the maps (Figure 5-24). 


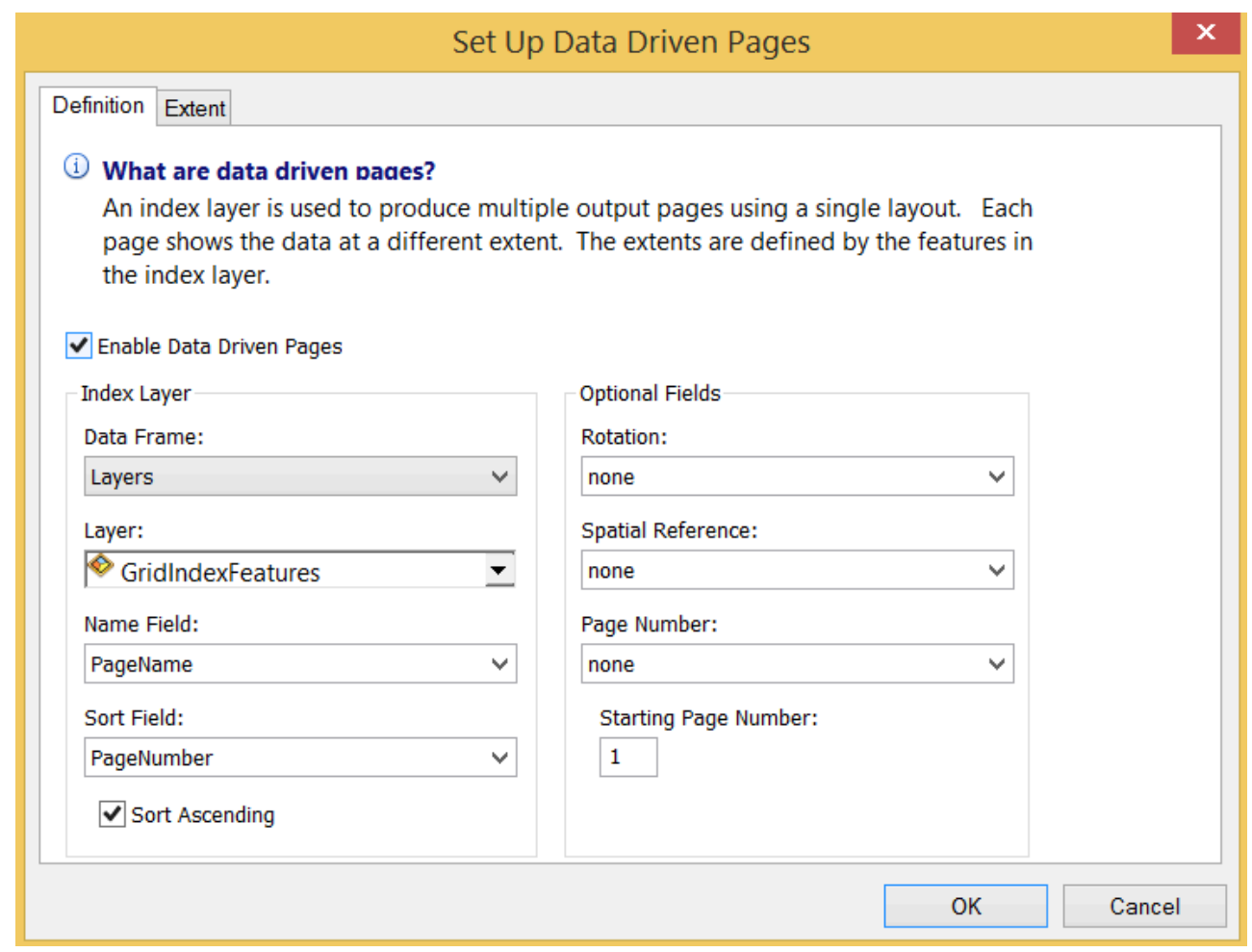

Figure 5-24: Data Driven Pages.

Once the pages were defined, each of the single and all aircraft crash locations series were exported using the defined pages, which allowed exporting all the maps together for each series. However, it could not be used to export the maps in the multiple aircraft crash locations all at once because there was another problem of having overlapped labels. Consequently, the labels had to be manually typed for each point in the layout and each map extent was exported individually. A sample map from the map series is shown here and the rest are saved in the DVD acompaning this report because the scale of the maps is designed for a larger page size. (Figure 5-25). A clip at full size is shown in Figure 5-26. 


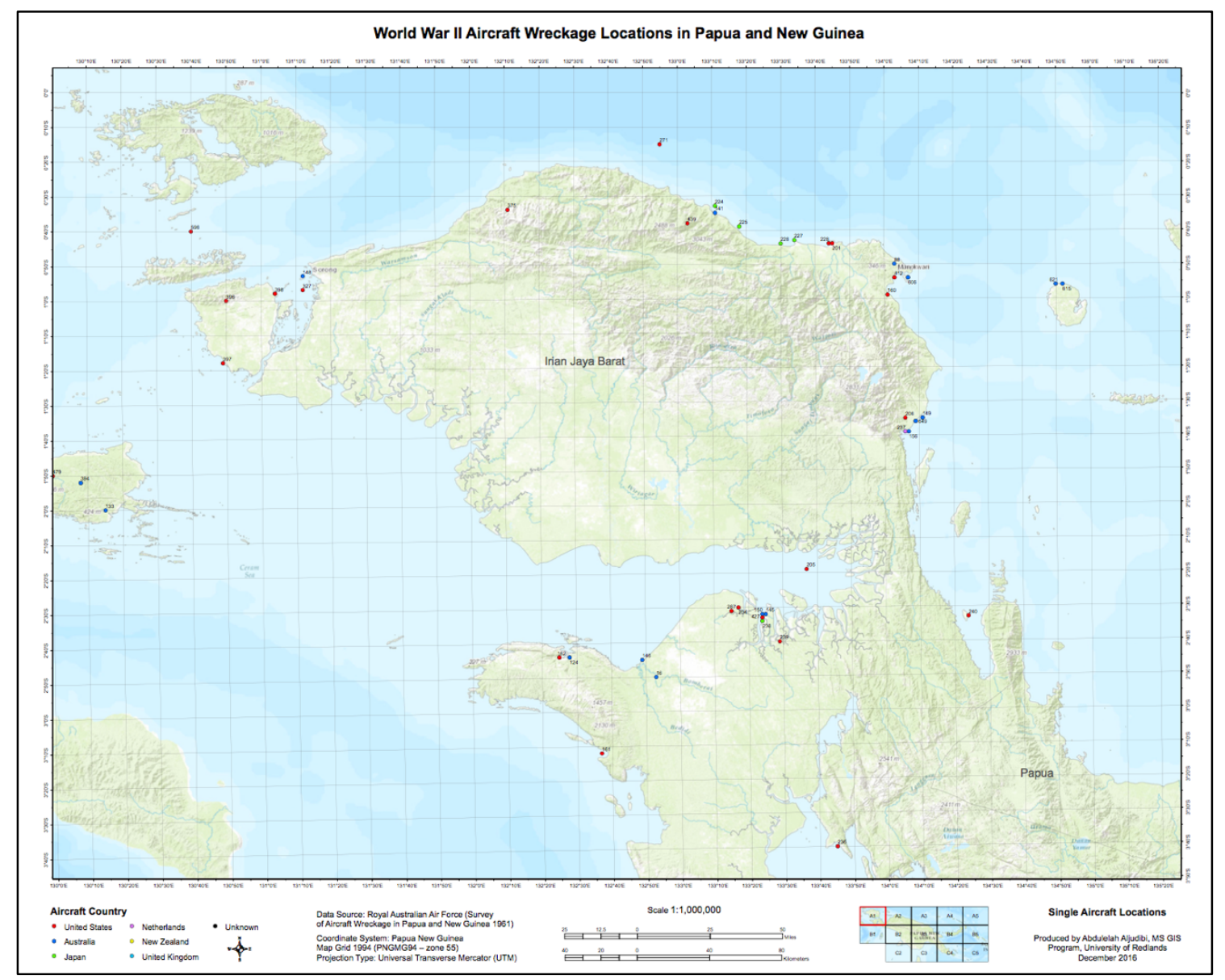

Figure 5-25: Aircraft Locations Map.

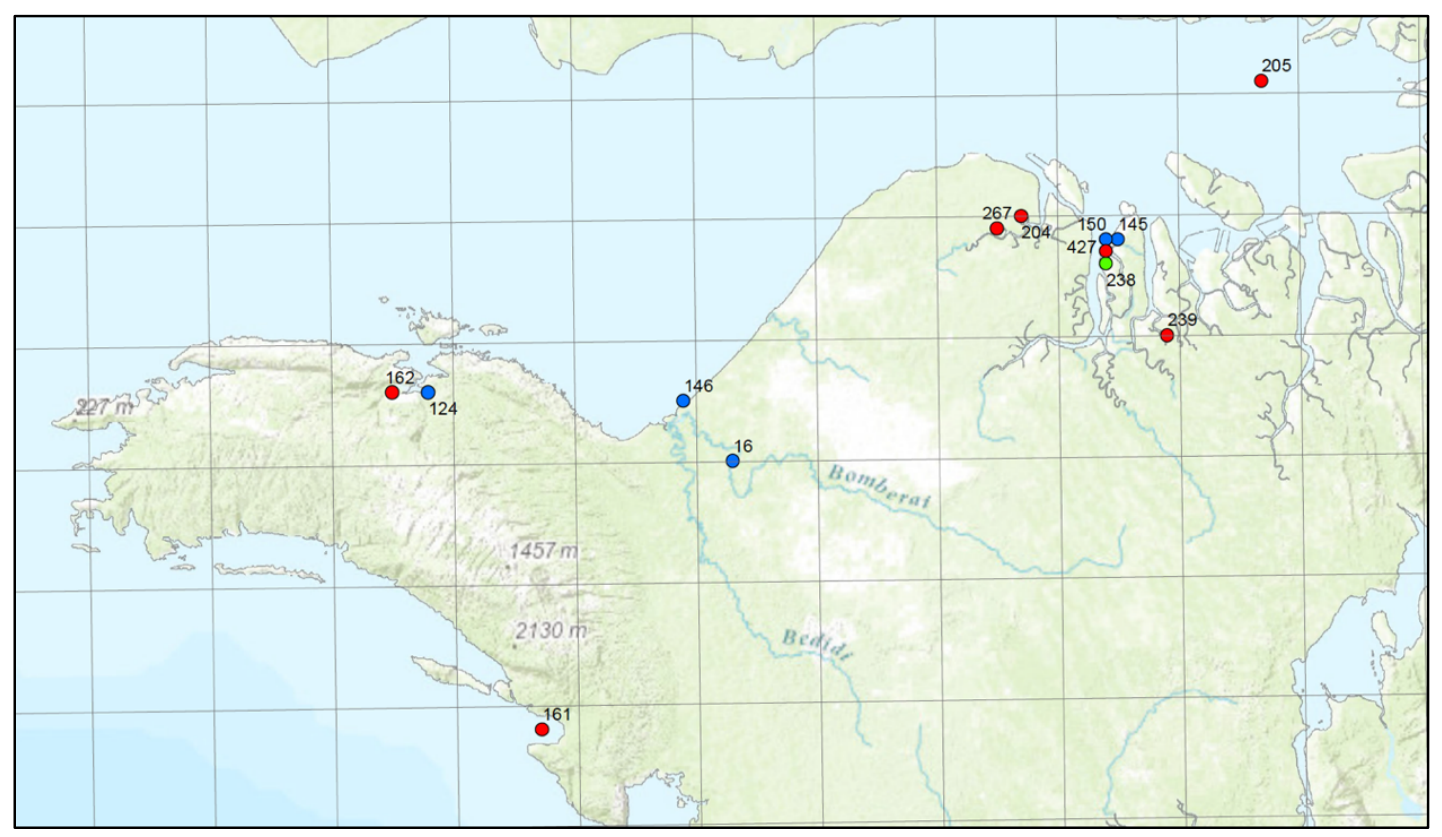

Figure 5-26: Location Map Clip at Full Size. 


\subsection{Summary}

Chapter Five addressed the implementation of the database and the data loading method. It explained visualizing the aircraft locations according to the client's needs, which were categorized based on the country of origin and the US designation code. The analyses that were conducted on the data and the tools used were explained, as well. The map production and the difficulties encountered in producing them were also addressed. 


\section{Chapter 6 - Results and Analysis}

This chapter describes the results and analysis for this project. There are four major components' results addressed and discussed in this chapter. The first component is the geodatabase. The second component is the interactive map. The third component is the analytical maps. The fourth component is the map series. Each component is addressed and analyzed to gauge its contribution to this project.

\subsection{Royal Australian Air Force Geodatabase}

The main purpose of this project was to convert the historical data from a PDF file to a format that allows data visualization and manipulation, as well as to have them stored in one container, a geodatabase, for faster retrieval of the data. The geodatabase was successfully designed and built to meet the client's requirements. The client can now perform different inquiries on the data such as automatically searching by attributes and viewing related information because all the tables in the geodatabase are connected to each other. This solved a problem the client had, which was searching over many pages, sometimes different documents, to find related information.

Not only was the database designed to hold the Royal Australian Air Force (RAAF) survey data, but it also was designed to use its schema to hold similar datasets. The database was normalized to ensure the consistency of the data and to avoid data duplication. This was accomplished by creating separate tables for data that are shared by many objects in other tables and by associating them by relationships. For example, instead of adding a field in the Aircraft Locations' table for the historical maps and adding each historical map multiple times for each related object, a table holding all the historical maps was created and related to the Aircraft Locations' table using a common field. The database was tested and it performed as expected to serve the client's needs.

\subsection{Interactive Map}

Integrating the RAAF's data into ArcGIS Desktop format allowed the client to view the data in ArcMap. The client was able to view the aircraft wreckage locations in an interactive map and categorize them by country of origin, as well as categorize them by US designation code (Figure 5-3 and 5-4). The ability to categorize them based on the country of origin allowed the user to quickly distinguish United States aircraft from other countries' aircraft. The user was also able to view the aircraft wreckage of only one country without the others being plotted on the map, which made it easier to exclusively conduct analyses on US aircraft (Section 6.3.3).

Moreover, having this data used in ArcMap, the client became able to add other aircraft wreckage datasets in the future, and visually compare them. The geoprocessing tools within ArcMap allowed performing different analyses on the data, which were not available when the data were in the PDF file. This offered a huge advantage to benefit from these data. 


\subsection{Analytical Maps}

Some analyses were conducted on the data to aid the employees at the Defense POW/MIA Accounting Agency (DPAA) do the planning of search and recovery missions more efficiently. Each analysis result answers a unique question. How many crashes per province? How many crashes per square kilometer in each province? Where are the areas concentrated with US aircraft wreckage?

\subsubsection{Number of Crashes Per Province Map}

As addressed in Chapter 5, the Spatial Join tool was used to calculate the number of aircraft in each province. Then, the province areas were symbolized based on the field resulting from that join. A choropleth map was created to show the relative numbers of aircraft crashes in each province, and a table with the actual numbers was added to the map (Figure 6-1).

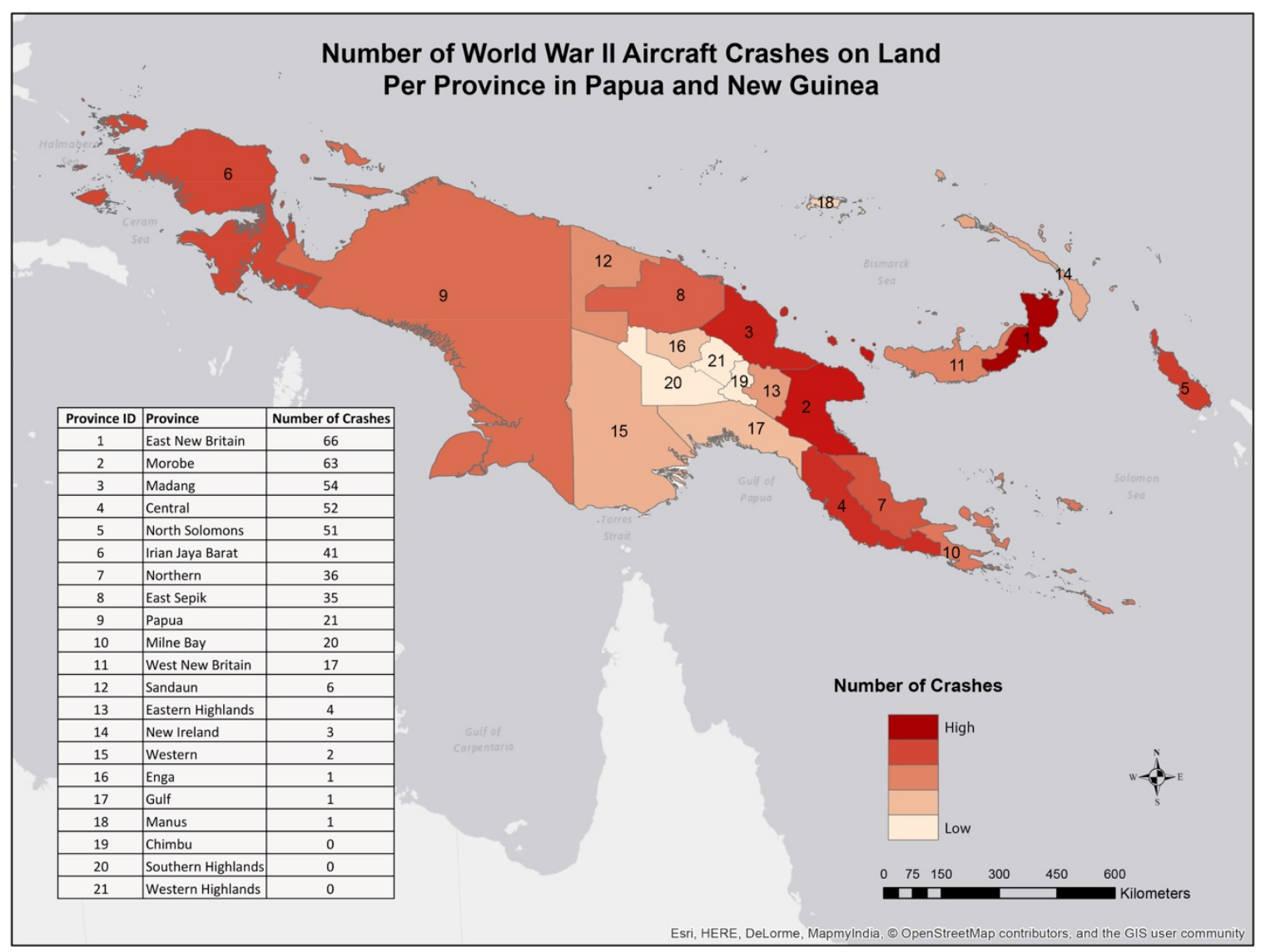

Figure 6-1: Number of Crashes Per Province.

This map gives a high value for the provinces with a high number of crashes on land by giving them dark colors and low value for the provinces with a low number of crashes on land by giving them light colors. It also provides the number of crashes in each province. 
While this information was useful in general, it was not in this specific case because the analysis did not take into consideration the size of each province. This may lead the map user to think that the chances of finding aircraft wreckage in provinces with high values is greater. To solve this issue, another analysis was conducted to give each province its value while taking the area into consideration (Section 6.3.2).

\subsubsection{Most Concentrated Provinces with Crashes Map}

This map provides statistical data about the aircraft crashes count for each country in the five most concentrated provinces (Figure 6-2). The outcome from this map can help the Defense POW/MIA Accounting Agency (DPAA) to know how many aircraft wreckages belong to the United States and how many to the other countries in each province. The DPAA could use this information to decide on collaborating with other countries to search and find aircraft wreckage.

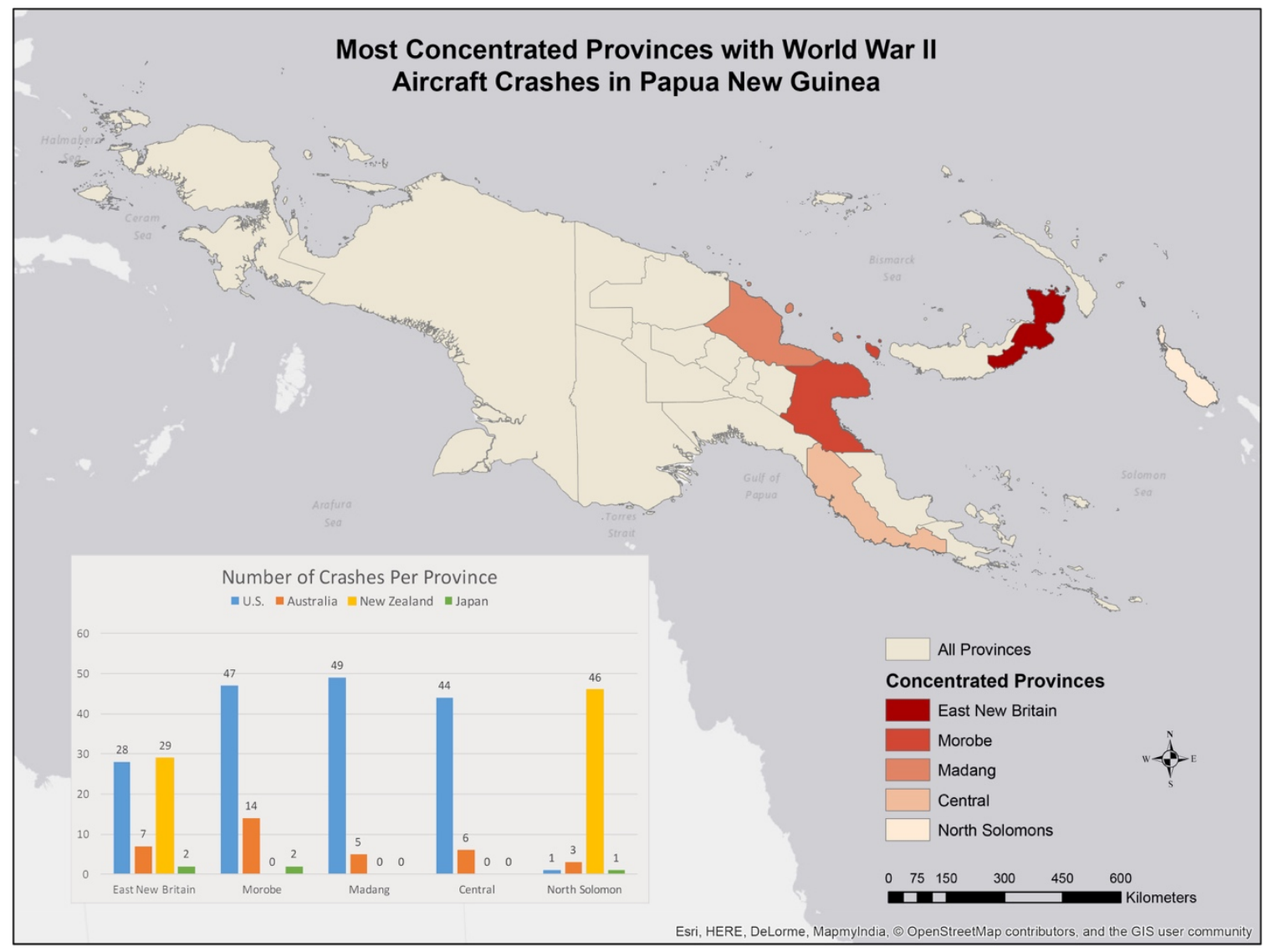

Figure 6-2: Most Concentrated Provinces with Crashes Map.

\subsubsection{Number of Crashes Per Square Kilometer Map}

This analysis solved the issue that may have been caused by the Number of Crashes Per Province analysis. The map in Figure 6-3 shows the number of aircraft per square kilometer. 


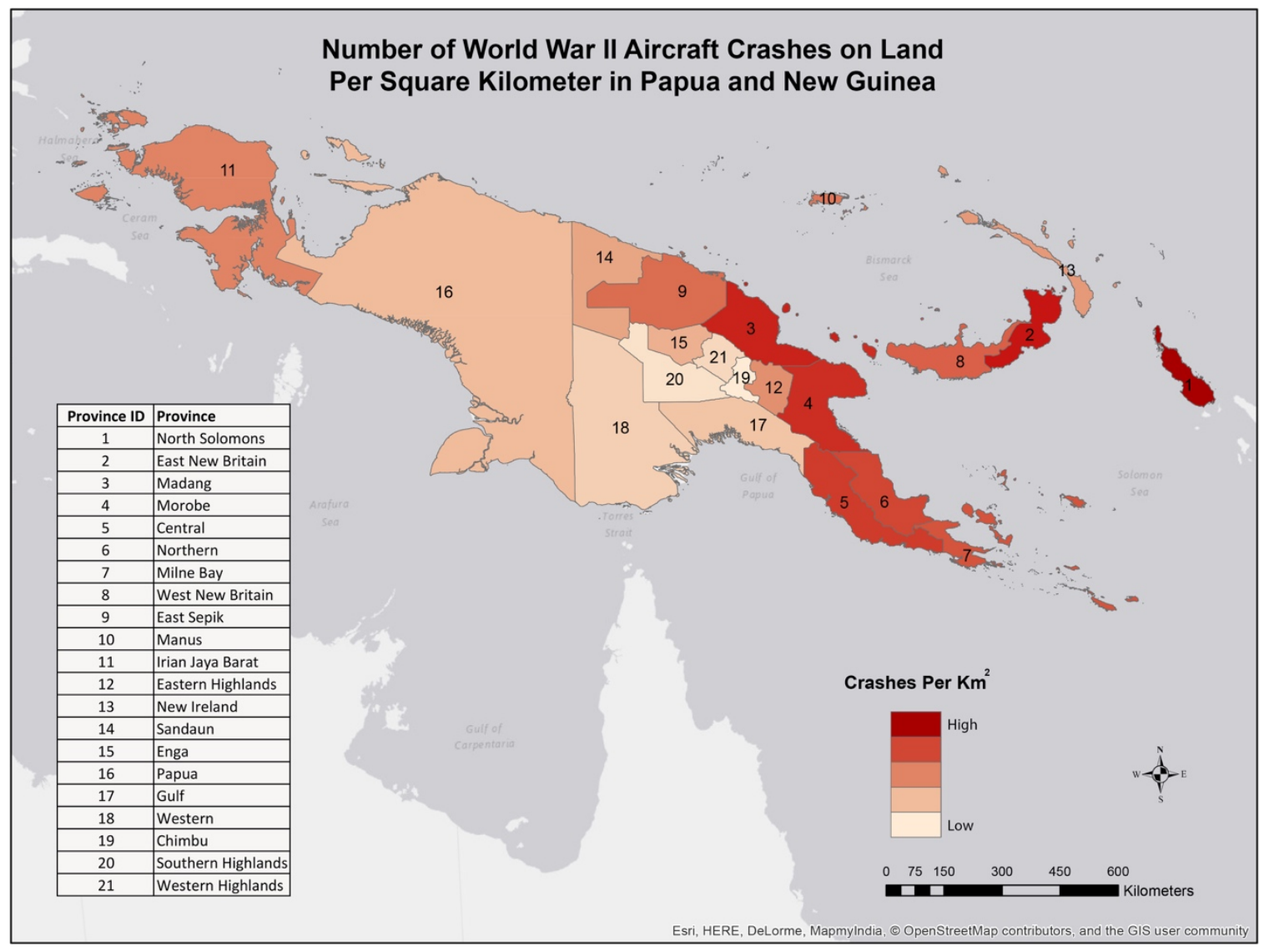

Figure 6-3: Number of Crashes Per Square Kilometer.

The number of crashes for each province was normalized by the province area which provided the number of crashes per square kilometer. Now a small province with fewer crashes may have a higher value than a larger province with more crashes. For example, the province Manus had a lower value than the province Papua in the first analysis, but it has a higher value in the second analysis. This approach provides a better result that can increase the chances of finding aircraft wrecks.

Even though the Number of Crashes Per Square Kilometer Map provided better information that can increase the likelihood of finding wrecks than the Number of Crashes Per Province Map, neither provided information about a specific search area in each province. Therefore, a density analysis for the wreckage locations was conducted to show specific areas of concentrations.

\subsubsection{Point Density Analysis Map}

The use of the Point Density tool was necessary to show the concentrated areas with aircraft crashes in each province. Showing the concentrated areas helps the client to decide on the search area for the search and recovery missions. The points in the data represented the crashes locations at sea and on land for all the participating countries. For this analysis, the data were filtered to only represent the US on land aircraft crashes to 
comply with the client interest. The concentrated areas with aircraft crashes are shown in Figure 6-4.

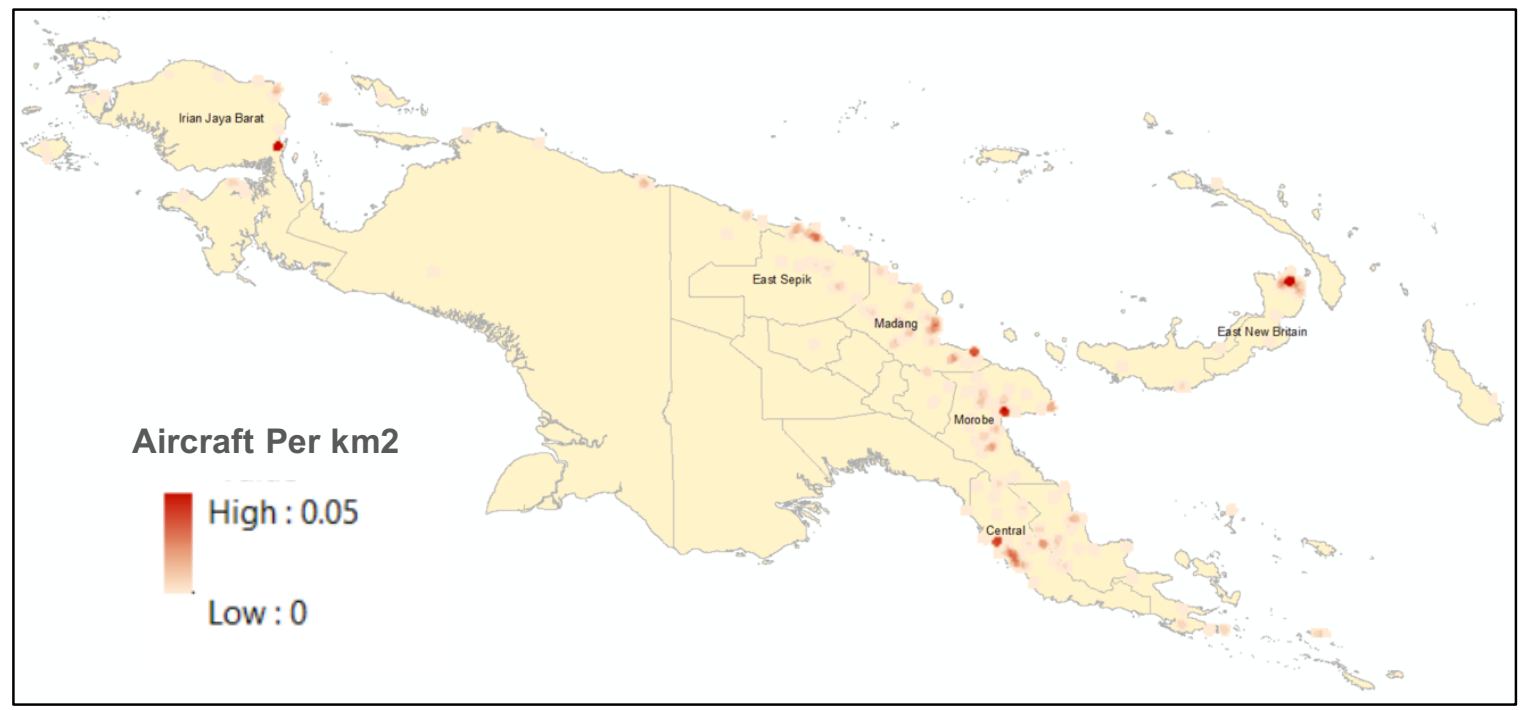

\section{Figure 6-4: Point Density Analysis Map.}

The concentrated areas of the US on land aircraft crashes are in 6 provinces: East New Britain, Central, Morobe, Madang, East Sepik, and Irian Jaya Barat. The concentrated areas are represented by orange color. The radius for each concentrated area was set to 10 square kilometers, which approximates a standard search area for the client. The result showed which parts of the provinces are crowded with crashes and that was better than the previous analysis which only indicated the concentrated provinces. Now, not only can the client decide on the province destination, but also on a specific area within each province.

\subsection{Map Series}

There were three map series produced for the data. All the map series showed the data on a topographic base map to help the client in the field work. The topographic base map provides terrain and river information. This information can help the map user to predict wrecks' locations. For example, if a crash site was shown to be at a mountain ridge, the user can assume that the aircraft shattered downhill and so the searchers should search for the wrecks downhill.

Each of the map series shows all countries' aircraft. However, one series exclusively shows single aircraft locations with labels that show the points serial numbers. The second series shows multiple aircraft locations with labels that show the points serial numbers. The third series shows single and multiple aircraft locations without the points' serial numbers, but it shows labels indicating the number of aircraft in each multiple aircraft location. These maps are helpful to the client because they represent the aircraft crash locations by the aircraft country of origin (Figure 6-5). 


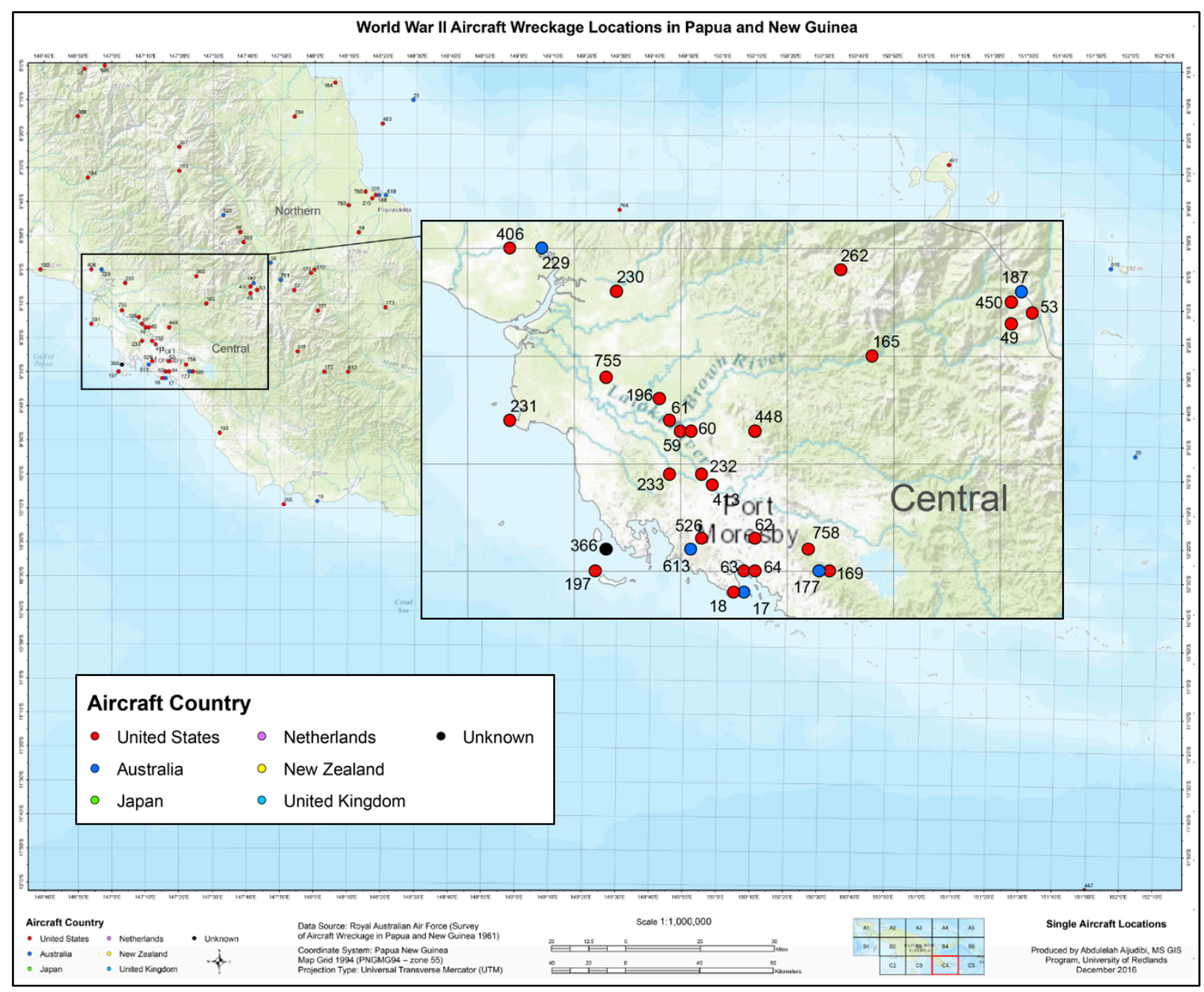

Figure 6-5: Map Series Symbolized by Country of Origin.

The client can rapidly know the aircraft belonging to the US without the trouble of going back to the attribute table to find out that piece of information. This map's quality also visually shows the areas that are crowded by other countries' aircraft as well as US aircraft to allow the client to know which areas to avoid and which areas to target.

While these maps serve the client needs and requirements, smaller scale maps would have provided better information about the environment around the crash sites and would have helped the client more efficiently.

\subsection{Summary}

This chapter discussed each of this project's results individually. The discussion of building the geodatabase addressed how the geodatabase solved the problem the DPAA had of not fully benefiting from the RAAF's survey data because they were in a PDF file. The advantages of having an interactive map included how the interactive map helped to conduct analyses on the data. This was followed by a discussion of how the analytical maps might assist the client in the planning for recovery missions and how the map series might contribute in the field. 


\section{Chapter 7 - Conclusions and Future Work}

\subsection{Conclusion}

The main goal of this project was to integrate the Royal Australian Air Force (RAAF) survey data into a geographic information system (GIS) so the Defense POW/MIA Accounting Agency (DPAA) employees can conduct analyses on them and compare the data to other datasets. The work involved building a geodatabase for the data. The geodatabase was designed in a way that ensures the consistency of the data, avoids data redundancy, and allows the client to use its schema for other similar datasets. By integration into a GIS, the functional requirements required by the client were met. The client can now:

- Categorize the data to view the aircraft in ArcMap by country of origin and by the aircraft's designation code.

- Search automatically for records through the tables.

- Search for records by their locations.

- Add, delete, and edit the data.

- Conduct analyses on the data.

- Create maps

Moreover, the client can add other datasets as different layers to visually compare them and to conduct analyses on them.

A variety of analyses were conducted on the data to help the client in the planning for search and recovery missions. The results of these analyses allow the client to minimize the time taken for planning for the search and recovery missions and so it would reduce costs. The map series produced will allow the user in the field to make better decisions about which specific areas the team should search for aircraft wrecks by providing terrain and river information. They also show the aircraft categorized by the country of origin which allows the client to focus on US aircraft crash locations and avoid other countries' aircraft crash locations.

In conclusion, this project was the first step to have the Royal Australian Air Force survey data in a form that allows data manipulation and allows automation dealing with the data so the Defense POW/MIA Accounting Agency (DPAA) employees can use them efficiently to do their mission.

\subsection{Future Work}

Integrating RAAF survey data into ArcGIS was a milestone that opened up the horizon for many other future projects. An expanding work for this Major Individual Project could be integrating terrain data and creating an aspect layer to determine the directions of the slopes. Knowing the aircraft crash site, this would aid the searcher to predict the locations of the aircraft wrecks.

Another extension to this project can be creating a mobile application. The Royal Australian Air Force geodatabase included descriptive information about the locations of the aircraft crash sites that can help the user to find the crash locations. Accessing the 
geodatabase from the field can provide all the related data to the aircraft the user is searching for.

Since this project included World War II aircraft crash location data from the RAAF survey, other datasets about aircraft crash locations from other forces could be acquired to conduct comparison analyses to study common locations. This could increase the chances of finding aircraft wreckage. 


\section{Works Cited}

Advances in Location Modeling: GIS Linkages and Contributions. (2010, January 14). Journal of Geographical Systems, 12-3(1435-5930), 341. Retrieved September 4, 2016, from

https://www.researchgate.net/profile/Alan_Murray6/publication/46459772 Adv ances in Location Modeling GIS Linkages and Contributions/links/542183f80 cf2ce3a91b78f7b.pdf.

Australia-Japan Research Project. (1975). Remembering the war in New Guinea. Retrieved November 25, 2016, from Australia-Japan Research Project: http://ajrp.awm.gov.au/ajrp/remember.nsf/WebPrinter/58EBD6D993E15CE8CA256D05002671FD?OpenDocument

Callander, B. D. (2005, June). The Search Goes On. Air Force Magazine, p. 69.

Defense POW/MIA Accounting Agency. (n.d.). Vision-Mission-Values. Retrieved from Defense POW/MIA Accounting Agency: http://www.dpaa.mil/About/VisionMission-Values/

Defense POW/MIA Accounting Agency. (n.d.). World War II. Retrieved from Defense POW/MIA Accounting Agency: http://www.dpaa.mil/Our-Missing/World-War$\underline{\text { II/ }}$

Dickerson, K. (2014, November 11). Project Recover Searches for Long-Lost World War II Heroes. Retrieved October 7, 2016, from Live Science: http://www.livescience.com/48724-project-recover-missing-soldiers.html

Esri. (2016a). Case studies. In Analyzing violent crime. Retrieved from http://desktop.arcgis.com/en/analytics/case-studies/broken-bottles-1overview.htm

Esri. (2016b). Case studies. In Twister! United States tornadoes. Retrieved from http://desktop.arcgis.com/en/analytics/case-studies/twister-analyzing-ustornadoes.htm

Henning, C. A. (2006, June 1). POWs and MIAs: Status and Accounting Issues. Retrieved from Federation of American Scientists: https://www.fas.org/sgp/crs/natsec/RL33452.pdf

Jain, S. (2015). Recovery of Crash Site Web Application (Master's thesis, University of Redlands). Retrieved from http://inspire.redlands.edu/gis gradproj/226

Janzen, N. R. (2012). Crash Site Debris Recovery Mobile Application (Master's thesis, University of Redlands). Retrieved from http://inspire.redlands.edu/gis gradproj/53

Krause, E. (2013, May 28). How should I interpret the output of density tools? Retrieved Sebtember 8, 2016, from ArcGIS Blog: https://blogs.esri.com/esri/arcgis/2013/05/28/how-should-i-interpret-the-outputof-density-tools/

Maguire, D. J., Batty, M., \& Goodchild, M. F. (2005). GIS, spatial analysis, and modeling. Redlands, CA, USA: ESRI Press.

Murray, A. T. (2010, January 14). Advances in Location Modeling: GIS Linkages and Contributions. Journal of Geographical Systems, 12-3(1435-5930). 
Royal Australian Air Force. (1961). Survey of World War II and Post War Aircraft Wreckage in Papua and New Guinea and Dutch New Guinea. Royal Australian Air Force.

United States Embassy in Papua and New Guinea. (2016, May 13). Repatriation Ceremony Honors WWII American Servicemen. Retrieved November 25, 2016, from Port Moresby. Papua and New Guinea - Embassy of The United States: https://portmoresby.usembassy.gov/repatriation.html

Vento, C. S. (2012, May 28). The Missing in Action (MIA) of World War II. Retrieved from Defense Media Network: http://www.defensemedianetwork.com/stories/themissing-in-action-mia-of-world-war-ii/ 


\section{Appendix A. Royal Australian Air Force Survey.}

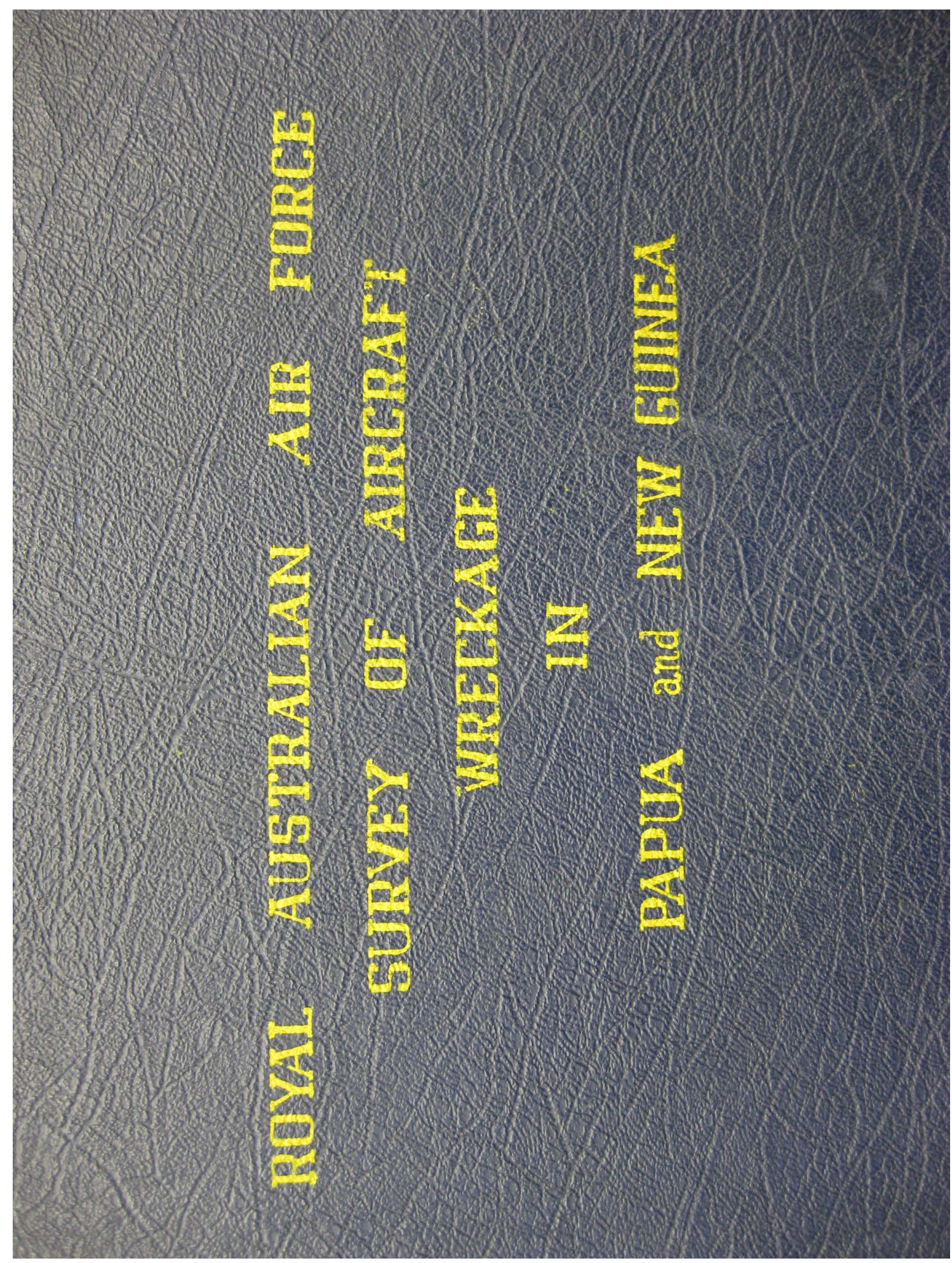




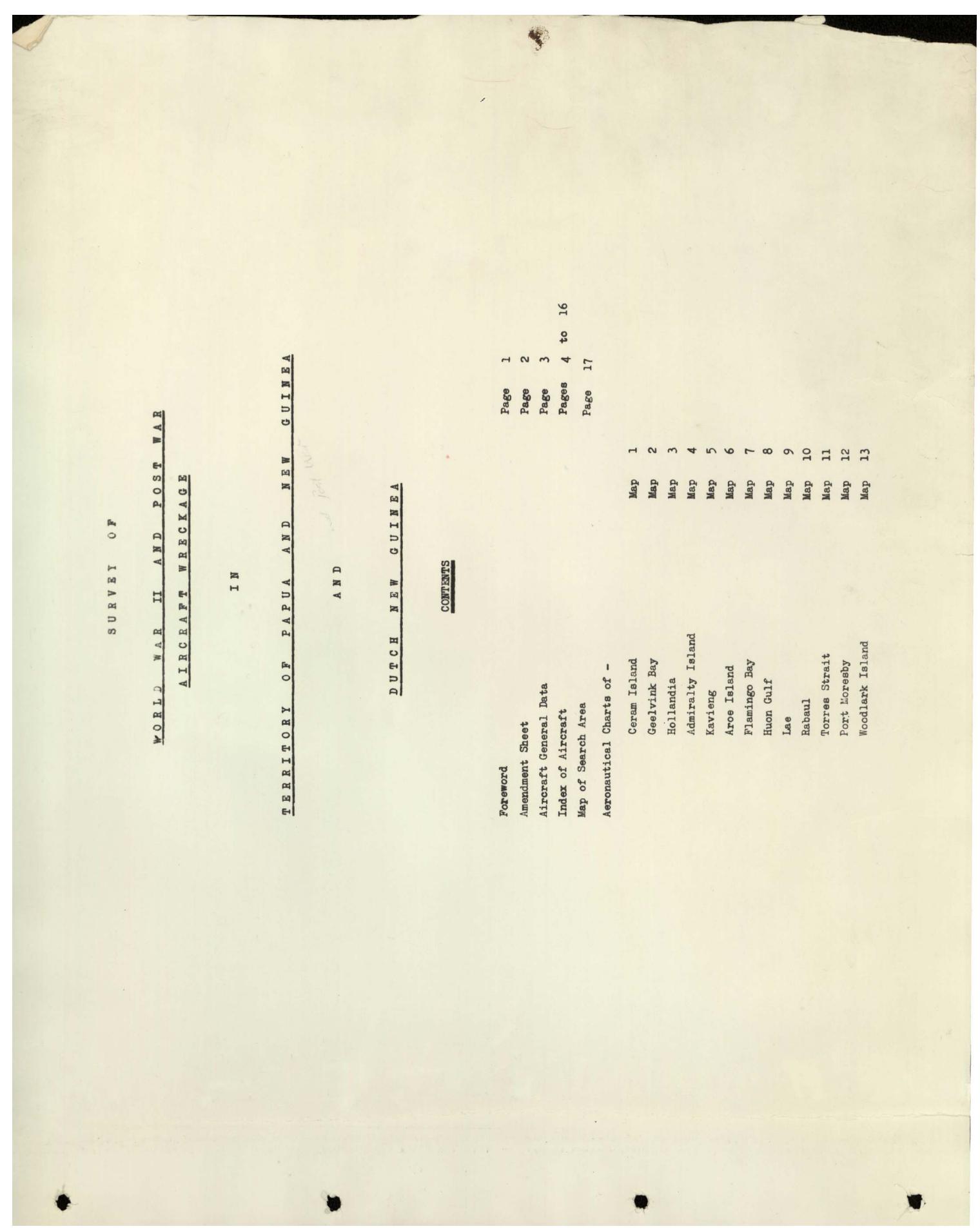




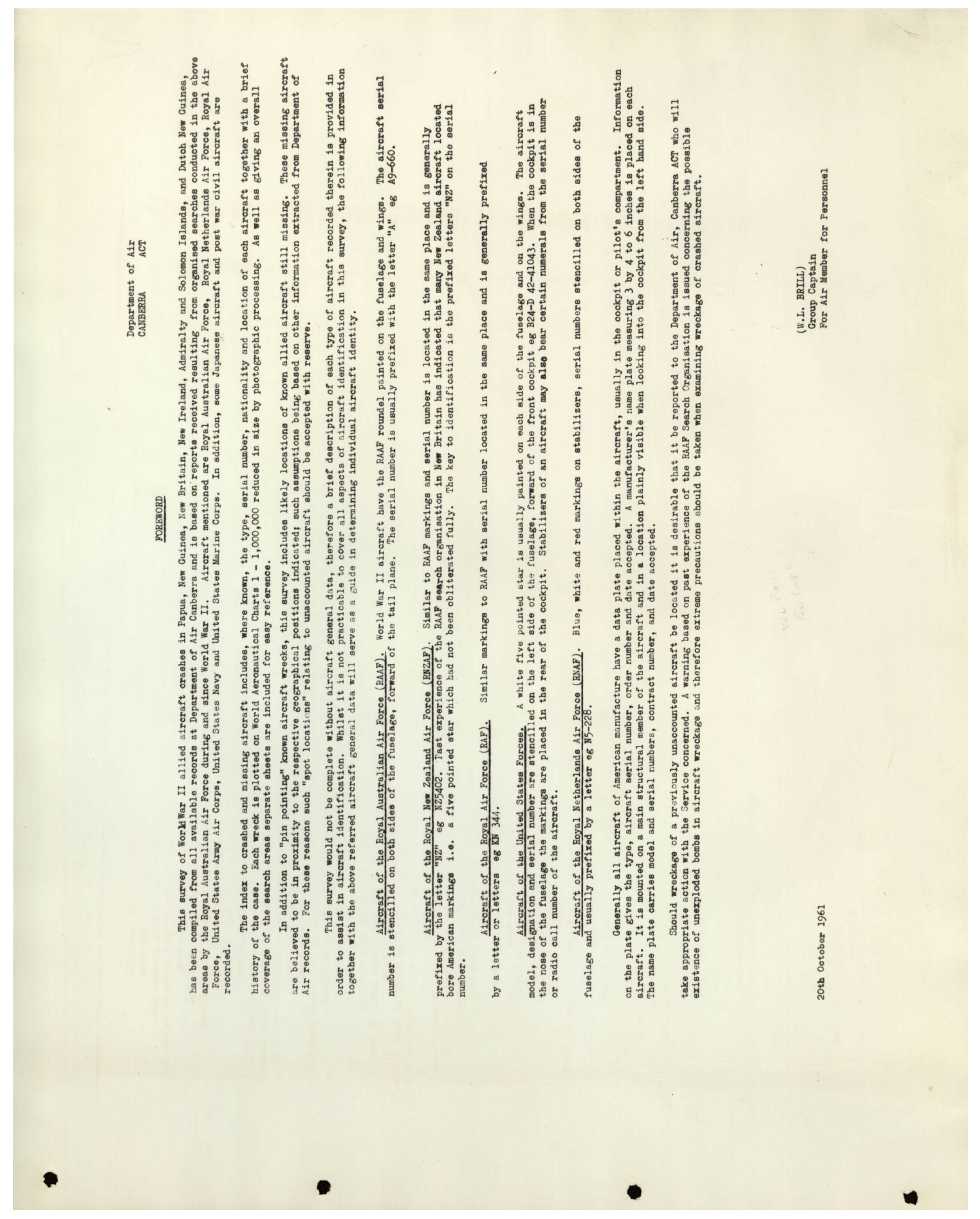




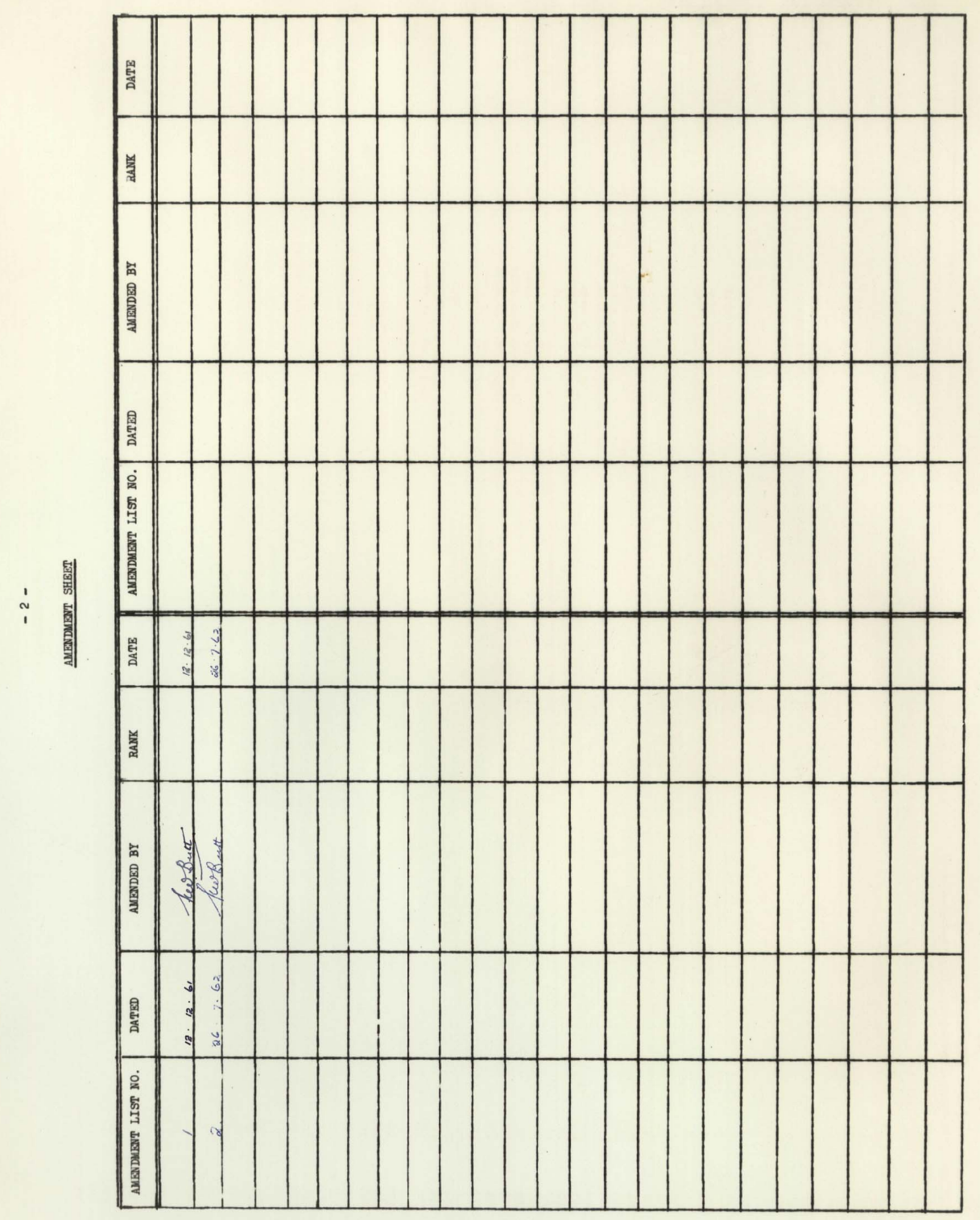




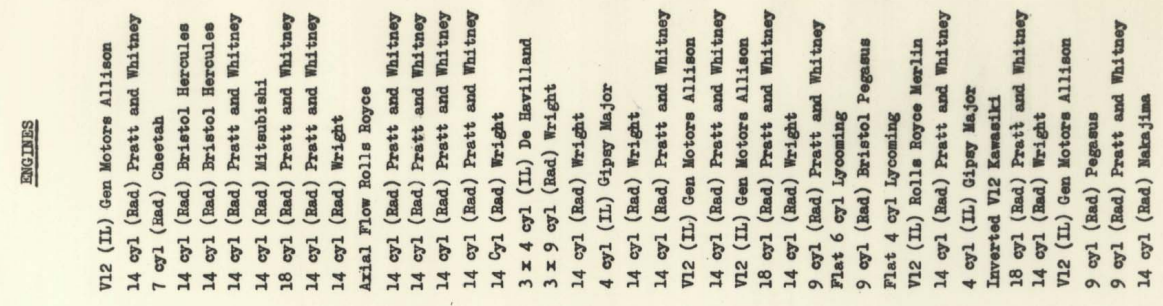

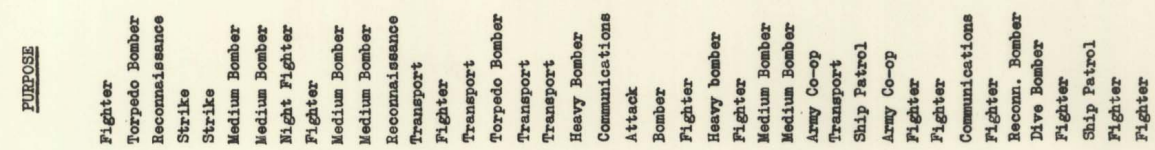

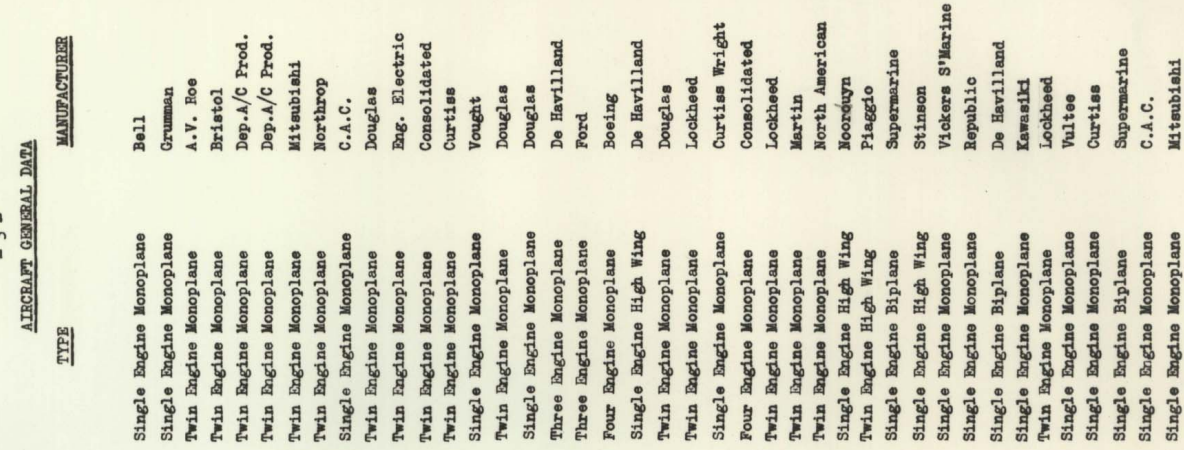

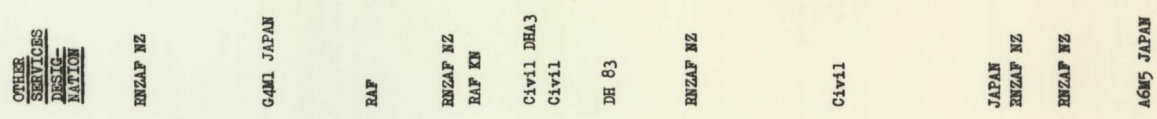

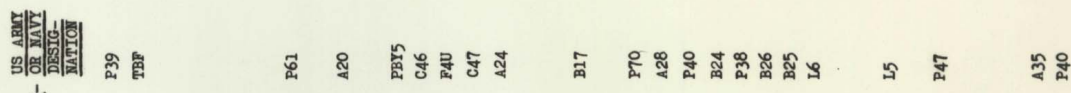

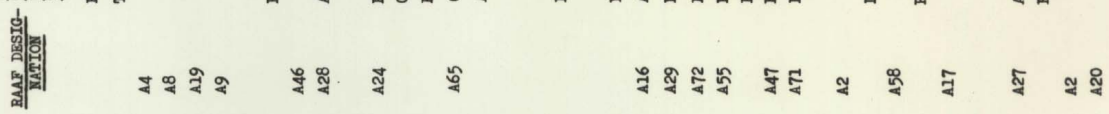

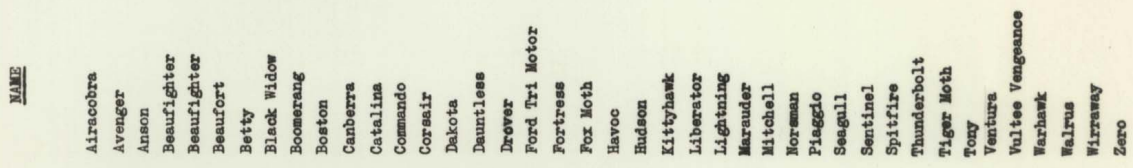




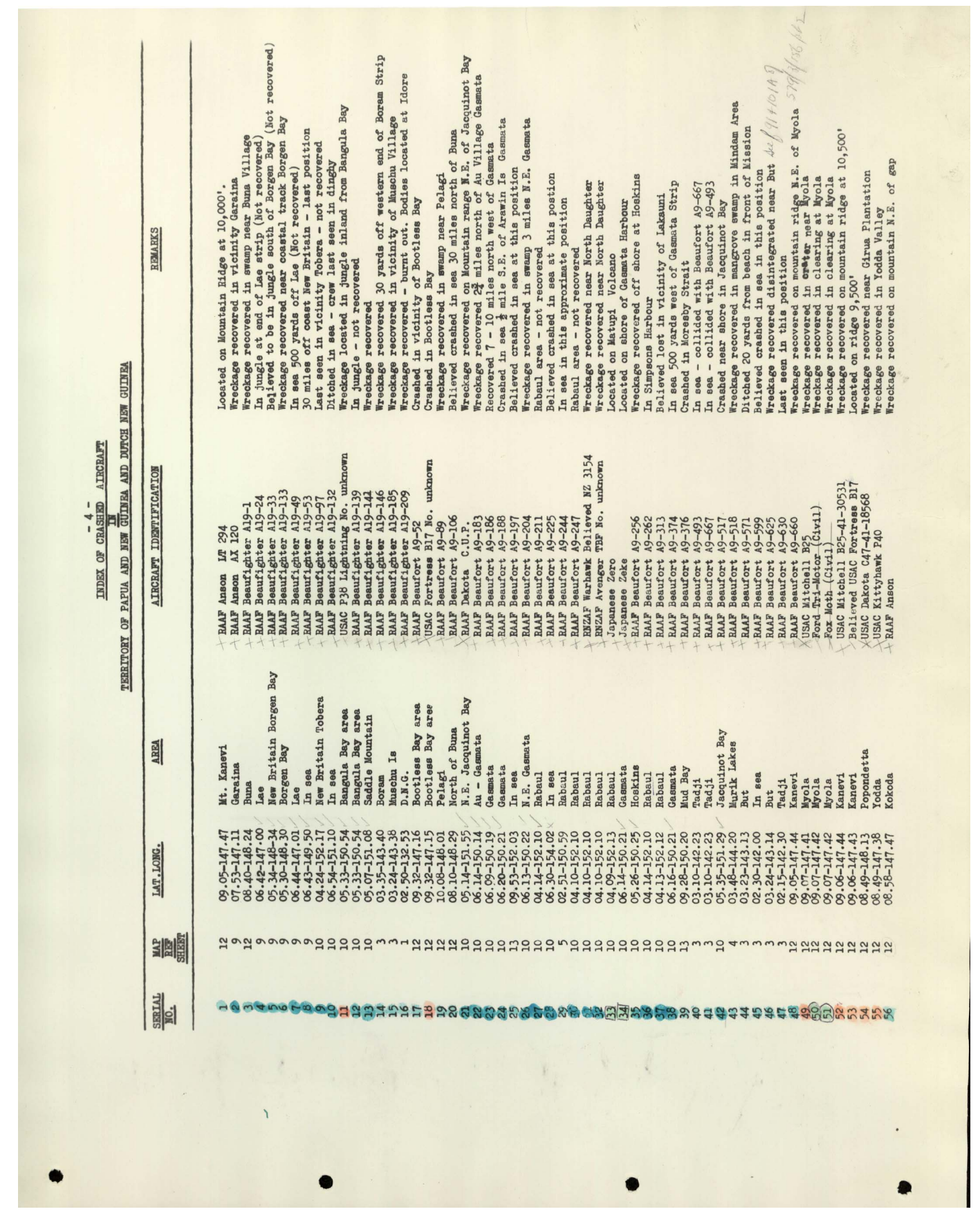




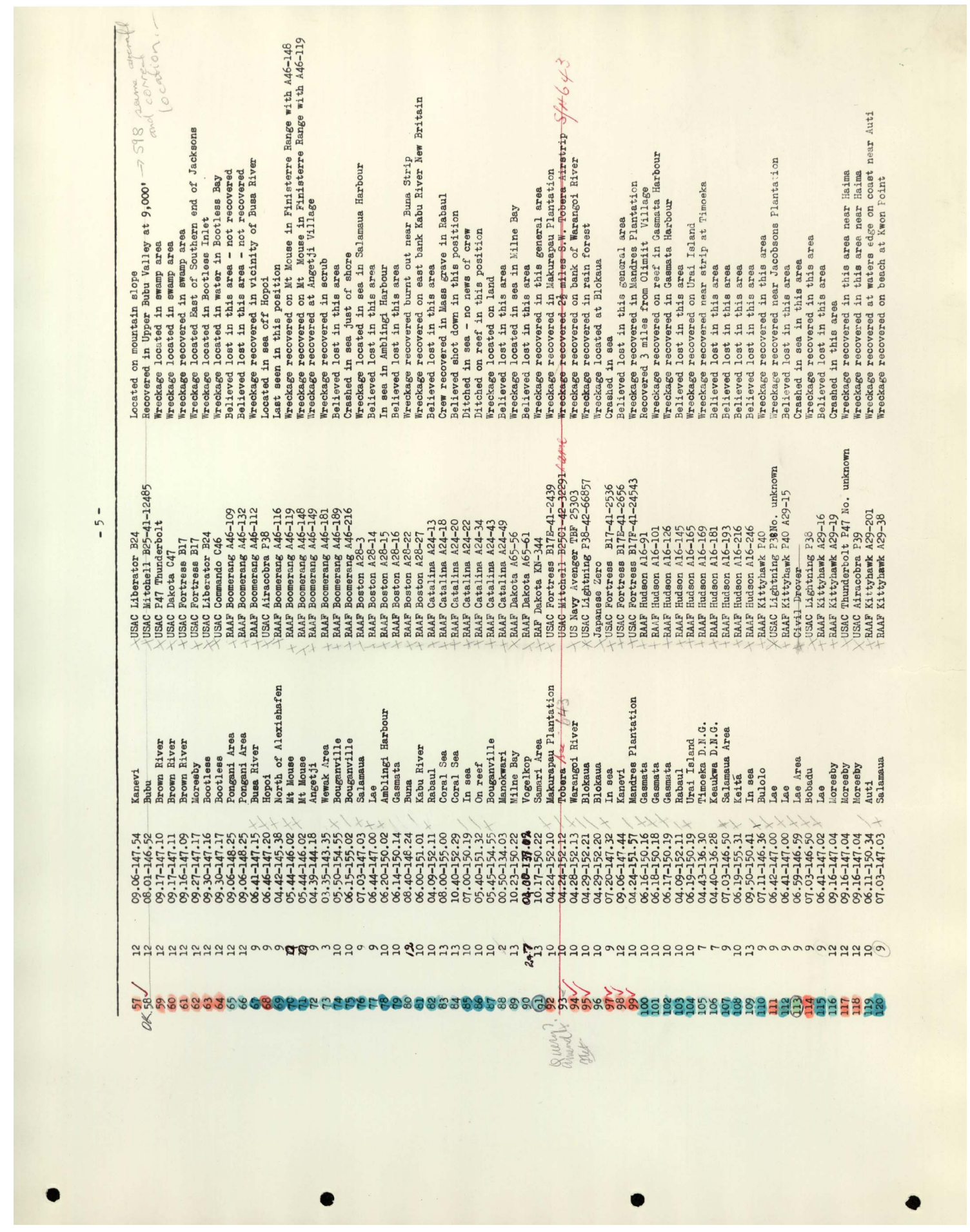




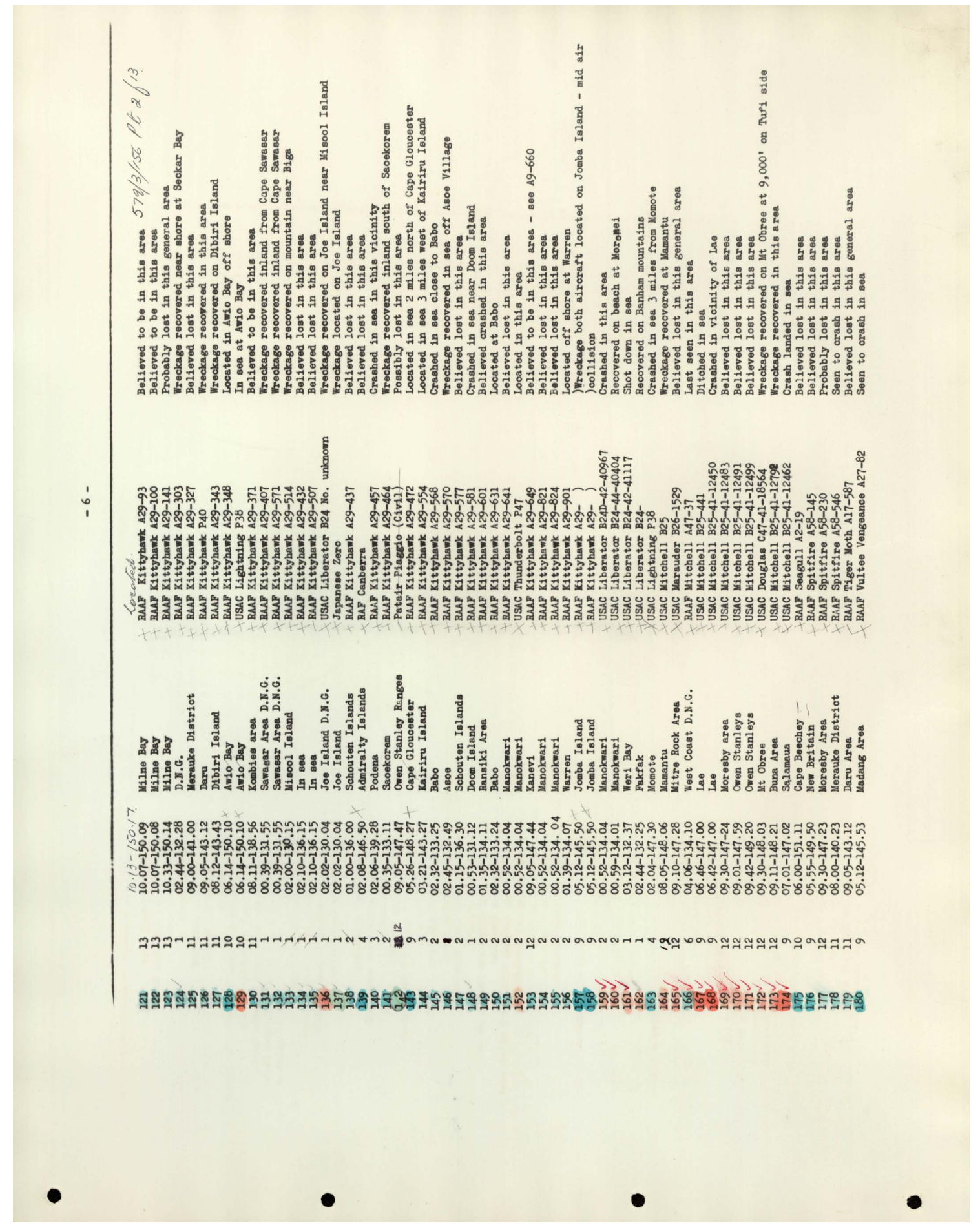




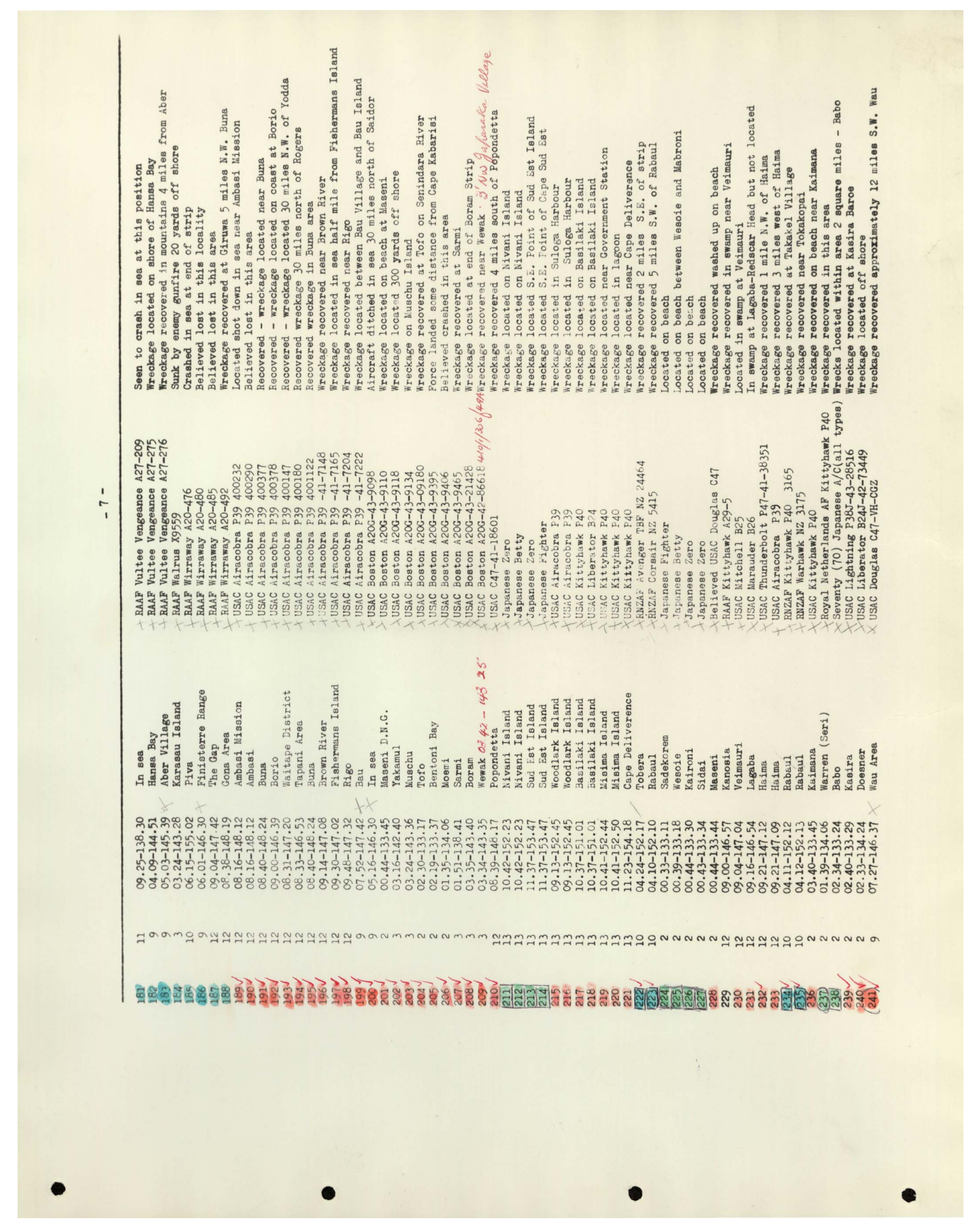




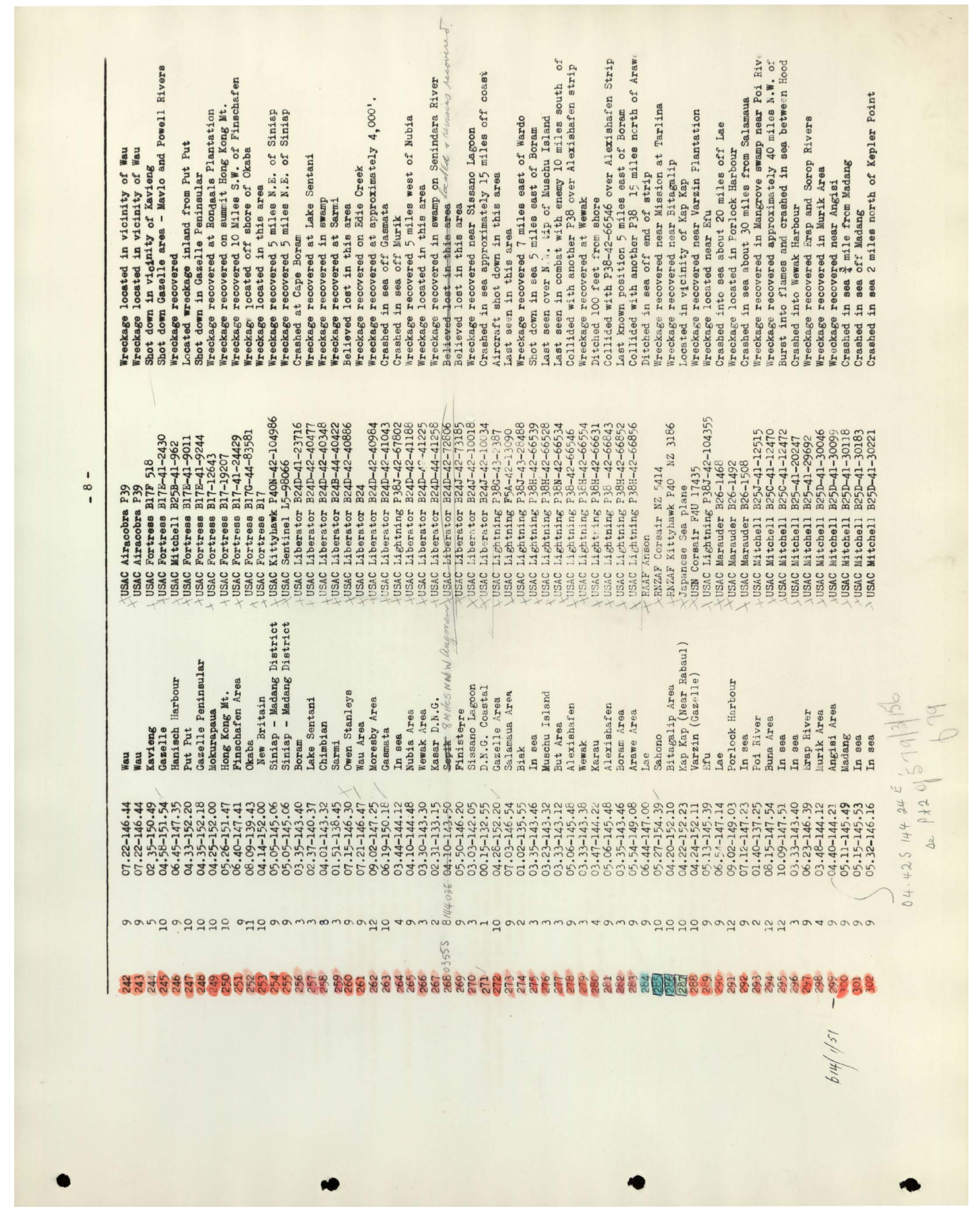




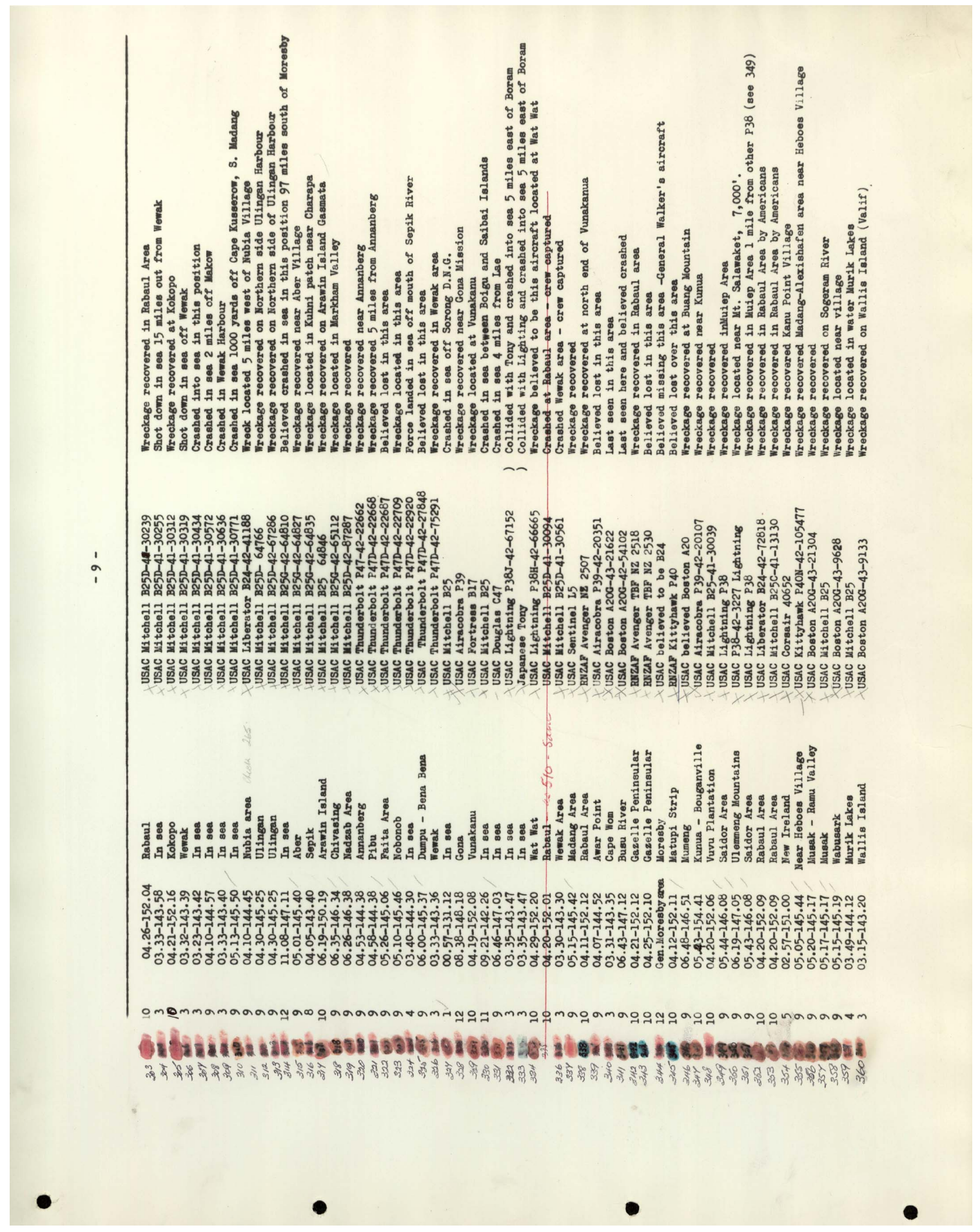




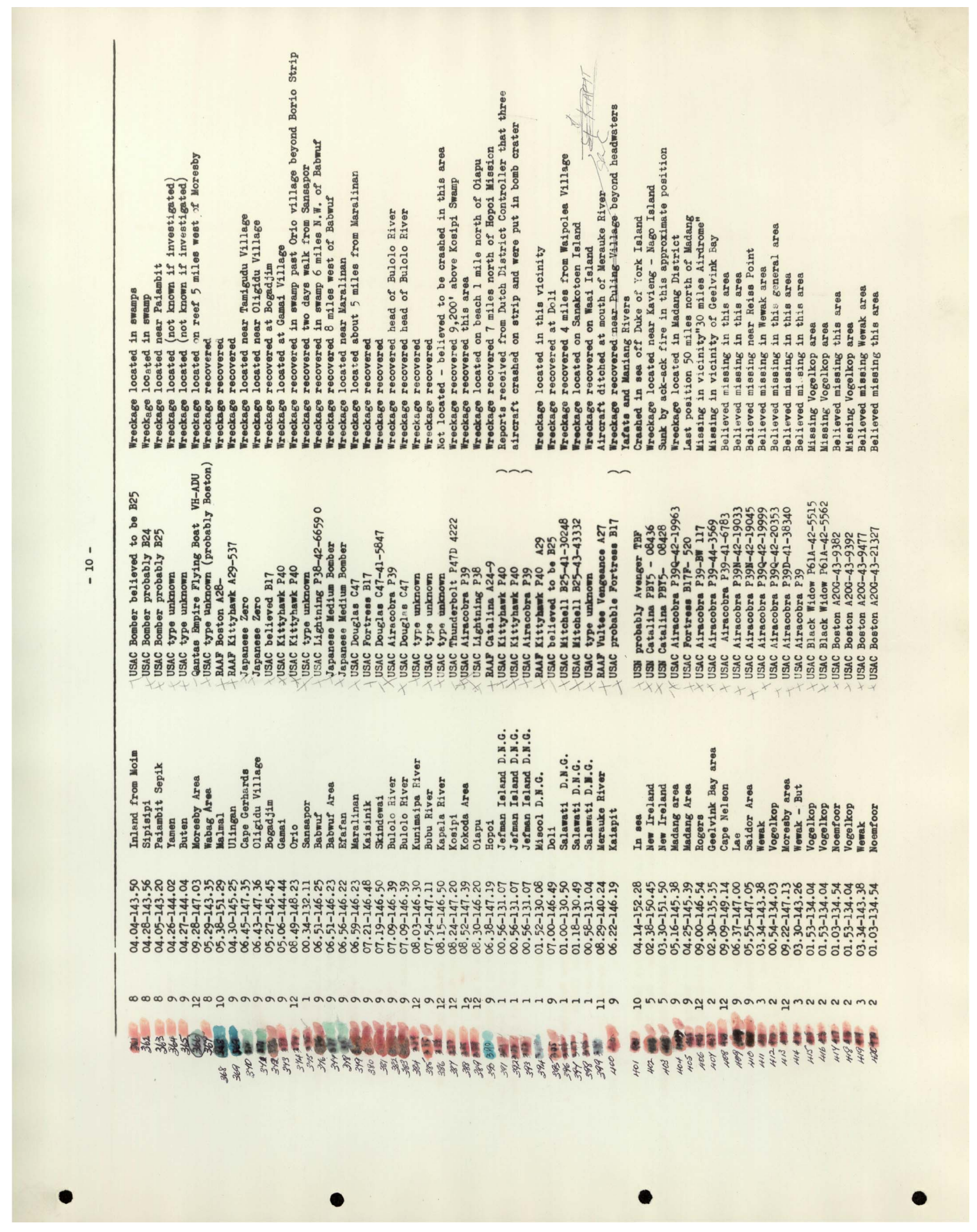




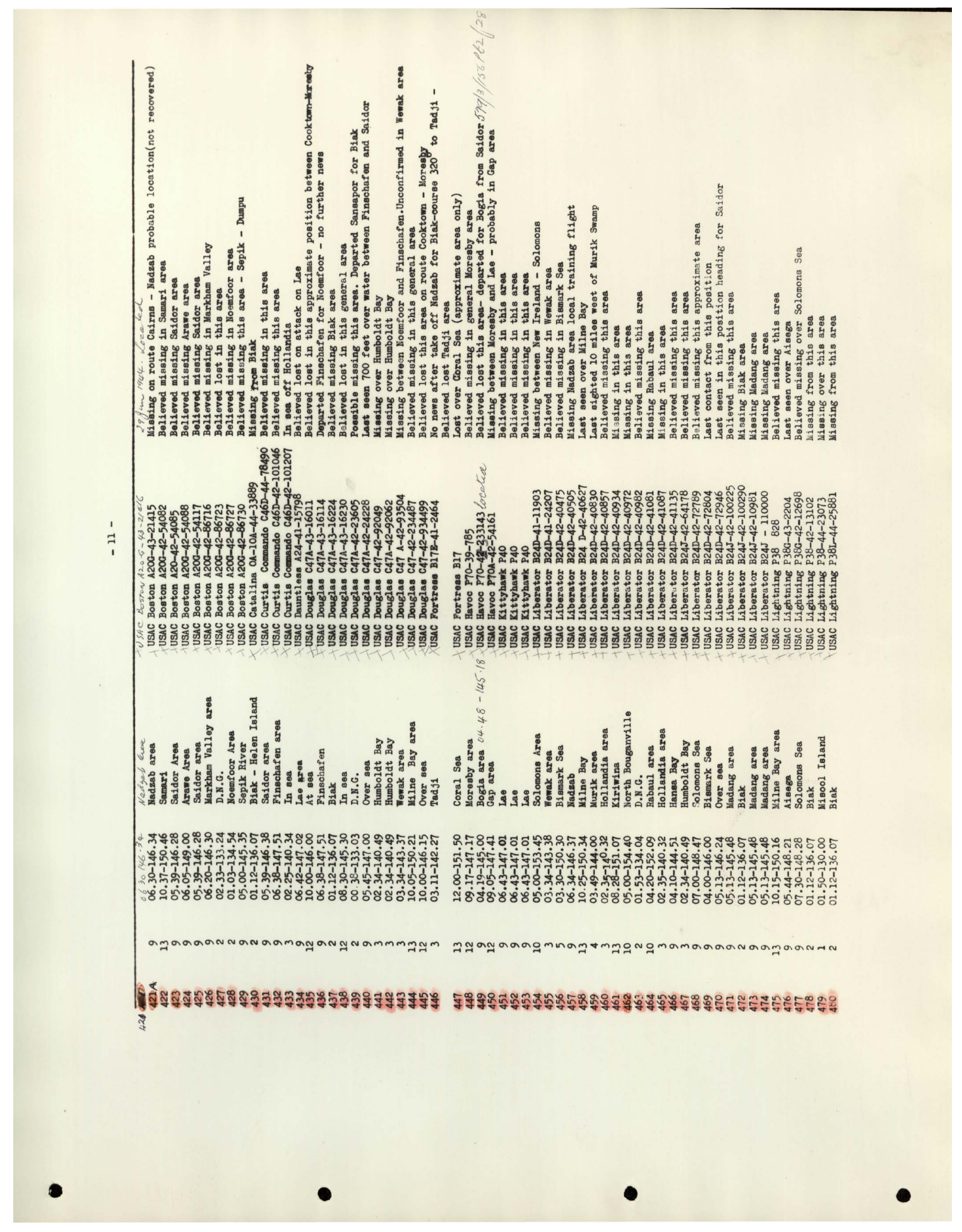




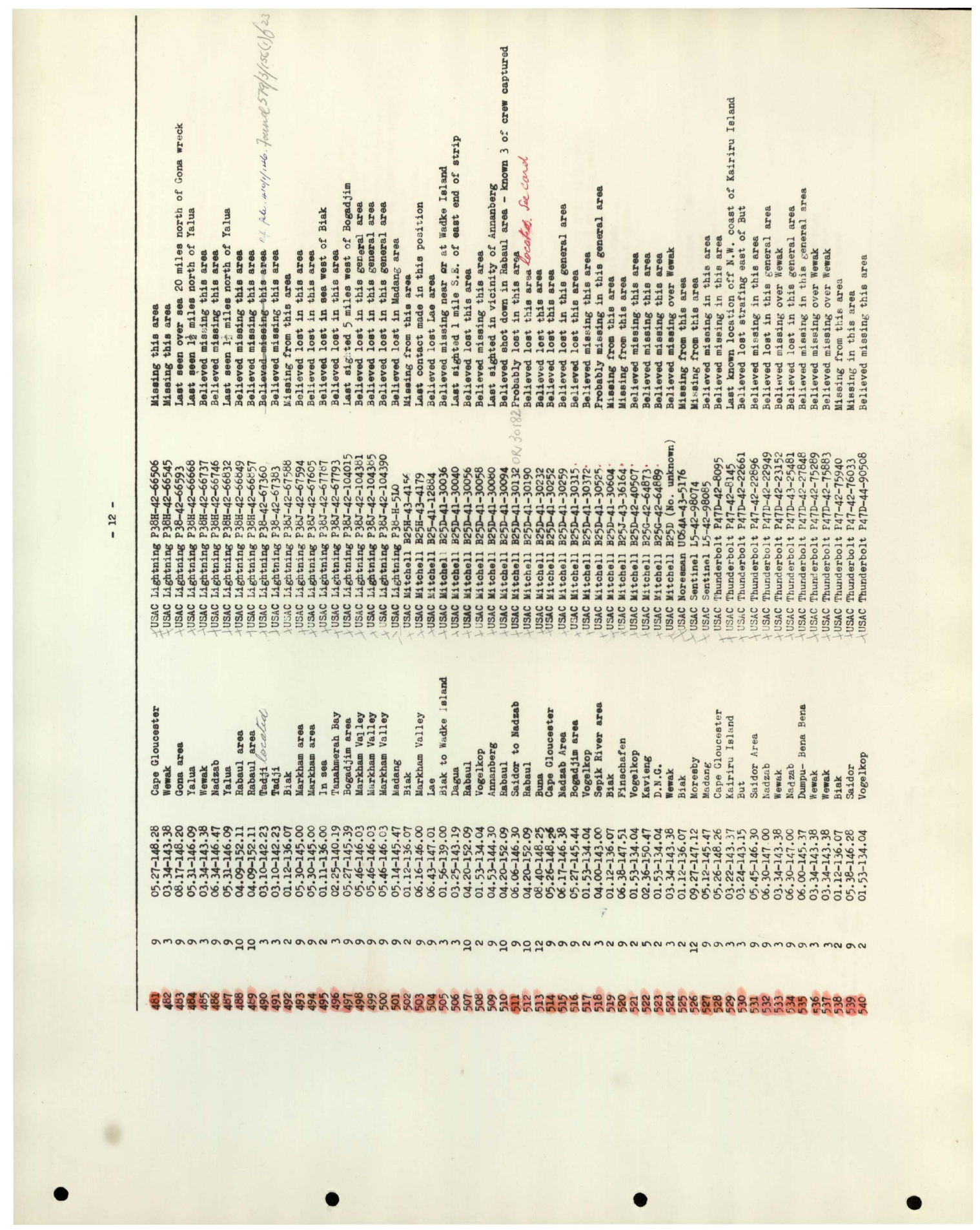




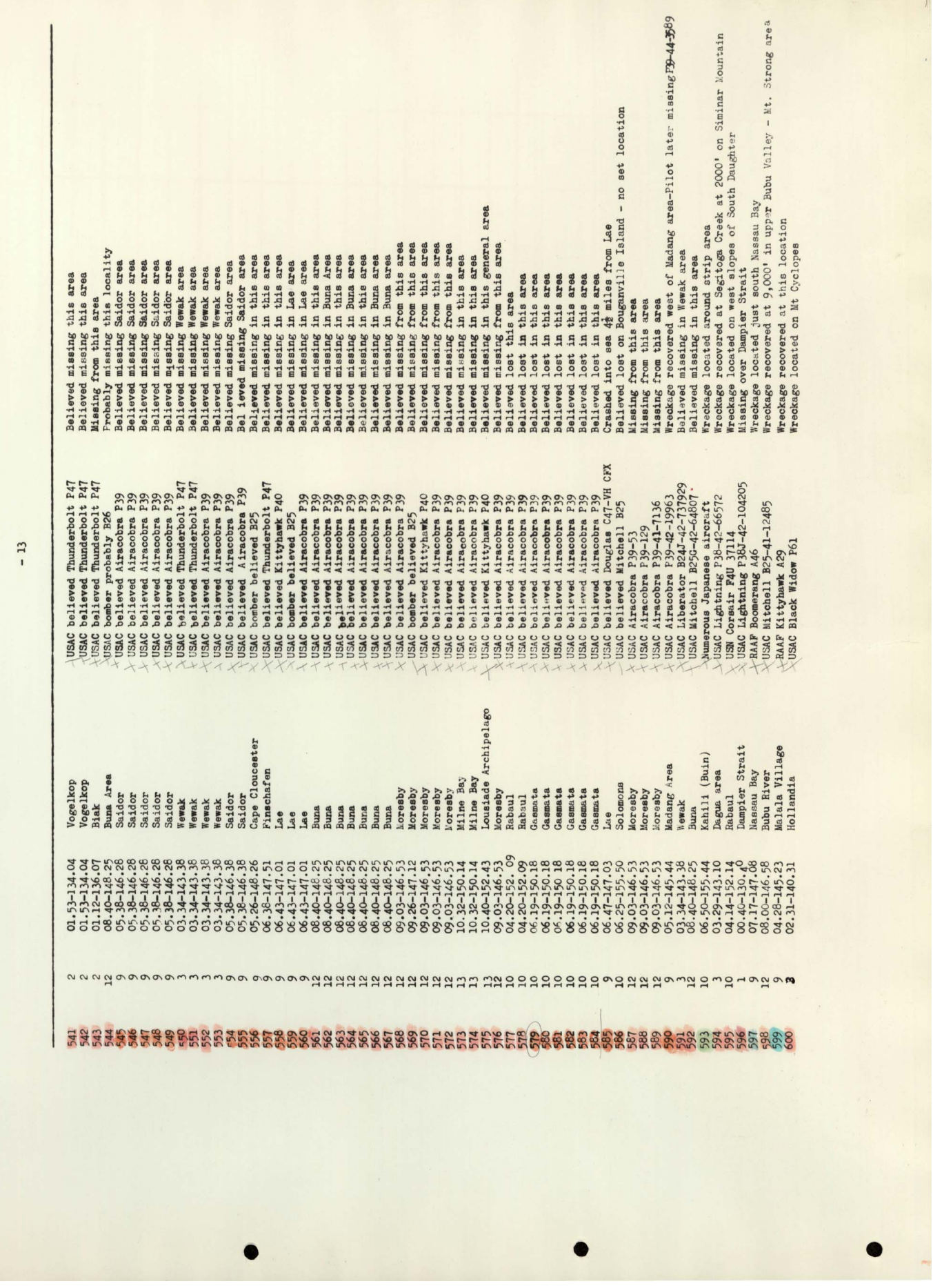




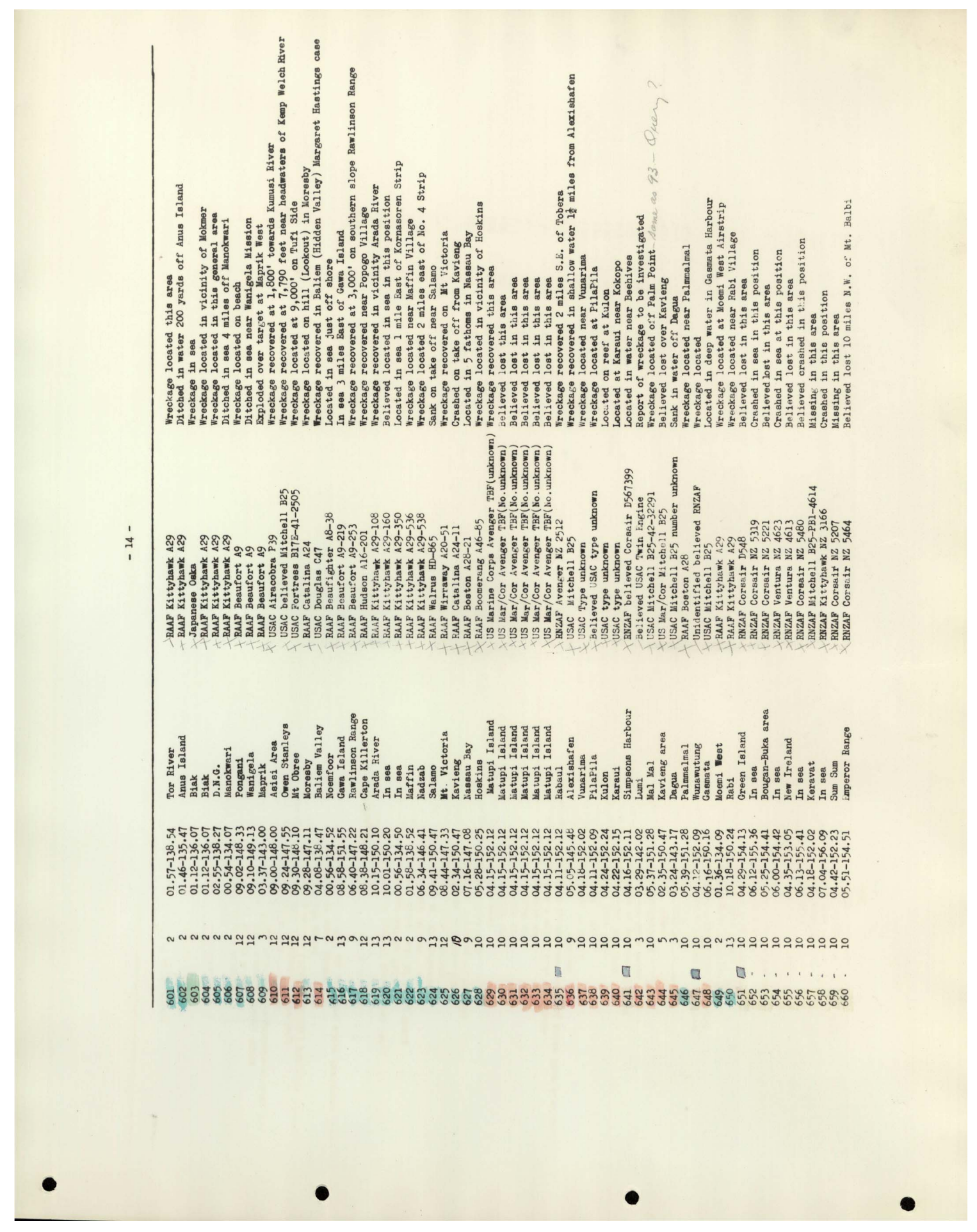




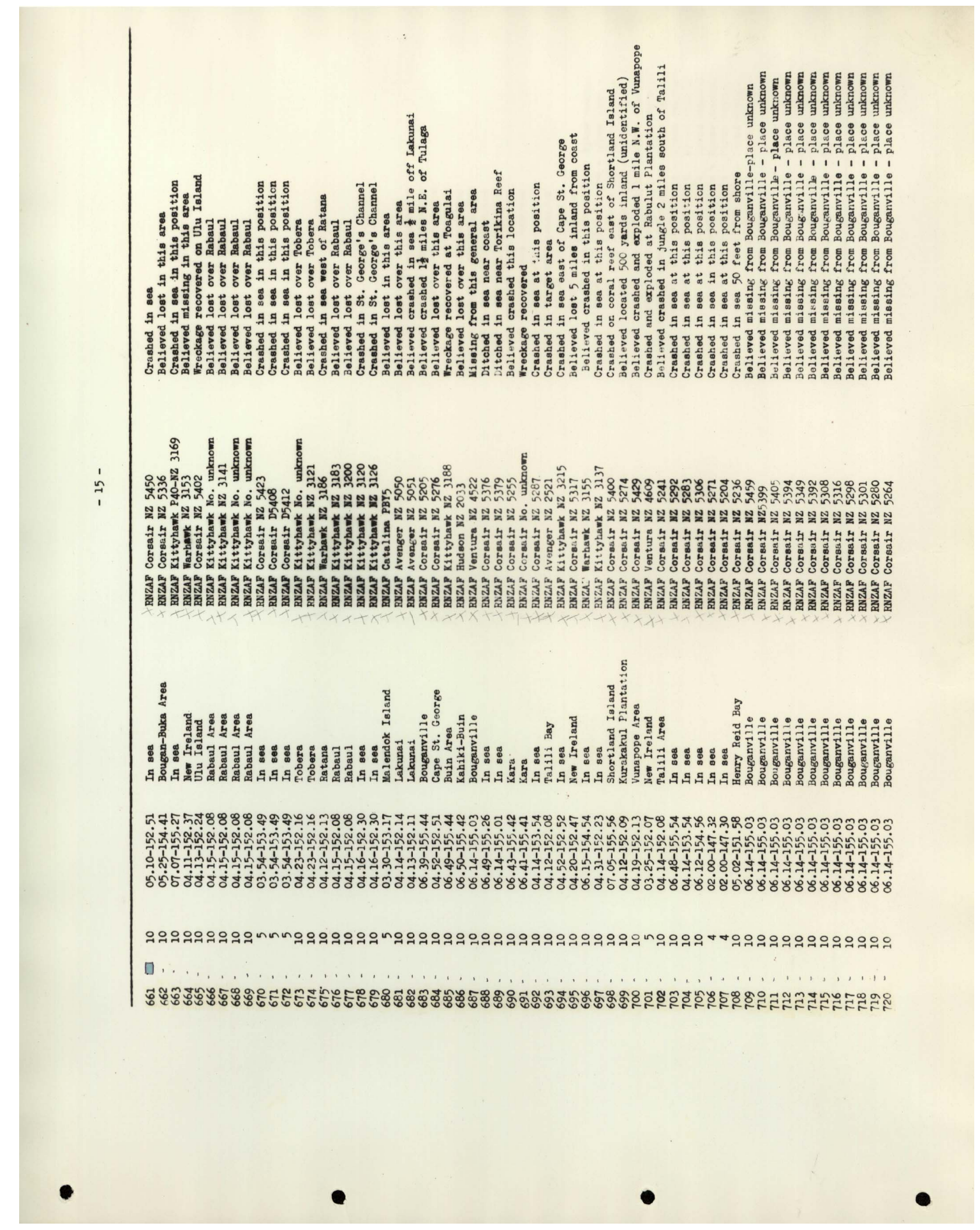




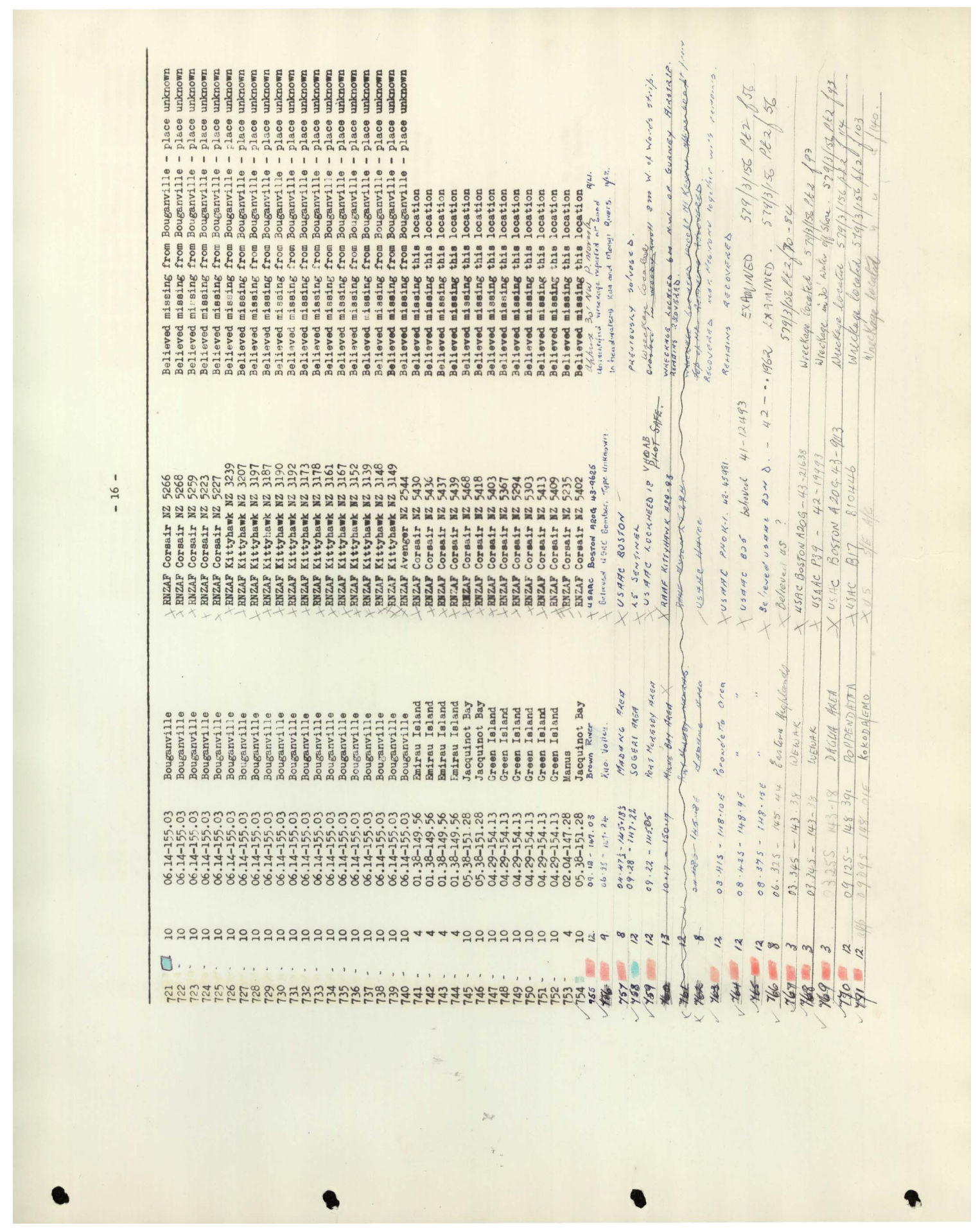




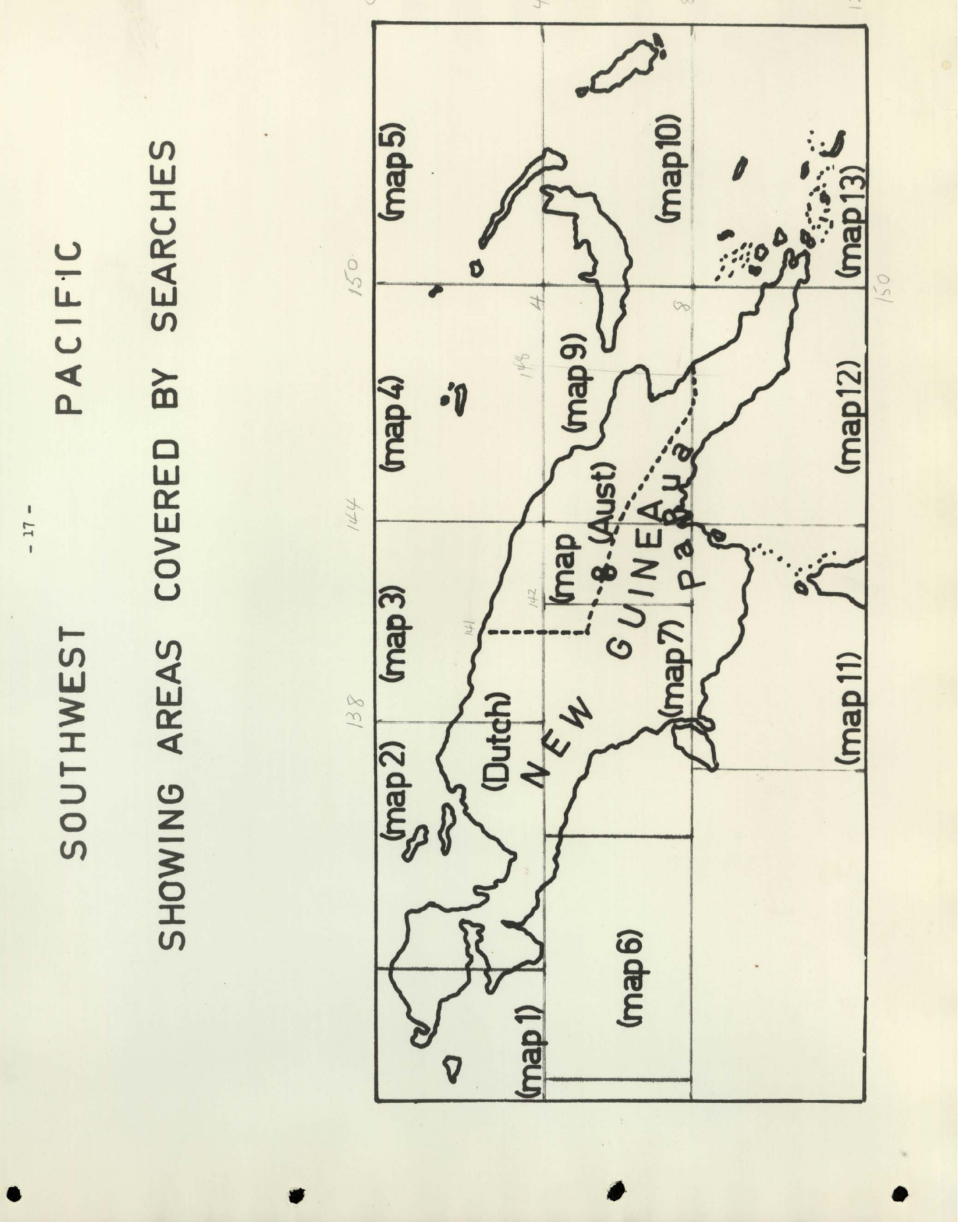




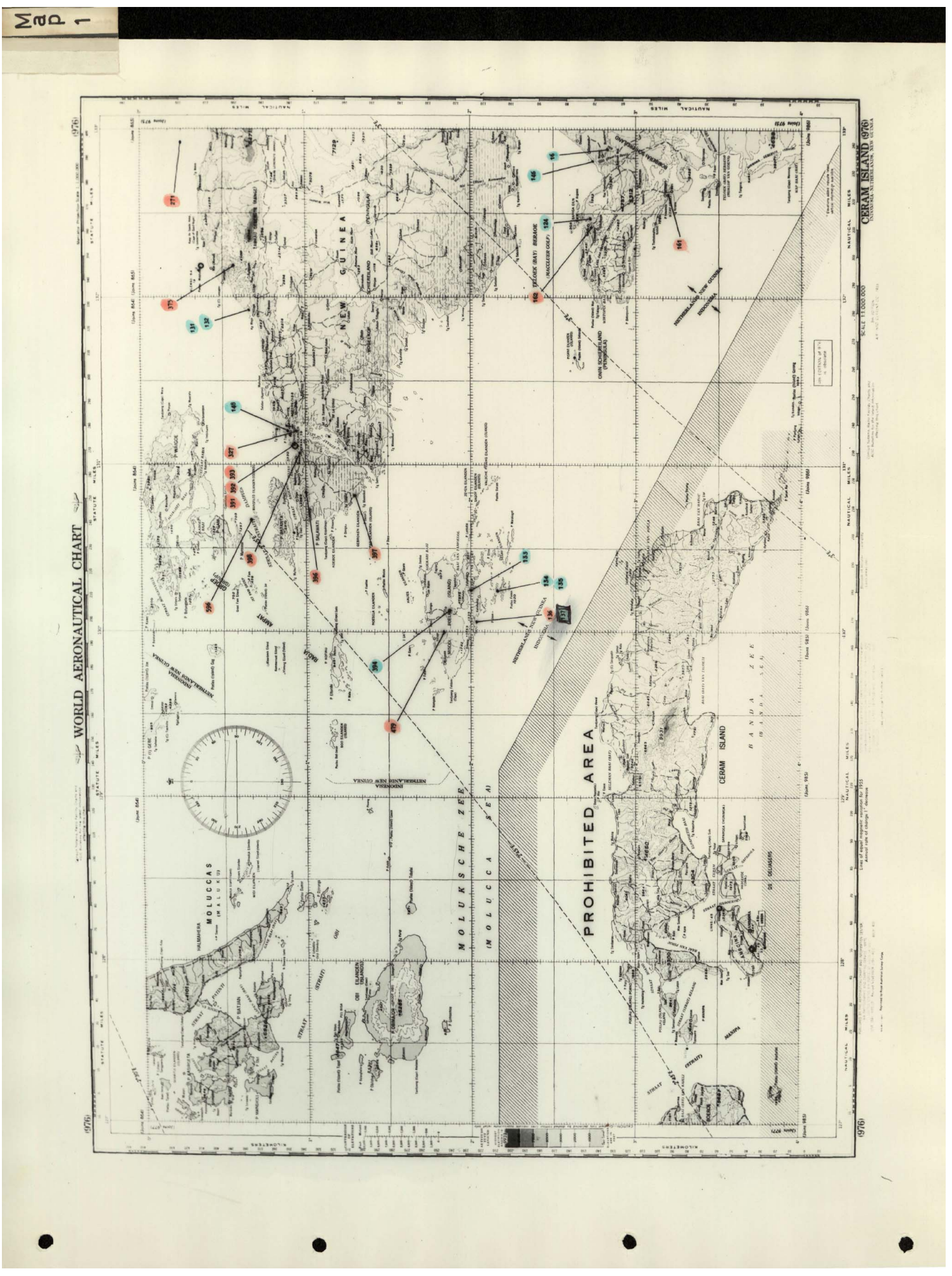




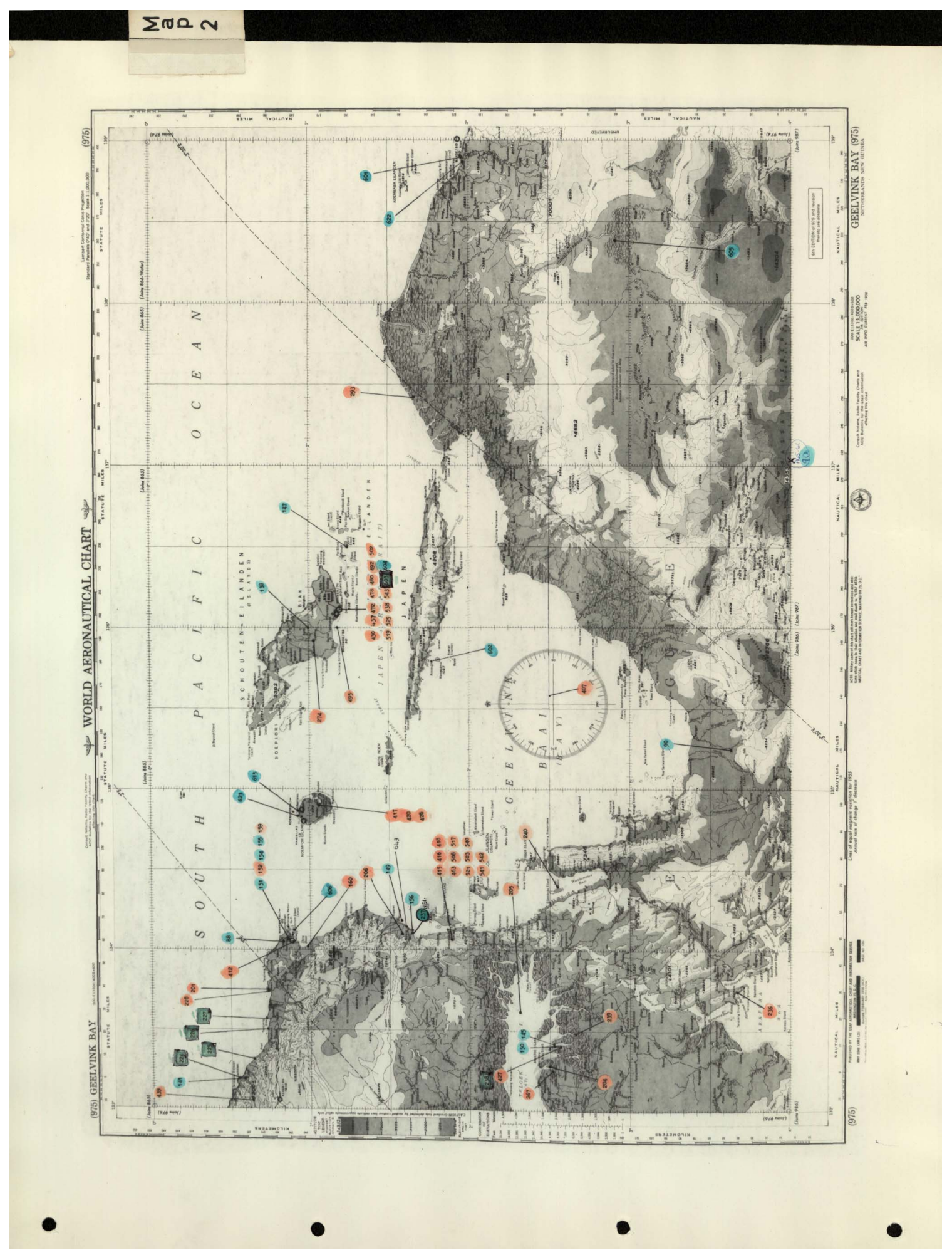




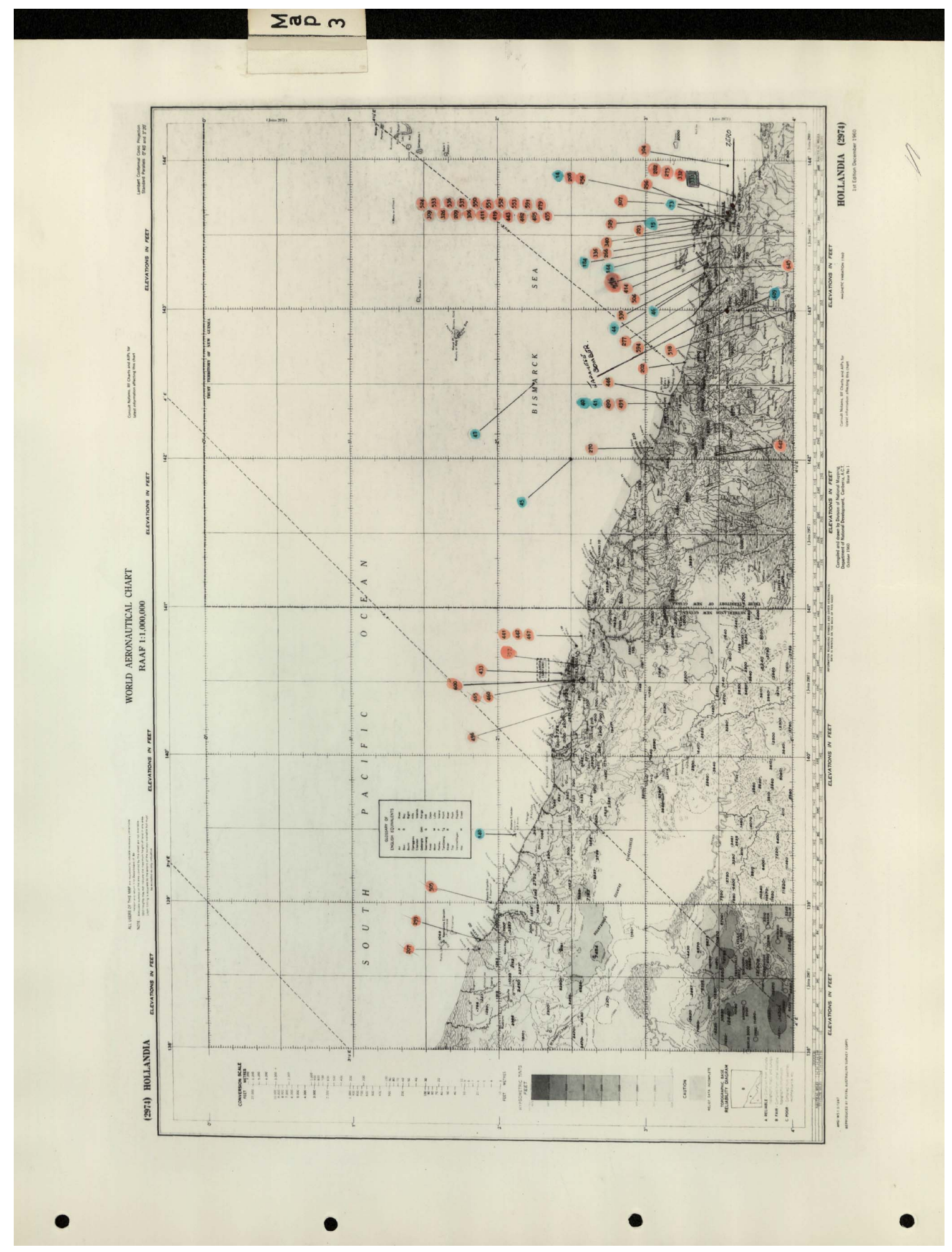




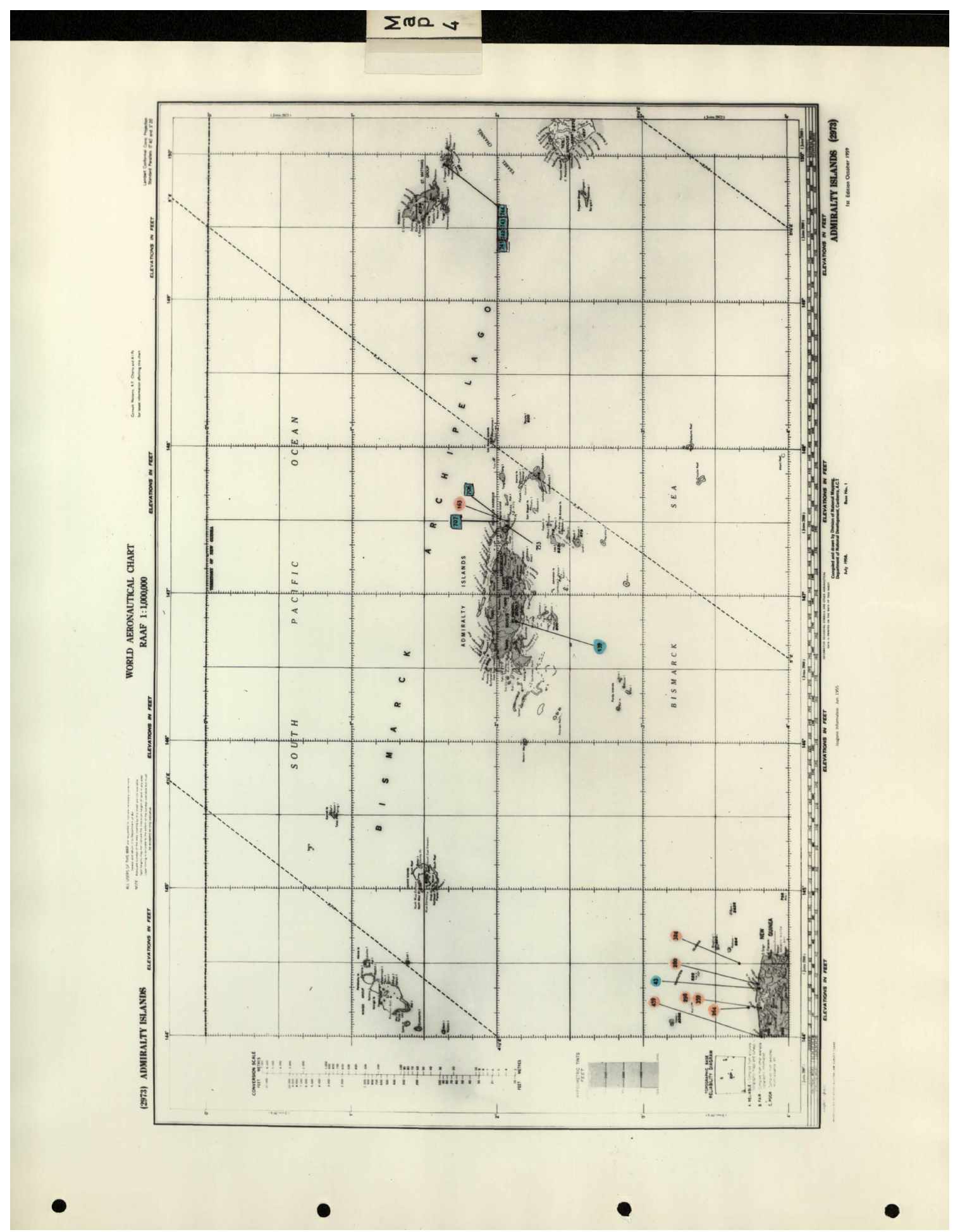




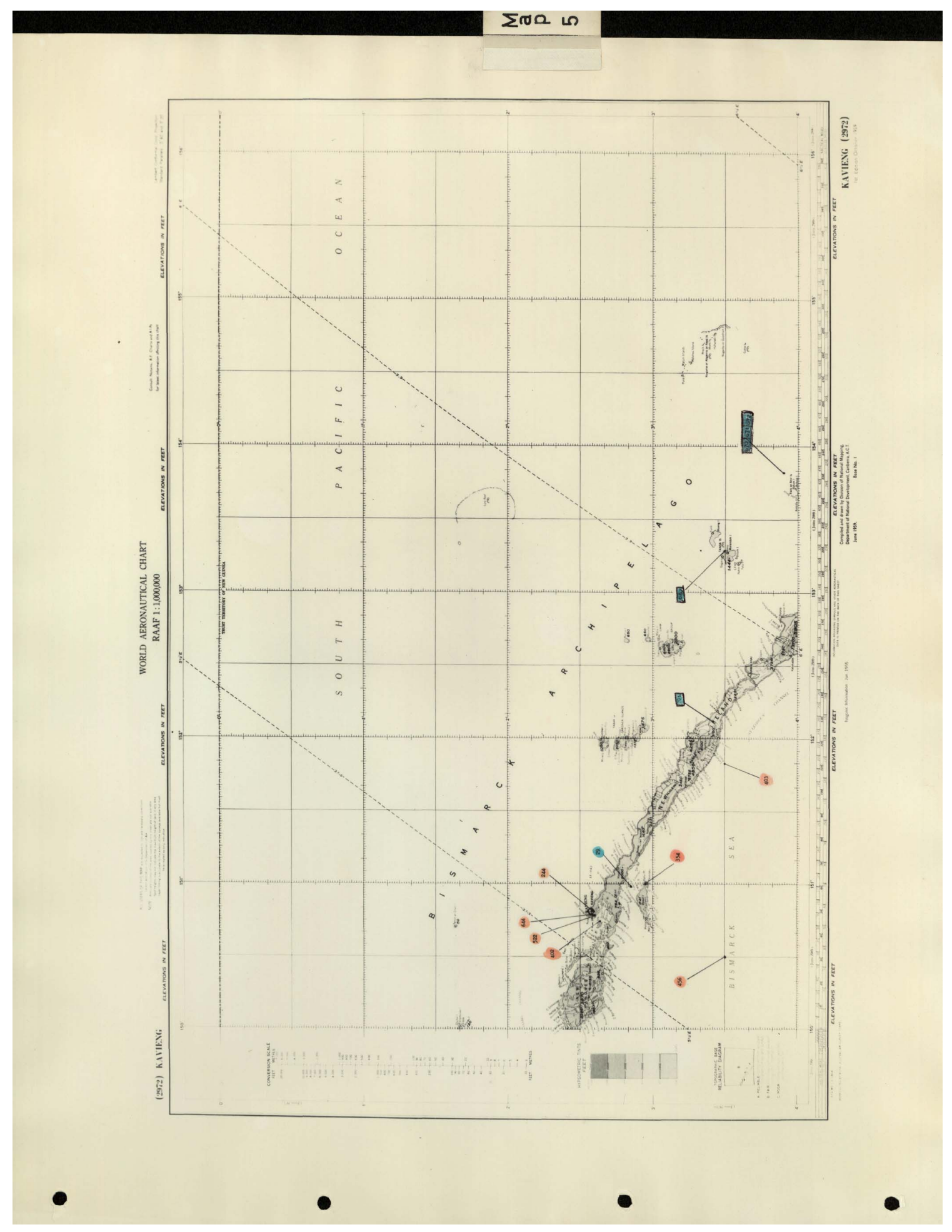




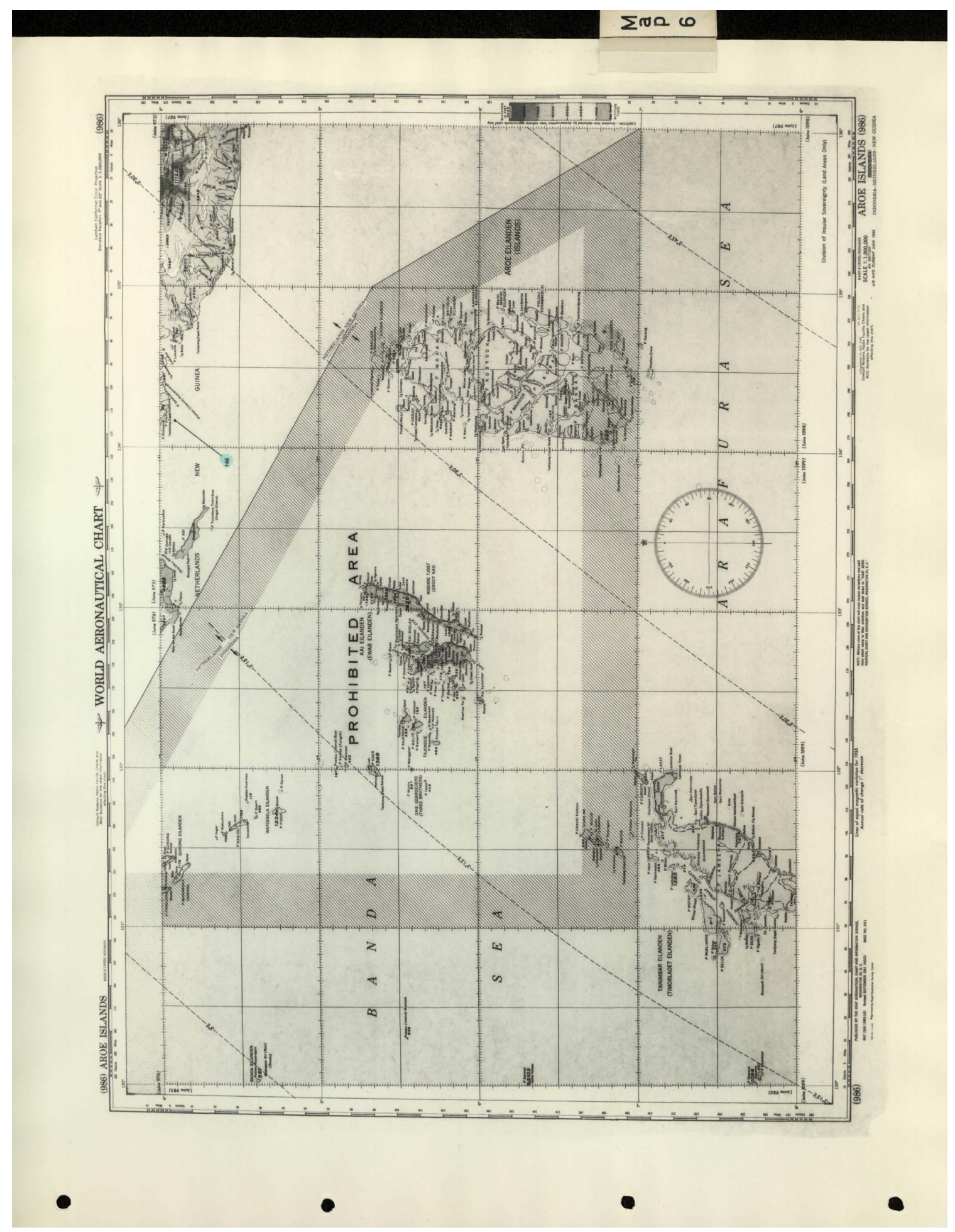




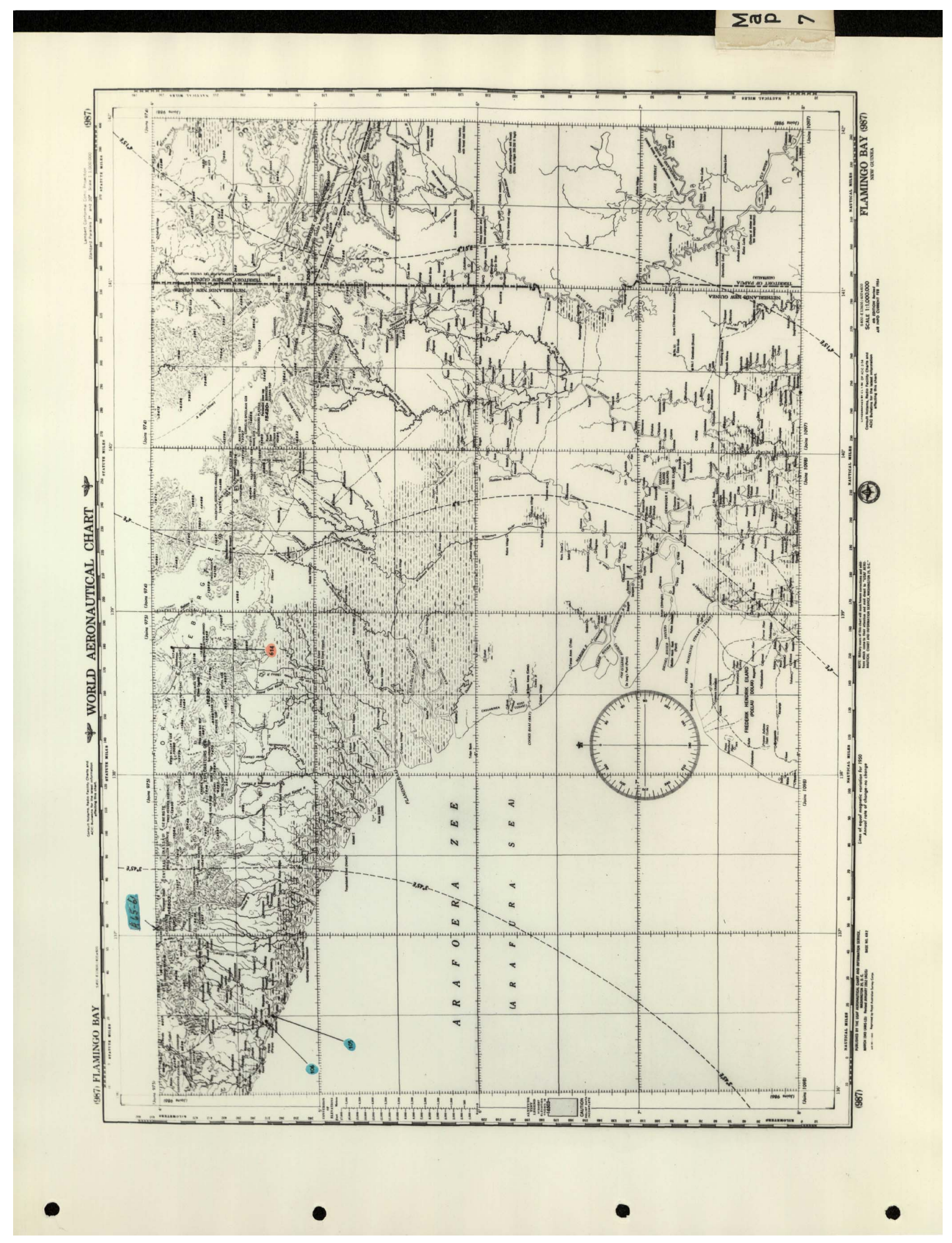




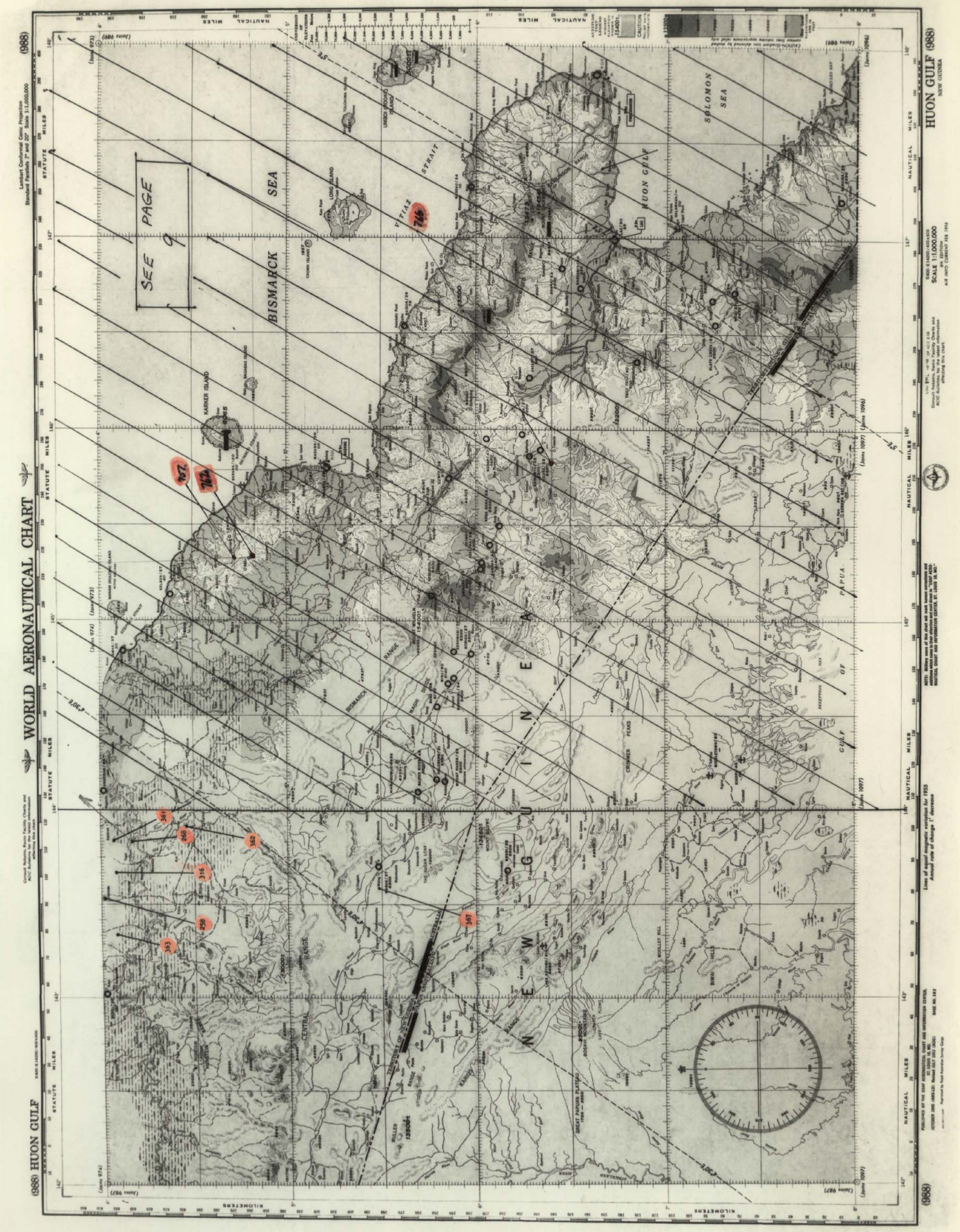




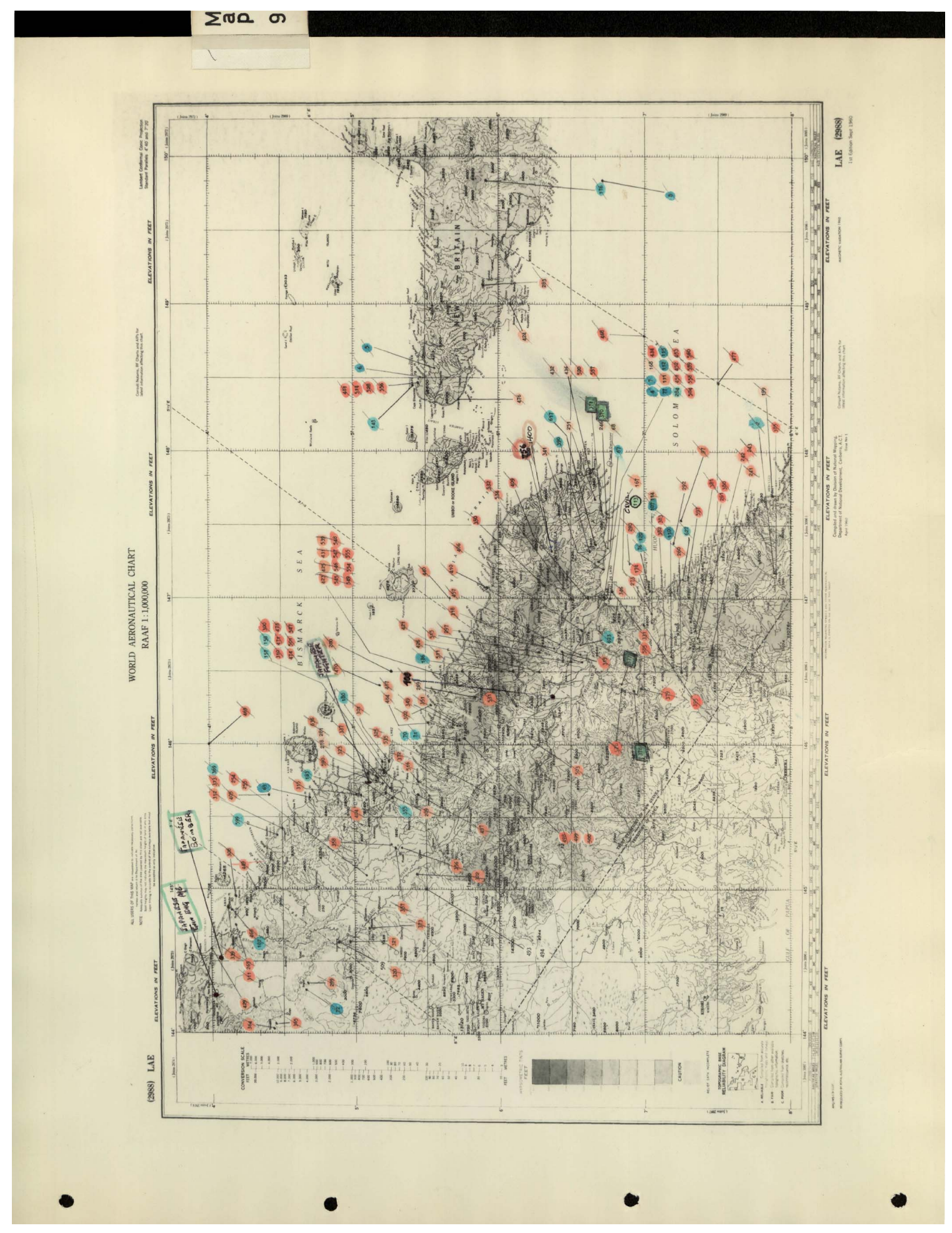




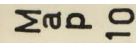

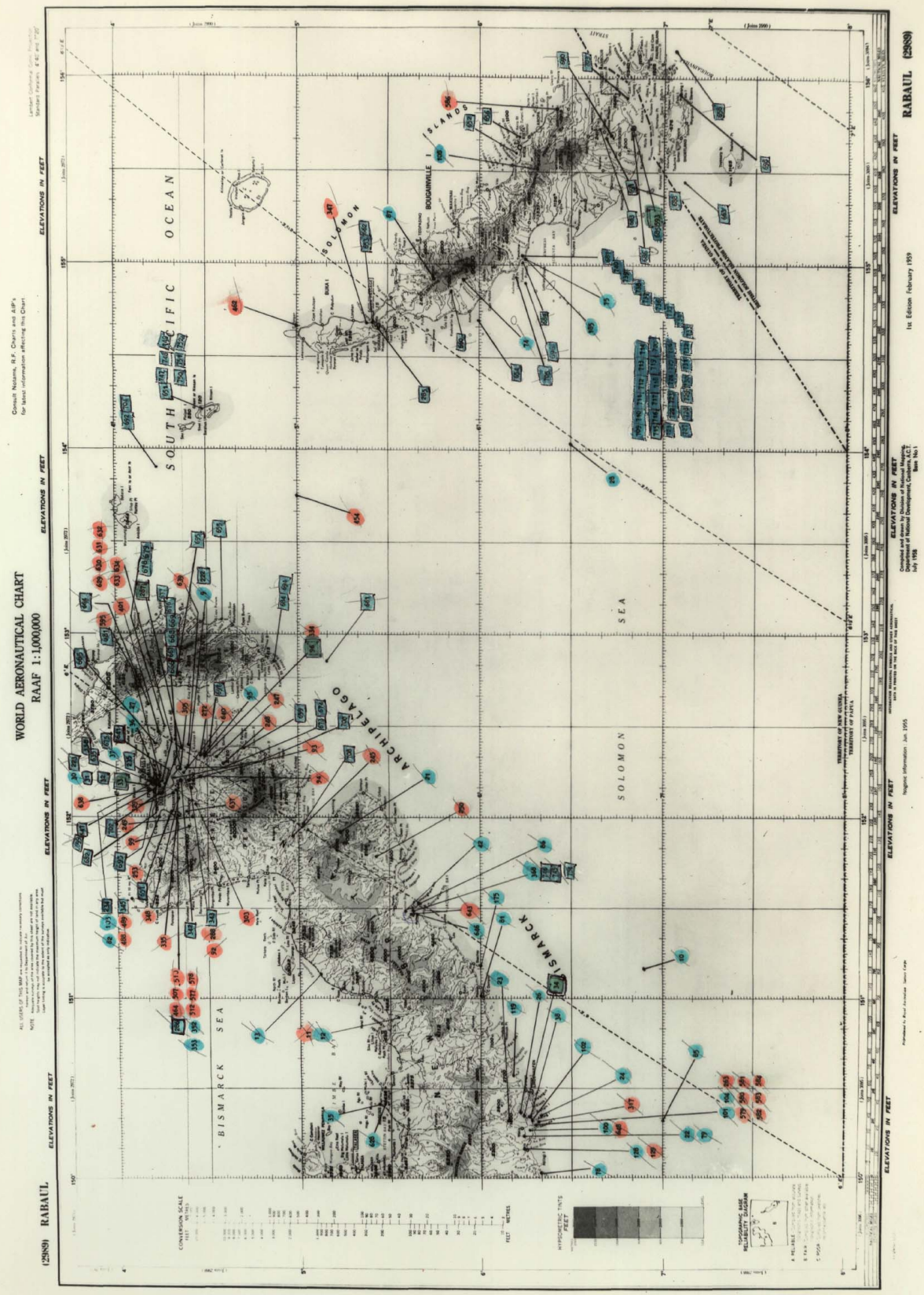




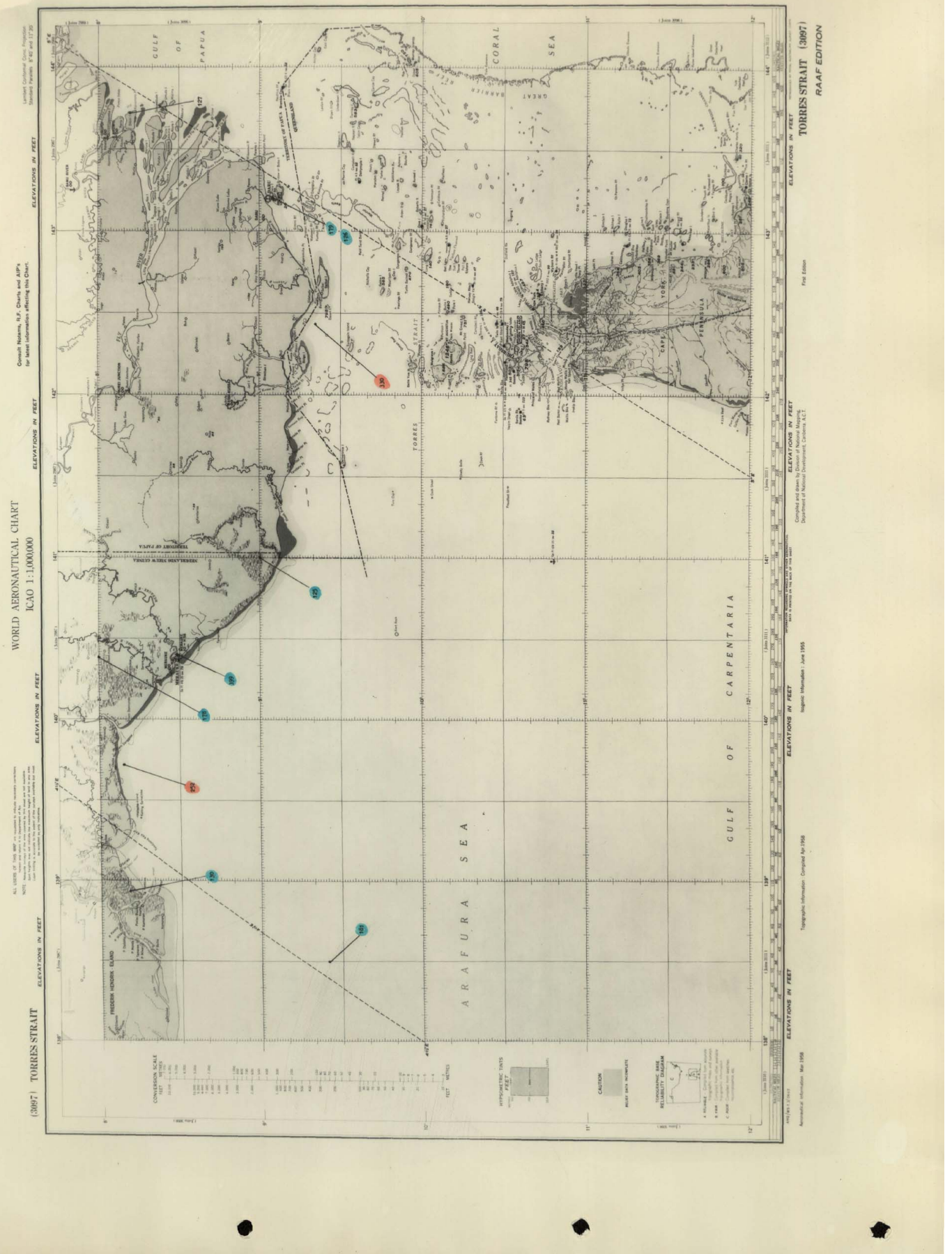




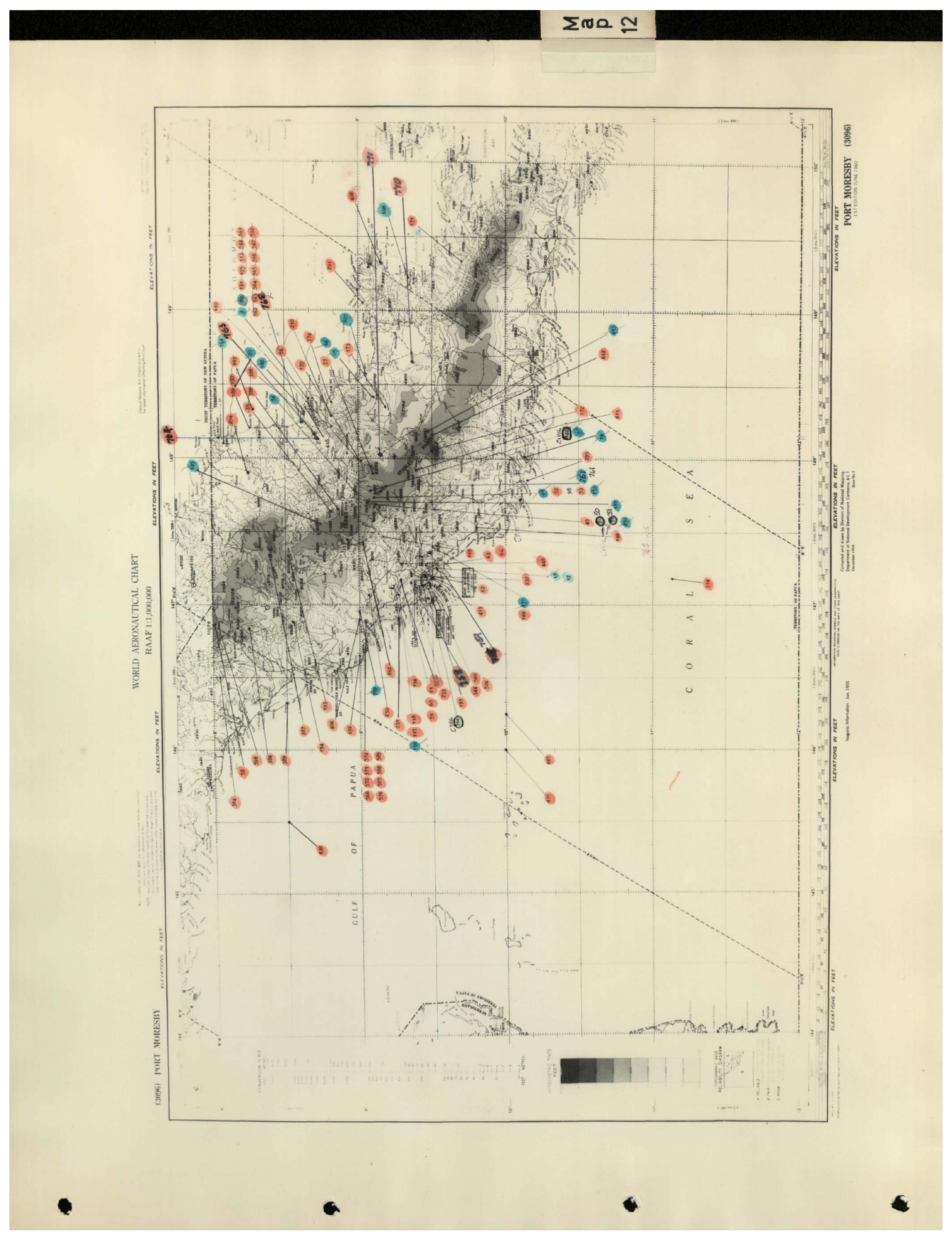




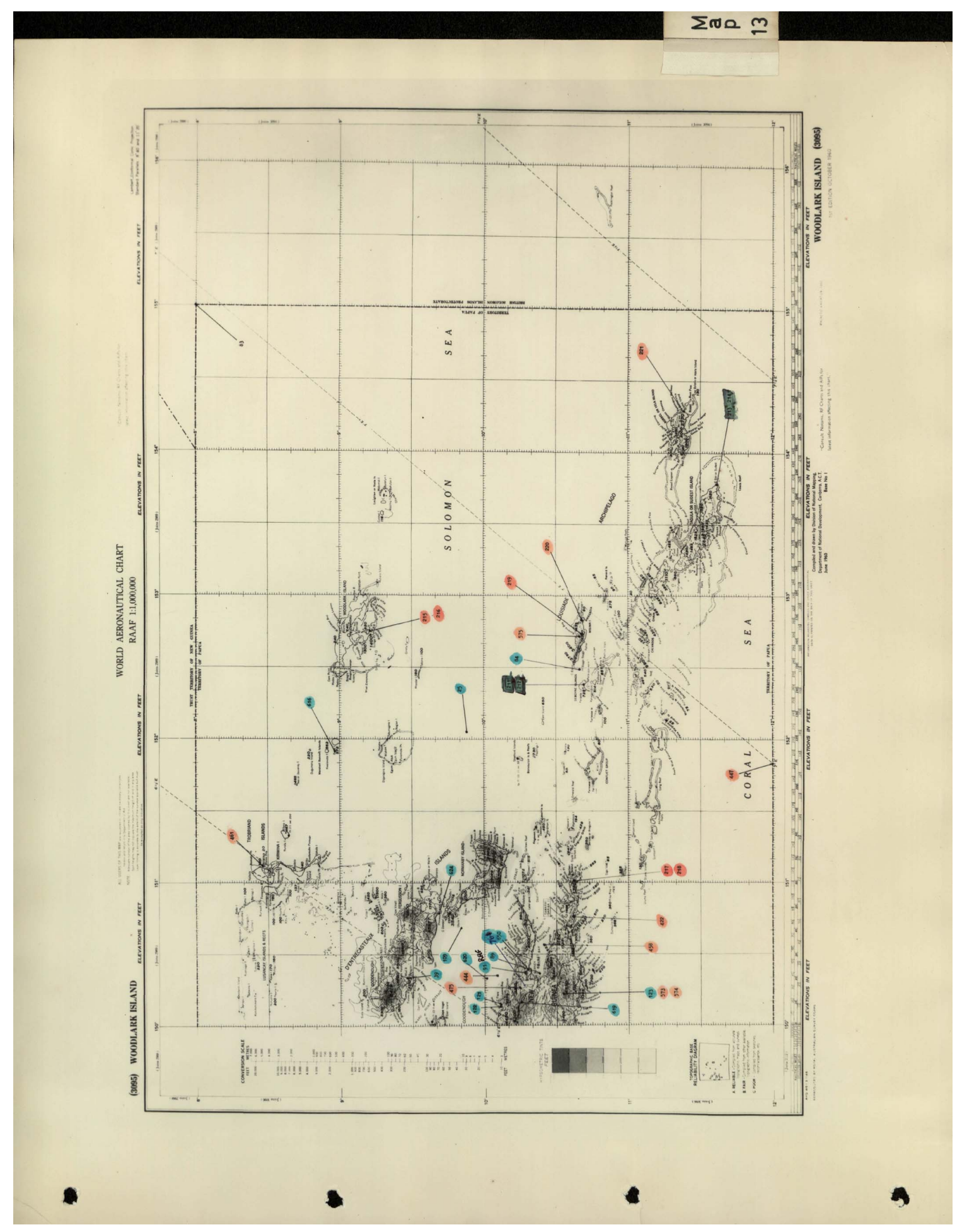

